\title{
EDUCATING THE JURY: MENTAL ILLNESS AND CRIMINAL RESPONSIBILITY IN THE CANADIAN COURTROOM
}

\author{
by \\ Kristin Leigh Fenwick \\ BA, Carleton University, 2011 \\ A thesis submitted to \\ the Faculty of Graduate and Postdoctoral Affairs \\ in partial fulfillment of the requirements for the degree of \\ Master of Arts \\ in \\ Psychology
}

Carleton University

Ottawa, Canada

(C)2014 Kristin Leigh Fenwick 


\begin{abstract}
This study explored juror stigma towards defendants with mental illness (MI), and examined the impact of education on juror decision-making in Not Criminally Responsible on account of Mental Disorder (NCRMD) cases in Canada. Four-hundred and eighty-six participants received two forms of education (MI or diabetes, and NCRMD or duress), read an NCRMD trial transcript in which the defendant's MI was manipulated, and provided a verdict (NCRMD or guilty), defendant perceptions, MI attitudes, and NCRMD attitudes. Continuous analyses revealed that MI and NCRMD education did not have a combined effect on defendant perceptions, MI stigma, or decision-making in NCRMD cases. Path analysis revealed that MI type was directly and indirectly related to guilt certainty via MI attitudes and defendant perceptions. However, NCRMD attitudes did not have an effect on verdicts. Results imply that MI attitudes are deeply ingrained in social and cultural norms and are not amenable to change despite education.
\end{abstract}




\section{Acknowledgements}

I would like to extend my appreciation and thanks to all of those who helped me during this process. First, I would like to thank my supervisor and mentor, Dr. Evelyn Maeder, a talented professor and passionate researcher. Evelyn provided me with constant feedback, valuable advice, and indispensable knowledge, for which I am eternally grateful. Thank you for appreciating my research strengths and patiently encouraging me to improve in my weaker areas. I would also like to thank my committee members - not only for their time and extreme patience, but for their expertise and thoughtful insights - Dr. Johanna Peetz, Dr. Adelle Forth, and Dr. Lara Karaian. In addition, I would like to give thanks to my family and friends. Thank you to my husband, Dylan Cotie, for your patience, love, and emotional support. Thank you for understanding and appreciating my goals and dreams, and for always bringing a smile to my face when needed. Thank you to my parents, Peter and Janice Fenwick, whose love and encouragement over the many years made this accomplishment possible. No matter what, they have always been there for me and I am grateful for their love and support. Thank you to the Carleton legal decision-making lab - Susan Yamamoto, your knowledge has helped me immensely. Last but not least, thank you to my Ottawa girls, for all the moral support they provided. 


\section{Table of Contents}

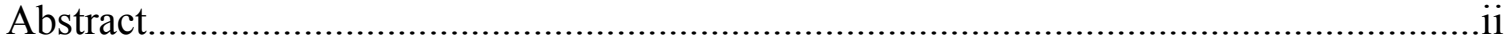

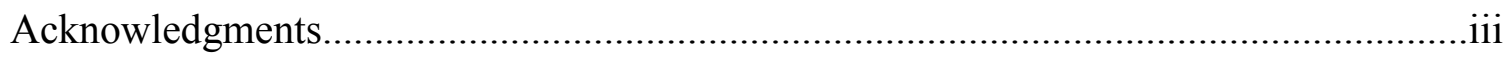

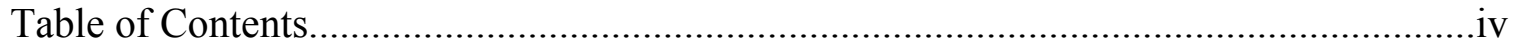

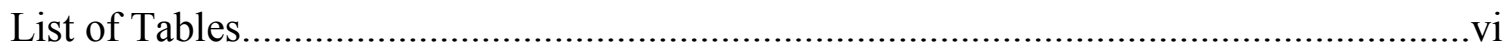





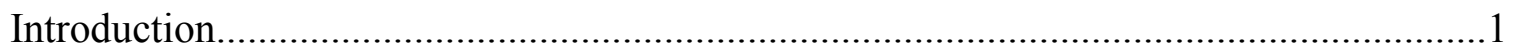

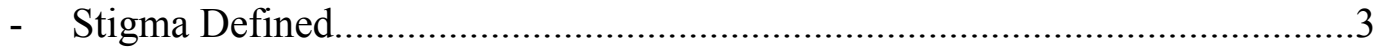

- History of the Not Criminally Responsible on account of Mental Disorder

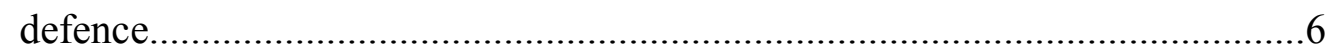

- Stigma towards the NCRMD defence.......................................................... 14

- Stigma towards Mental Illness..................................................................21

- $\quad$ Legal Context: Juror Decision-Making biases............................................28

- Education: Reducing stigma towards Mental illness....................................34

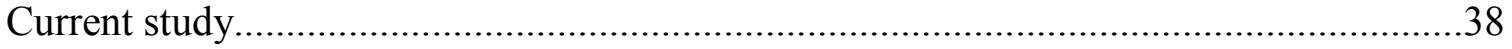

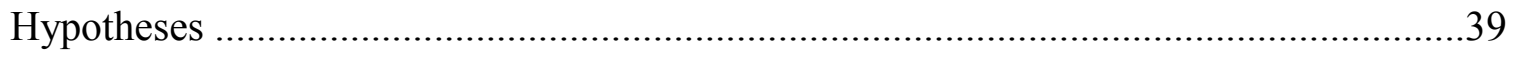

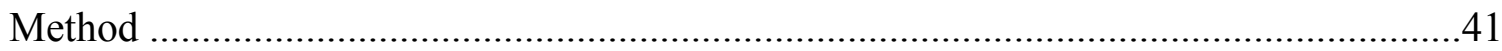

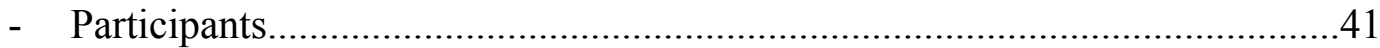







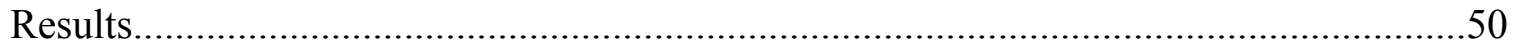

- Dichotomous verdict............................................................................ 51 


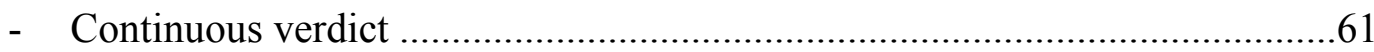

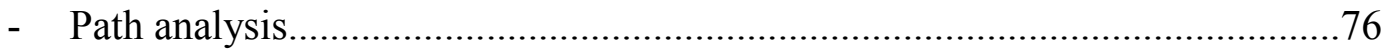

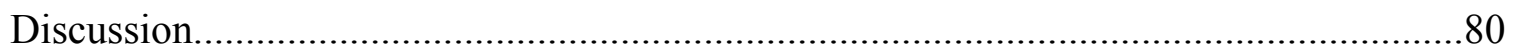

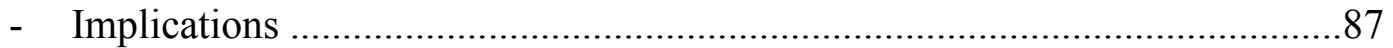

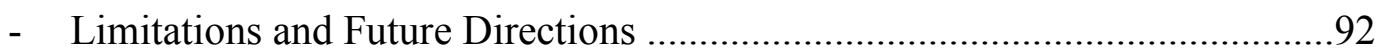

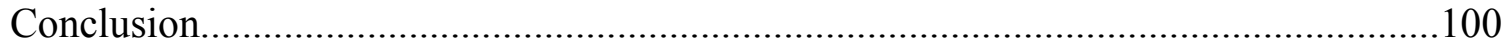

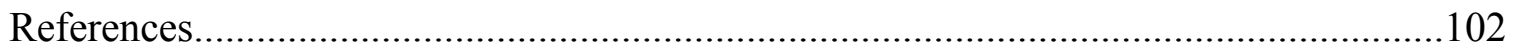




\section{List of Tables}

Table 1. Failed Defendant Mental Illness Manipulation Checks per Defendant Mental Illness Type.

Table 2. Summary of Logistic Regression Analysis Predicting Verdict

Selections. 53

Table 3. Percentage of Verdicts as a Function of Defence Education and Bipolar vs

Substance Use .55

Table 4. Percentage of Verdicts as a Function of Defence Education and Depression vs Substance Use .57

Table 5. Percentage of Verdicts as a Function of Mental Health Education and Depression vs Substance Use .59

Table 6. Percentage of Verdicts as a Function of Defence education, Mental Health Education and Depression vs Substance Use .61 


\section{List of Figures}

Figure 1. The Verdict-Mental Illness Stigma Model............................................41

Figure 2. Mean effect of mental illness on defendant perceptions........................62

Figure 3. Simple effects of mental illness type on defendant perceptions for defence

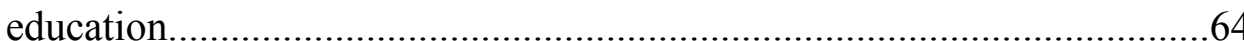

Figure 4. Simple main effects of mental illness type on defendant perceptions for duress education and mental illness education.....................................66

Figure 5. Main effect of mental illness type on mental illness attitudes.................67

Figure 6. Main effect of mental illness type on NCRMD defence attitudes ...........68

Figure 7. Simple main effects of mental health education on NCRMD attitudes for

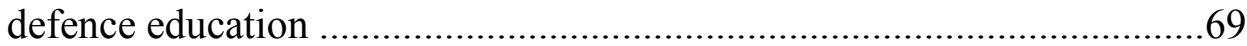

Figure 8. Simple main effects of mental illness type on NCRMD attitudes for duress

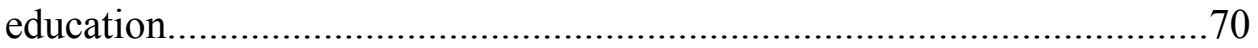

Figure 9. Main effects of mental illness type on continuous verdict.......................71

Figure 10. Simple main effects of defence education on continuous verdict for each



Figure 11. Simple main effects of mental illness type on continuous verdict for duress and mental illness education.......................................................75

Figure 12. Fully saturated Verdict-Mental Illness Stigma Model............................78 


\section{List of Appendices}

Appendix A. Not Criminally Responsible on account of Mental Disorder

Education.................................................... 131

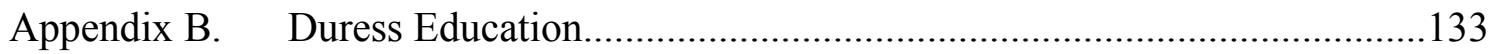

Appendix C. Mental Illness Education.............................................................. 135

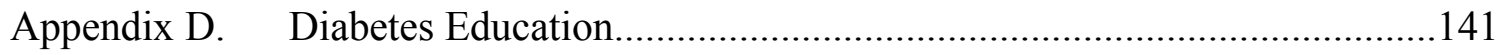

Appendix E. Trial Transcript: Substance abuse..................................................144

Appendix F. Trial Transcript: Schizophrenia.................................................149

Appendix G. Trial Transcript: Bipolar disorder..................................................154

Appendix H. Trial Transcript: Depression................................................... 160

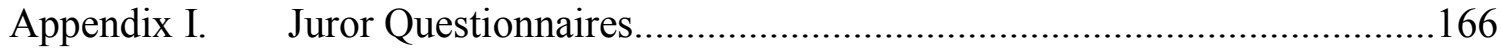

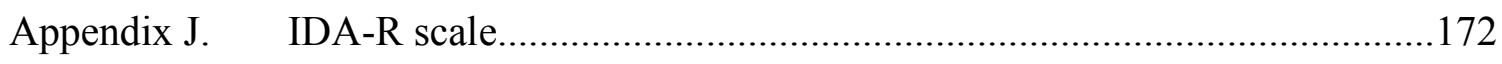

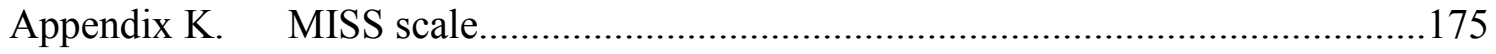

Appendix L. Study Recruitment Notice............................................................. 179

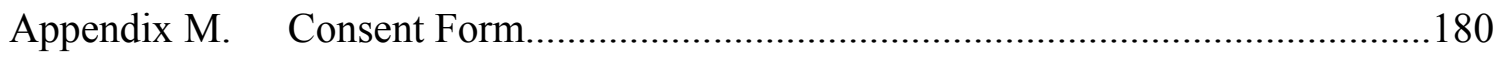

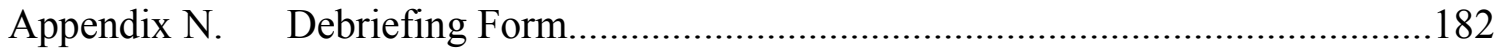

Appendix O. Study Consent-to-keep-date form........................................... 184 


\section{Educating the Jury: Mental Illness and Criminal Responsibility in the Canadian \\ Courtroom}

Mental illness directly or indirectly affects all Canadians, regardless of age, religion, culture, socioeconomic status, or education level. Approximately $20 \%$ of Canadians will personally experience a mental illness during their lifetime (Health Canada, 2002). Although the majority of persons with mental illness do not come into contact with the criminal justice system, Canada's correctional facilities have seen a considerable increase in the number of offenders experiencing mental health problems upon admission (Correctional Service of Canada, 2009). This increase could be due to the closing of civil psychiatric facilities or better measurement for the detection of mental illness (Prins, 2011; Sheth, 2009; Stall, 2013). Furthermore, when compared with the general population, offenders have a higher prevalence rate of mental illness (Canadian Institute for Health Information, 2008; Correctional Service of Canada, 2009). However, this high prevalence rate could be due to the fact that mentally ill people are less adept at committing crime, more likely to get arrested due to their behaviour, and are more likely to plead guilty (Bland, Newman, Dyck, \& Orn, 1990; Canadian Mental Health Association, 2004; Teplin, 1984). In 2010-2011, Correctional Service Canada reported that $62 \%$ of offenders entering a federal penitentiary had been identified for a follow-up mental health assessment or service (Office of the Correctional Investigator, 2012). In addition, approximately 4 out of 5 offenders in federal custody are afflicted by more than one mental illness, most commonly substance use disorder (Office of the Correctional Investigator, 2012). Although initiatives have been established to provide appropriate services and interventions that will assist mentally ill offenders, these offenders pose a 
variety of challenges for prison administrators and mental health professionals (Adams \& Ferrandino, 2008; Office of the Correctional Investigator, 2012), resulting in limited treatment and support for mentally ill inmates in Canadian prisons (Olley, Nicholls, \& Brink, 2009). However, rehabilitation initiatives are receiving an increasing amount of attention given that the mentally ill inmate population, and the seriousness of their illnesses, are increasing (Adams \& Ferrandino, 2008). The issue of mental illness within the criminal justice system not only poses problems within prison settings, but it also raises a serious issue of stigma in the courtroom during trial proceedings, a research area that has been neglected.

One area where stigma is an issue in the Canadian legal system is the Not Criminally Responsible on Account of Mental Disorder (NCRMD) defence. The NCRMD defence is available to people who commit criminal acts yet lack the mens rea for the criminal act. Thus, the defence allows mentally ill offenders to be exempt from criminal responsibility if their mental disorder rendered them incapable of appreciating the nature and quality of the act or omission (S. 16, Criminal Code, 1985). In such a case, a judge or a jury is asked to impartially render a verdict of NCRMD or guilty based on evidence provided in court. In addition, the Canadian Charter of Rights and Freedoms guarantees the right of a defendant "to be presumed innocent until proven guilty according to law in a fair and public hearing by an independent and impartial tribunal" (section 11d); however, research within the United States has found that juror attitudes toward the Not Guilty by Reason of Insanity (NGRI) defence overpowers jurors' ability to apply the legal Insanity test (Finkel, 1988, 1995), thus decreasing the likelihood of a defendant receiving a fair trial. An inappropriate guilty verdict contradicts a defendant's 
rights and freedoms and contributes to the challenges Canadian prisons already face with mentally ill offenders. This study explored juror stigma towards defendants with mental illness, and examined the impact of education on juror decision-making in NCRMD cases. Specifically, this study explored whether mental illness education and NCRMD education can affect jurors attitudes towards mental illness and decision-making in NCRMD trials. In addition, this study examined the effects of mental illness type (schizophrenia, bipolar disorder, depression, substance use disorder) on defendant perceptions, mental illness stigma, NCRMD attitudes, and decision-making in NCRMD trials.

\section{Stigma Defined}

Stigma is a concept that has generated a vast amount of variability within the literature while providing no singular definition. However, it is agreed that stigma is a powerful phenomenon that causes daunting effects on its targets, such as low social status, poor mental health, reduced education, and unfair criminal trials (Corrigan, River, Lundin, Penn, Uphoff-Wasowki et al., 2001; Link, Phelan, Bresnahan, Stueve, \& Pescosolido, 1999). In one of the earliest definitions, Goffman (1963, p. 3) described stigma as an "attribute that is deeply discrediting and that reduces the bearer from a whole and usual person to a tainted, discounted one." Expanding on this individualist definition, Jones and colleagues (1984) described stigma as a 'mark' resulting from a relationship between an attribute and a stereotype, which links the target to an undesirable categorization. Stigmatization suggests that the condition labelled deviates from normal. Thus, stigma is a social construct whereby a label is attached by society. 
In order to understand social stigma, one must understand three strongly linked components most commonly directed towards stigmatized groups and individuals: stereotypes, prejudice, and discrimination. Stereotypes are the cognitive component our knowledge structures representing our impression towards a group or towards a member of the group (Fiske, 1998). Such structures are efficient in that they allow us to quickly generate impressions of individuals or groups (Rusch, Angermeyer, \& Corrigan, 2005). Often times, stereotypes are viewed negatively; however, it is important to note that stereotypes can be both positive and negative. Prejudice is the emotional component - once stereotypes are adopted, unfavourable affective attitudes and evaluations towards a social group or its members can be formed (Fiske, 1998). Discrimination is the behavioural prejudicial treatment that is directed towards the stigmatized group on the basis of perceived category membership (Nelson, 2009).

These concepts are especially important when viewed together because they collectively influence our motivations, behaviours, and judgments towards groups or members of groups (Bargh, Chen, \& Burrows, 1996; Wheeler \& Petty, 2001). Often, these reactions are automatic, unconscious, and unexamined, resulting in centralized reactions to social groups (Clausell \& Fiske, 2005; Fiske, 1998; Glick \& Fiske, 2001). Each component potentially provides an opportunity for error, given that such automatic reactions can be based on negative, inaccurate, and unfair attitudes. Thus, our attitudes provide a foundation for stigmatization.

According to Fishbein and Ajzen (1975), attitudes are learned evaluations toward a given object. Attitudes are especially relevant to stigma given that they affect our perceptions and judgments and can predict our overt behaviours (Ajzen \& Gilbert, 2008; 
Fazio, 1986). The notion that attitudes affect our perceptions and judgments is outlined in Fazio's (1990, 1995) MODE model of attitude-behavior processes. The MODE model presumes that perceptions and judgments towards an object can be influenced and biased by general attitudes relevant to the object. The activation of attitudes causes bias to occur either by spontaneous or deliberative attitude-to-behaviour processes. Attitudes can be retrieved by deliberative attitude-to-behaviour processes when motivation and cognitive capacity is high. However, if motivation and/or cognitive capacity are low, the activation of attitudes can only occur spontaneously and automatically. This spontaneous and automatic retrieval is thought to occur for strong attitudes, both negative and positive. These mental shortcuts are effective in that they allow quick and efficient judgments; however, they may also cause errors in judgments, resulting in cognitive biasing and stereotyping (Evans, 1984). Strong attitudes can increase the risk of unfavourable predispositions, causing errors in judgment and increasing the likelihood of stigmatization. In other words, "the trouble with people is not that they don't know, but that they know so much that ain't so" (Billings, 1874).

More recently, Link and Phelan (2001) have attempted to broaden the conceptualization of stigma while also addressing necessary criticisms regarding interpretations of stigma. They stressed the need for a transparent definition of stigma that can be universally applicable. In addition to stereotypes, prejudice, and discrimination, they stressed that societal aspects should be given attention. They proposed that stigma exists when the following social aspects converge. First, human differences are distinguished and labelled. Differences that have a high degree of social salience are considered to be socially relevant and essential components of stigma. 
Second, negative stereotypes are developed and labelled by dominant cultural beliefs. Third, such negative stereotypes and labels place individuals in distinct categories in order to create a separation of 'us' from 'them'. Thus, the stigmatized members are thought to be different kinds of individuals from 'us'. Finally, as a result of labelling, these individuals are devalued, causing a decrease in social, cultural, economic, and political power and an increase in discriminatory judgments. Therefore, Link and Phelan (2001) proposed that "stigma exists when elements of labelling, stereotyping, separation, status loss, and discrimination co-occur in a power situation that allows these processes to unfold" (p. 377). Despite how stigma is formulated, it is robust and can be difficult to overcome. However, researchers believe that we can overcome stigma and that education is the key (Schmetzer, Lafuze, \& Jack, 2008).

\section{History of the Not Criminally Responsible on account of Mental Disorder Defence}

An area within the criminal justice system that fosters stigmatized attitudes is the concept of criminal responsibility. The Canadian justice system holds the belief that individuals who are unaware of their actions or who cannot control their actions are not criminally accountable for their behaviour (Criminal Code, 1985). Canada follows the fundamental principle that in order to be found guilty of an offence, an accused must possess the capacity to understand that his or her behaviour was wrong. A mental illness is characterized as an alteration to a person's cognition, mood, or behaviour that is associated with a significant amount of distress and impaired functioning (Government of Canada, 2006). According to section 16 of the Criminal Code (1985), "No person is criminally responsible for an act committed or an omission made while suffering from a mental disorder that rendered the person incapable of appreciating the nature and quality 
of the act or omissions, or of knowing that it was wrong." This is known as the Not Criminally Responsible on account of Mental Disorder defence (NCRMD; Criminal Code, 1985). Thus, individuals who have committed a criminal offence can be exempt from criminal responsibility if their mental disorder precluded them from understanding the consequences of their actions or comprehending that the action itself was wrong. A verdict of NCRMD is not synonymous with a finding of guilt or a conviction. Rather, the verdict means that the court has ruled that the accused was not criminally responsible for his or her actions at the time the offence was committed.

The issue of criminal responsibility for mentally ill persons has a long history, which has been met with controversy, mistrust, and prejudice. The first serious issue of criminal responsibility in a legal context was dealt with by the British House of Lords in 1843 in a trial known as the M'Naghten case (R. v. M'Naghten, 1843). In this case, Daniel M'Naghten shot and killed English civil servant Edward Drummond while suffering from paranoid delusions. M'Naghten mistook Edward Drummond for Prime Minister Robert Peel, whom M'Naghten felt was the leader of an international conspiracy to which he had fallen victim (R. v. M'Naghten, 1843). After much deliberation, a jury rendered a verdict of NGRI - a decision that caused a public outcry and severe backlash (Weiner et al., 2003). As a result of the decision, the common law defence of Insanity was formulated along with key principles for conviction. The House of Lords set out the following principles:

The jurors ought to be told in all cases that every man is presumed to be sane, and to possess a sufficient degree of reason to be responsible for his crimes until the contrary be proved to their satisfaction; and that to establish a defence on the 
ground of Insanity, it must be clearly proved that, at the time of the committing of the act, the party accused was labouring under such a defect of reason, from disease of the mind, as not to know the nature and quality of the act he was doing; or, if he did know it, that what he was doing was wrong. (R. v. M'Naghten, 1843) As a result of the M'Naghten case, Canada implemented the defence of Insanity into its first Criminal Code (1892). To this day, Canada utilizes the test derived from the M'Naghten case; however, there have been numerous changes to the original provision. The original provision allowed insane defendants to be sentenced to automatic indeterminate detention. However, this was later found to infringe upon an individual's right to life, liberty, and security (R. v. Swain, 1991). After numerous controversial cases and drafts, proposals to amend the Insanity defence were introduced. These proposals were laid out in Bill C-30, which was adopted in 1992. Bill C-30 included new terminology, new definitions for determining an accused unfit to stand trial, and new sentencing provisions (Pilon, 1999). The most notable amendment in Bill C-30 was the replacement of 'not guilty on account of Insanity' with 'not criminally responsible on account of mental disorder.' With this new terminology, it is incorrect to say that a defendant has been acquitted or convicted of the original offence in question. Rather, a third alternative is offered that aims to treat mentally ill offenders while also protecting the public. This revision was made in response to R. v. Swain (1991), which ruled that automatic detention was unconstitutional for individuals acquitted by reason of Insanity. To reflect this amendment, a defendant who is exempt from criminal liability is thought to suffer from 'a mental disorder' rather than the previous term, 'disease of the mind'. Among other things, as a result of Bill C-30, courts are no longer obliged to hold an 
accused in automatic indeterminate detention. Instead, immediate absolute discharges can be issued to some defendants, whereas others can be given a conditional discharge or hospitalized detention. Defendants who are given a sentence other than an absolute discharge are subject to annual review board hearings in order to ensure that the least restrictive disposition is imposed on the mentally disordered individual (Pilon, 1999; Winko v. British Columbia, 1999). According to an examination of NCRMD cases processed through the Review Board systems in Canada between 1992 and 2004, the most common disposition among NCRMD accused was hospitalized detention (51.7\%), followed by conditional discharge (34.9\%), absolute discharge (12.5\%), and other dispositions (.9\%; Latimer \& Lawrence, 2006). Further to a Parliamentary review required by Bill C-30, recommendations intended to improve the legislation were introduced in 2005 when Bill C-10 was adopted. The Bill expanded the powers of review boards by allowing the order of publication bans, psychological assessments, the option for psychological assessments to be administered by persons other than medical practitioners, victim impact statements presented at hearings, and the option to include mentally ill offenders in a dangerous person provision.

Although limited statistical information is available regarding the NCRMD defence, Livingston and colleagues (2003) and Latimer and Lawrence (2006) have examined characteristics of individuals found NCRMD following the Bill C-30 provisions. According to profile data, the average age at the time of NCRMD finding was 36 years (Latimer \& Lawrence, 2006; Livingston, Wilson, Tien, \& Bond, 2003). In addition, more than three quarters of NCRMD individuals were male. According to Livingston and colleagues (2003), the majority of offences in British Columbia with 
which NCRMD persons were charged were assault offences (36.4\%), followed by nuisance offences $(22.4 \%)$, property offences $(11.0 \%)$, theft $(9.9 \%)$, weapons offences (7.5\%), murder or attempted murder (6.6\%), sexual assault $(4.1 \%)$, and robbery $(2.0 \%)$. However, in a larger sample size, Latimer and Lawrence (2006) examined NCRMD populations across Quebec, Ontario, and British Columbia and found that serious violent offences represented a small proportion of all NCRMD offences. The majority of offences were identified as major assault (level II, III; 22\%), assault (level I; 20.4\%), threats $(10.6 \%)$, other non-violent offences $(7.7 \%)$, homicide $(7.2 \%)$, attempted murder (6.5\%), criminal harassment (6.3\%), arson (4.8\%), sexual assault (level I, II, III; 3.7\%), robbery $(3.6 \%)$, break and enter $(3.1 \%)$, theft $(2.4 \%)$, other violent offences $(2.8 \%)$, weapons offences (1.2\%), and other sexual offences (.6\%; Latimer \& Lawrence, 2006). Of all NCRMD index offences, attempted murder represented $3.3 \%$, homicides $2.6 \%$, and sex offences $2.1 \%$ (Latimer \& Lawrence, 2006). However, there are some inconsistencies in research regarding the diagnosis of NCRMD individuals. Latimer and Lawrence (2006) found that NCRMD individuals accused of a serious violent offence were most likely to receive a psychiatric diagnosis in the psychosis spectrum at the time of the verdict (68.9\%). Following the psychosis spectrum, NCRMD individuals received a diagnosis of substance use disorder $(27.9 \%)$, mood disorder $(23.6 \%)$, personality disorder $(21.2 \%)$, other (16.4\%), organic disorder (2.4\%), and anxiety disorder $(1.8 \%)$. Conversely, Livingston and colleagues (2003) found that individuals who received an Axis I DSM-III-R diagnosis were most frequently identified as having schizophrenia (39.5\%), organic mental disorder (19.9\%), mood disorder $(15.6 \%)$, or unclassified psychotic disorders (13.4\%), and the most common Axis II diagnoses were cluster B 
(dramatic, emotional, or erratic disorders) personality disorders (antisocial, borderline, histrionic, and narcissistic personality disorders; 6.2\%), cluster C (anxious or fearful disorders) personality disorders (avoidant, dependant, and obsessive-compulsive personality disorders; $6.9 \%)$ and developmental disorders (2.1\%). In addition, Roesch and colleagues (1997) reviewed court selected defendants remanded for diagnosis in fitness to stand trial and NCRMD cases and found that NCRMD individuals were most often diagnosed with schizophrenia (26.5\%), personality disorders (17.7\%), bipolar disorder (13.2\%), substance abuse (10.3\%), no disorder (7.4\%), and depression (4.4\%). Such inconsistencies may be due to the limited sample size within each study or varying DSM criteria.

The Unites States also has a similar defence to that of Canada's NCRMD defence; however, there are important differences. First, legislative guidelines for a defence of mental disorder in the United States vary among states, whereas the NCRMD defence is under the purview of the Canadian federal government (Criminal Code, 1985; Sloat \& Frierson, 2005). Furthermore, not all states offer a defence of mental disorder of any kind (Sloat \& Frierson, 2005). Of those states that do, the two major options for mentally ill offenders are the Not Guilty by Reason of Insanity (NGRI) defence, and the more recently introduced Guilty but Mentally Ill (GBMI) option. The NGRI defence is the most similar to that of the NCRMD defence as the NGRI defence is available to a defendant who had been suffering from a severe mental illness at the time of the commission of the action constituting the offence. Furthermore, the defendant must have been unable to appreciate the nature and quality of the wrongfulness of his or her acts. Although the burden of proof that an accused was suffering from a mental disorder so as 
to be exempt from criminal responsibility lays with the defence for the NCRMD defence (Criminal Code, 1985), the burden of proof is not consistent across states for the NGRI defence. However, the majority place the burden of proof on the defendant to demonstrate that he or she was legally insane at the time of the crime. Another vast difference to the Canadian defence is the standards used for determining whether a defendant is legally insane. Each state, and the District of Columbia, utilizes their own legal test to determine whether the individual in question was insane during the act. These include the M'Naghten Rule, the Irresistible Impulse test, the Durham Rule, and the Model Penal Code test (Sloat \& Frierson, 2005). The majority of the states follow the M'Naghten rule, which states the actor, as a result of severe mental disease or defect, was incapable of understanding that his conduct was wrong (R. v. M'Naghten, 1843). Several states also recognize the 'irresistible impulse' standard, which allows a defendant to be found NGRI if they were overcome by such a mental state that he or she loses the ability to control his or her actions. In this instance, the offender must suffer from a mental disease or defect and lack the capacity to appreciate the criminality of his or her conduct (M'Naghten prong), or lack the ability to conform his or her conduct to the requirements of law (Irresistible impulse prong) due to his or her disease or defect (R. v. Byrne, 1960). However, the irresistible impulse rule has been criticized for its leniency and broad classification (Miller, 1985). The Model Penal Code test provides a broad test given that an individual can be found to be NGRI if the offender was suffering from a mental disease or defect and the offender lacked the capacity to appreciate the criminality of his or her conduct (M'Naghten prong) or confirm his or her conduct to the requirements of law (Irresistible Impulse prong; U.S. v. Brawner, 1972). However, following the Insanity 
Defence Reform Act (1984), the irresistible impulse prong was removed, indicating that Insanity may be used as a defence only if the defendant lacked the ability to understand the nature and wrongfulness of his/her act. Nearly half of the states employ the Model Penal Code (Neville, 2010). Lastly, the Durham rule allows a defendant to be found NGRI if the criminal act was the result of a mental disease or defect at the time of the incident (Durham v. United States, 1954). However, New Hampshire is the only state that has not rejected the Durham rule (Collins, 2012). The M'Naghten rule and the Model Penal Code are the most commonly used rules in the United States. However, Montana, Idaho, and Utah have abolished the Insanity defence altogether.

A notable difference from the United States and Canada is the United States' establishment of the GBMI verdict. Unlike the NCRMD and the NGRI defence, the GBMI is not a criminal defence (Kutys \& Esterman, 2009). It is an alternative verdict that allows a defendant to be guilty of his or her criminal acts but recognized as suffering from a mental illness. If a defendant does not meet the legal Insanity standard, he or she can be found GBMI (S.C. Code Ann. § 17-24-20, 2003). The defendant will be sentenced as a regular offender; however, the courts will determine treatment options for the offender. Thus, the offender will receive treatment until deemed sufficiently recovered, and then will be transferred to a prison to serve the remainder of his or her sentence. In an examination of how individuals' beliefs about insanity and responsibility influence decision-making, Roberts and colleagues (1987) found that jurors chose the GBMI verdict 2.5 times more often than either the NGRI or guilty verdict for cases without planned intentionality. Therefore, the public appears to be more accepting of the GBMI option. 


\section{Stigma towards the NCRMD defence}

In North America, the concept of criminal responsibility has generated an abundant amount of negative attitudes. As a result, there has been a public outcry in both Canada and the United States to abolish the defence that exempts an accused with a mental illness from criminal responsibility (Hans, 1986; Leblanc, 2007). Research demonstrates that the public maintains a negative perception towards the NCRMD and the Insanity defence (Leblanc, 2007; Maeder \& Fenwick, 2011). Unfortunately, the media intensifies stigma towards the 'criminally insane' and the Insanity defence among the general public. The media selectively portray mentally ill characters as violent individuals who are involved in unpredictable, bizarre criminal activities - failing to provide an accurate representation of offenders who become institutionalized (Diefenbach \& West, 2007). Furthermore, cinema frequently dramatizes the defence, suggesting that a large proportion of successful defendants malinger as a means to 'get off scot free' (Douglas, Zaentz, \& Forman, 1975). Silver and colleagues (1994) suggest that "such distorted perceptions feed the public's fear which in turn is reflected in negativity toward the Insanity defense" (p. 69).

Research on the public's perception of the Insanity defence within the United States has consistently shown that such a defence is perceived as a loophole within the criminal justice system that allows guilty defendants to go free (Hans, 1986; Pilon, 1990). Furthermore, laypeople often express that the Insanity defence is grossly overused, when in reality the actual plea rate is less than $1 \%$ of all criminal cases (National Commission on the Insanity Defense, 1983; Skeem, 2001; Vitacco et al., 2009). In a general public survey, only $20 \%$ of respondents believed that individuals found NGRI actually were 
insane (Hans, 1986). As a result, laypeople hold the belief that judges and juries have a difficult time evaluating whether defendants are truly sane or insane and therefore are sceptical of the legal process (Bloechl, Vitacco, Neumann, \& Erickson, 2007; Hans, 1986).

Another area that seems to generate fear among the public is the misconception that mentally ill defendants who are found NGRI are released into the community without provisions. Those who estimate that Insanity acquittees immediately go free are more likely to be unsupportive towards the Insanity defence and more likely to render a guilty verdict (Skeem et al., 2004). In addition, people seem to be concerned that an Insanity acquittal releases extremely dangerous individuals into the community with no conditions, putting the public in harm's reach.

Juror bias in Insanity trials. In Canada, jurors are presumed to act impartially and are expected to decide issues of fact and apply them to legal standards. When an NCRMD case comes to trial, the outcome is said to be based on a strict legal test of mental disorder (Criminal Code, 1985). If an accused is found NCRMD, they are diverted to a provincial or territorial Review Board, which will determine the most appropriate disposition. It is up to a judge or a jury to render an NCRMD verdict if the level of evidence exceeds any reasonable doubt whereby the accused is not a discerning moral agent, capable of making choices between right and wrong. However, research in the United States has found that stigma towards the Insanity defence decreases the likelihood of a mentally ill defendant receiving a fair trial (Finkel, 1988, 1995).

Stigma surrounding the Insanity defence makes it difficult for jurors to remain impartial; therefore, many accused who suffer from a mental disorder do not receive a 
fair trial. Negative attitudes toward the NGRI defence in the United States have been found to be a prevalent and powerful source of bias, especially within juror verdicts (Finkel, 1988, 1995). According to Skeem and colleagues (2004), such bias towards the NGRI defence is largely based on myths that reflect inaccurate knowledge. Furthermore, jurors frequently place great importance in their own perceptions of a moral agent when rendering a verdict, despite legal definitions (Finkel, 1997; Roberts \& Golding, 1991; Skeem \& Louden, 2000). Roberts and Golding (1991) found that jurors' attitudes toward the insanity defence, particularly perceptions of the defendant's mental state and blameworthiness, were strongly related to verdicts rendered. Furthermore, jurors' perceptions of blameworthiness were more strongly related to verdict decisions than manipulation of case facts, such as premeditation (Roberts \& Golding, 1991). In addition, regardless of whether jurors were given judicial instruction on legal definitions of insanity, jurors' verdicts did not differ, suggesting that mock jurors fail to apply the legal insanity test (Finkel, 1989, 1991). Thus, stigma and negative attitudes toward the NGRI defence may overpower the application of Insanity standards (Finkel, 1989, 1991)

In an assessment of the level of support for the Insanity defence and attitudes towards mental illness, Butler (2006) found that increased levels of support for the Insanity defence were significantly related to participants' willingness to find a defendant NGRI. However, the majority of participants indicated that they opposed the defence but would consider the defence under certain circumstances. Butler explains that the defendant's past history of mental illness, ability to accurately remember the offence, and relationship with the victim may influence jurors' willingness to consider the defence; however, certain circumstances specific to this study were not disclosed. 
In an innovative study that investigated bias in juror decision-making, Skeem and colleagues (2004) examined the effects of jurors' attitudes towards the NGRI defence on verdict decisions. Such data were used as a means to develop, refine, and cross-validate a measure of public attitudes towards the Insanity defence: the Insanity Defence AttitudesRevised scale (IDA-R). Results suggest that there are two dimensions that help explain Insanity defence attitudes: orientation toward strict liability, and concern about perceived injustice and danger associated with the defence. Strict liability pertains to the extent to which individuals believe mental illness implies reduced capacity for rational decisionmaking (e.g., I believe that that all human beings know what they are doing and have the power to control themselves) or that mentally ill defendants are responsible for their crimes regardless of their mental illness (e.g., I believe that people should be held responsible for their actions no matter what their mental condition). Injustice and danger reflects the extent to which individuals perceive that the Insanity defence is misused (e.g., as a last resort, defence attorneys will encourage their clients to act strangely and lie through their teeth to appear 'mentally ill') and its potential to threaten public safety (e.g., the Insanity defence returns disturbed, dangerous people to the streets). In their second study, participants were given a brief insanity case vignette and were asked to render a categorical verdict (guilty or NGRI), indicate how likely they were to find the defendant insane, answer construal items such as perceptions towards the defendant, and answer the IDA-R to test the scale's predictive and convergent validity. Correlations were computed between the IDA-R dimensions, the insanity case vignette construal items, and the insanity likelihood ratings. The strict liability and the injustice and danger dimensions assessed within the IDA-R were found to have strong predictive utility for 
jurors' case judgements, convergent and divergent validity, and internal consistency.

These results also suggest that attitudes towards the Insanity defence strongly influence verdict outcomes.

In addition to verdicts rendered, studies have also examined how jurors process information and arrive at their verdict outcomes. Skeem and Golding (2001) assessed the nature, variability, and effect of jurors' conceptions of Insanity to determine individual differences among jurors. They found that jurors demonstrated significant individual differences in their conceptions. Specifically, jurors possessed three prototypes of Insanity: the severely mentally disabled (severe functional impairment and intellectual disabilities that are longstanding and resistant to treatment), the morally insane (unpredictable behaviour, irrational, violent, characteristics of psychopathy and psychosis), and the mental state centered (credible expert believes s/he is insane, incapable of choosing between right and wrong, and is more than merely impassioned or enraged). Jurors who possessed these prototypes were more likely to differ in both their attitudes toward the Insanity defence and their case judgements. Those with a mental state centered prototype were more likely to find a mentally ill defendant NGRI when compared to those with a severely mentally disabled prototype and a morally insane prototype. However, the severely mentally disabled prototype and the morally insane prototype did not significantly differ from one another. In addition, jurors with a severely mentally disabled prototype or a morally insane prototype valued crime control over due process and were more likely to endorse the belief that the Insanity defence is easily abused when compared to a mental state centered prototype. Individuals who value the crime control model are concerned with the repression of crime, victim rights rather than 
defendant rights, and the expansion of police powers. Conversely, individuals who value the due process model are concerned with defendant rights rather than victim rights, limited police powers, constitutional rights, and a fundamental fairness under the law. Thus, Skeem and Golding (2001) concluded that prototypes of Insanity contribute to juror decision-making. Extending upon the previous findings, Louden and Skeem (2007) assessed the effects of attitudes toward the Insanity defence and prototypes of Insanity on jurors' case judgements, as well as the extent to which the three stereotypes or prototypes identified in Skeem and Golding's (2001) research generalize to other jurors. One hundred and thirteen former prospective jurors in Nevada were asked to construct a detailed image of the prototypical person who is NGRI. Consistent with previous research, Louden and Skeem (2007) found that jurors' general information processing was powerfully influenced by their attitudes towards the Insanity defence. Such attitudes strongly affected jurors' Insanity case judgements and verdicts; however, results indicated that prototypes of Insanity only had a modest effect. Based on their findings, Louden and Skeem (2007) concluded that biased jurors should be identified by focusing on jurors' attitudes towards the Insanity defence rather than their prototypes of Insanity. Research involving the effect of attitudes toward the Insanity defence on juror decision-making in Insanity trials has consistently shown that there is a bias held against the Insanity defence. Jurors are more willing to find a mentally ill defendant GBMI rather than NGRI due to the negative attitudes associated with labelling a defendant not criminally responsible (Roberts \& Golding, 1991). As mentioned earlier, a GBMI plea is similar to that of a guilty plea, but conveys the fact that the defendant is in need of mental health treatment in addition to punishment for his or her crimes once mental health has 
been restored (Roberts \& Golding, 1991). Negative attitudes associated with labelling a defendant not criminally responsible decreases jurors' ability to put faith in the Insanity defence and decreases the likelihood that jurors will find a defendant NGRI (Roberts \& Golding, 1991). Attitudes towards the NGRI defence seem to overcome legal instructions and evidence presented. However, recent knowledge suggests that biased verdicts may not stem solely from stigma towards the NCRMD defence.

My previous work (Fenwick \& Maeder, 2010; Maeder \& Fenwick, 2012; Maeder \& Fenwick, in preparation) tested NCRMD attitudes in a Canadian context. The first study examined 114 undergraduate psychology students (54 men and 60 women). Each participant was given an education sheet, containing either information regarding the NCRMD defence (e.g., the prevalence of NCRMD trials and success rates, outcomes for defendants who are found NCRMD), or irrelevant information regarding computer knowledge. Participants were then asked to read through a case vignette involving a murder charge with two child victims, in which the defendant pled NCRMD. Participants then provided a verdict and completed an NCRMD attitude scale, adapted to a Canadian context from the IDA-R (Skeem et al., 2004). It was found that mock jurors' attitudes toward the NCRMD defence were significantly more positive if they received education about the defence (i.e., the rarity of its use, its consequences, etc.). However, this effect did not translate into differences in verdicts.

The second study attempted to extend the findings of the first study using a different trial scenario, and both community and student samples. We were also interested in investigating potential differences between student and community samples in NCRMD attitudes and trial decision-making. We examined 127 undergraduate 
students and 131 community members. The material and procedure in this study were the same as those in Study 1, with a few exceptions. First, we replaced the irrelevant education regarding computer knowledge with irrelevant education regarding the structure of Canadian courts to ensure a better control condition. We also used a different case vignette, in which a defendant pled NCRMD to a murder charge involving the death of another adult rather than a child in an attempt to reduce any victim bias. With this sample, there was no effect of education on attitudes toward the defence or verdict decisions (Maeder \& Fenwick, 2012). However, there was a marginally significant effect of sample type on attitudes toward the NCRMD defence, such that students had more favourable attitudes toward the defence than did community members. Despite different case summaries (child victim vs. adult victim), verdicts remained unaffected by education. In addition, the second study was conducted online. The lack of an effect of education on verdicts in both of these studies suggests that factors other than misconceptions about the defence may drive verdict decisions in NCRMD cases. Even when participants' attitudes improved with education, they were still largely unwilling to find the defendant NCRMD. Such results may imply that juror attitudes towards the NCRMD defence may be driven by the effects of knowledge and stigma towards mental illness. Given that stigma towards mental illness is a prevalent issue in today's society, it could be a main source of bias in NCRMD verdicts.

\section{Stigma towards Mental Illness}

Living with mental illness can be an extremely distressing experience due to stigmatized attitudes towards mental illness. In general, people with mental illness are stereotyped as crazy, dangerous, violent, and unpredictable (Health Promotion and 
Programs Branch Health Canada, 1996; Hyler, Gabbard, \& Schneider, 1991), yet less than $3 \%$ of violent offences can be attributed to people with mental illness (Stuart \& Arboleda-Florez, 2001). The relationship between mental illness and violence has been highly debated (Shiply \& Borynski, 2013; Stuart, 2003). The majority of research indicates that individuals with mental illness are no more violent than individuals with no mental illness (Appelbaum, 2006; Torrey, 1998; Shipley \& Borynski, 2013). However, research suggests that certain subsets of mentally ill individuals are more dangerous and more likely to engage in violent behaviour in comparison to individuals with no mental illness (Swanson, Holzer, Ganju, \& Jono, 1990; Torrey, 1994, 1998). Within this subset are individuals with a history of violent behaviour, noncompliance with medication, and substance abuse (Cirincione, Steadman, Clark-Robbins, and Monahan, 1992; Torrey, 1994). Although there is a relationship between mental illness and violence, other studies suggest that demographics including ethnicity and gender are better predictors of violent behaviour than mental illness (Corrigan \& Watson, 2005). However, the media over exaggerates the link between mental illness and violence. Negative and inaccurate portrayals of mentally ill individuals are often associated with one sided, selective reporting by the mass media (Francis et al., 2005). Diefenbach and West's (2007) content analysis of television programs found that the media portrays mentally ill individuals as 10 times more violent than individuals with no mental illness. Furthermore, they found that participants' fear and avoidance reaction increases as the participants' television viewing increases. As a result, participants were less likely to support living next to someone who was mentally ill and more likely to support the notion that locating mental health services in residential neighbourhood would endanger residents. These 
negative portrayals are especially damaging since the mass media is the public's most important source of information about mental illness (Bornstein, 1992).

Although the media is criticized for its negative role in mental illness attitudes, the media can play a positive role. Dietrich and colleagues (2006) found that the unbiased media can neutralize negative impacts on attitudes towards people with mental illness. They found that adolescent participants were more likely to describe a mentally ill person as dangerous and violent if they read a newspaper article depicting a mentally ill individual negatively. However, when participants read a factual newspaper article, participants were significantly less likely to describe the mentally ill individual with negative terms such as violent and dangerous. Thus, corrective information appeared to neutralize negative descriptions of mentally ill individuals.

Furthermore, the general misunderstanding of a variety of mental disorders tends to increase stigmatized attitudes (Rusch et al., 2005). Studies show that a large majority of individuals within North America endorse stigmatizing attitudes about mental illness (Brockington, Hall, Levings, \& Murphy, 1993; Hamre, Dahl, \& Malt, 1994). As a result, the public's perception is that mental illness is comorbid with dangerous criminal behaviours. These conceptions tend to generate prejudicial reactions such as fear, anger, hostility, and defensive indifference. Studies have found that fear prejudice can lead to avoidant behaviours and anger prejudice tends to lead to the inclination to replace mental health care with the criminal justice system (Link et al., 1999; Rusch et al., 2005). The public's misunderstanding and stigma towards mental illness tends to generate through social dimensions, the most predominant being the media. The media portrays a distorted 
view of mental illness, which creates a negative reaction towards mental illness among the general population.

Unfortunately, many individuals make judgements without an understanding of mental illnesses and their characteristics. Schizophrenia is often perceived as the most controversial and ambiguous mental disorder. It is a mental disorder that makes it difficult to think clearly, have normal emotional responses, and distinguish reality from illusions (American Psychiatric Association, 2000; Schizophrenia: An information guide, 1999). People with schizophrenia have bizarre behaviour, social withdrawal, and delusions and/or hallucinations. Bipolar disorder, also known as manic depressive disorder, causes individuals to experience alternating mood swings, from emotional highs (mania) to emotional lows (depression; American Psychiatric Association, 2000; Mental Health addiction information: Bipolar disorder, 2000). Mania can cause an individual to have feelings of euphoria, decreased need for sleep, and impulsive behaviour whereas depression can cause feelings of worthlessness, thoughts of death or suicide, and difficulty concentrating or making decisions. Clinical depression is similar to the symptoms of the bipolar depression phase; however, clinical depressive symptoms become more severe, last several weeks, and begin to interfere with one's work and social life (American Psychiatric Association, 2000; Mental health addiction information, 2008). Substance use disorder refers to the abuse and dependence of any physical substance, most commonly drugs or alcohol (American Psychiatric Association, 2000). Substance use disorder is usually characterized by dangerous patterns of substance use, withdrawal symptoms when the substance is discontinued or reduced, and the persistence of abuse despite awareness of the physical and emotional problems that it causes. 
In addition to ill-informed judgements, individuals with a mental illness are viewed as their mental illness label rather than an individual living with mental illness. As Link and Phelan (2001) describe, "the linking of the labels to undesirable attributes becomes the rationale for believing that negatively labelled persons are fundamentally different from those who don't share the label" (p.370). Therefore, individuals with bipolar disorder or schizophrenia are consequently viewed as 'bipolar' or 'schizophrenic' and thought to be fundamentally different from the general public. Each specific mental illness label has marked differences in the public's concerns. Attitudes toward persons with schizophrenia tend to be the most negative in comparison to other mental illness labels and are most often associated with dangerousness, unpredictability, fear, anxiety, and social distance (Angermeyer \& Dietrich, 2006). The public believes that prospects for treatability, professional efficacy, and recovery are extremely reduced for persons with schizophrenia (Day, Edren, \& Eshleman, 2007). Unfortunately, endorsing such stereotypes increases strong negative reactions towards individuals with schizophrenia and increases preferences for social distance (Angermeyer \& Matschinger, 2003). Consequently, rejection is more pronounced in persons with schizophrenia than persons with other mental illnesses such as depression and anxiety disorders.

Similarly, individuals with substance use disorders are viewed as unpredictable and violent (Angermeyer \& Dietrich, 2006). However, rejection and social distance are more pronounced towards individuals with substance use problems (i.e., drug abuse and alcohol dependence) in comparison to schizophrenia (Martin, Pescosolido \& Tuch, 2000). Respondents often attribute substance use problems to the individual and view the problem to be within one's control. As a result, individuals are less empathic and 
more rejecting towards individuals with substance use problems. In addition, when a mental illness is viewed to be within one's control, persons are more likely to endorse coercive treatment (Corrigan, Markowitz, Watson, Rowan, \& Kubiak, 2003; Link et al., 1999). Furthermore, there has been a great deal of discussion of whether substance use disorder (i.e., alcoholism and drug addiction) should even be considered a disease (Heyman, 2009; Jellinek, 1960; Leshner, 1997).

Stigma towards depression and bipolar disorder seems to be relatively low when compared to schizophrenia and substance use disorder. Lay people are more sympathetic towards individuals with depression and feel the need to help them (Angermeyer \& Dietrich, 2006). In addition, treatment and recovery options for depression are viewed optimistically, although the majority of individuals are pessimistic towards the use of antidepressants as they feel antidepressants are addictive (Priest, Vize, Roberts, Roberts, \& Tylee, 1996). However, research has found that attitudes toward manic episodes of bipolar disorder are significantly more negative in comparison to depressive states (Wolkenstein \& Meyer, 2008).

Such prejudicial reactions have led people to argue that mentally ill offenders should be incarcerated in order to decrease the likelihood that they will reoffend. Although research has shown there is a relationship between mental illness and the likelihood of violent and criminal behaviour (Bonta, Law, \& Hanson, 1998; Link, Andrews, \& Cullen, 1992; Monahan, 1992; Monahan et al., 2001; Swanson et al., 2006), little research analyzes treatment outcomes for mentally ill offenders. In a meta-analysis of treatment outcomes among mentally disordered offenders, Morgan and colleagues (2012) found that treatments targeting psychopathology improved mental health 
symptoms; however, treatments that targeted psychopathology and 'criminalness' were inconclusive with regard to the effects of criminal or psychiatric recidivism. Furthermore, recidivism outcomes for the NCRMD population appear to be positive when compared to the general offender population. Crocker, Seto, Nicholls, and Cote (2013) examined 165 persons found NCRMD for a serious violent offence in Quebec, Ontario, and British Columbia in the early 2000's. During a three year follow-up period of NCRMD individuals under the purview of the Review Board or absolutely discharged, it was found that $10.4 \%$ of these individuals recidivated. For those who reoffended, $7.3 \%$ committed a violent offence and 3\% committed a non-violence offence. However, higher recidivism rates were found for those whose NCRMD index offence was a sexual offence (14.3\%). By comparison, the reconviction rate for a sample of non-mentally ill federal offenders released during 1994 to 1997 was $44 \%$ during their first year of release (Bonta, Rugge, \& Dauvergne, 2003). However, the reconviction rate for violence was only $14 \%$. Although these studies identify differences among mentally disordered offenders and non-mentally disordered offenders, these comparisons should be interpreted with caution due to differences in sampling, offence type, and period of detention.

Therefore, pleading NCRMD seems to be a beneficial option for mentally ill offenders as mentally ill individuals will receive specialized treatment. However, an accused or an accused's counsel may decide that raising issues of mental illness during a criminal process may not be in the defendant's best interest. An NCRMD verdict may avoid a criminal conviction, but outcomes may be worse. Often, this leads to stigmatization as well as an indeterminate confinement within the system responsible for managing mentally disordered persons (Latimer \& Lawrence, 2006). Research 
conducted in British Columbia has found that the period of institutionalization following a finding of NCRMD may be longer than the period of incarceration following a guilty verdict for the same offence (Vincent, 1999). Similar results have been found in the United States, indicating that accused persons who were found to have a mental illness whether rendered NGRI, GBMI, or guilty - receive harsher punishments than an accused without a mental disorder (Callahan, Steadman, McGreevy, \& Robins, 1991). This signifies that stigmatizing attitudes contribute to legal judgments, and that mentally ill defendants are not judged equally or fairly within the criminal justice system. Therefore, judges or jurors may not be as impartial as the criminal justice system assumes them to be.

Juror bias towards mental illness remains an understudied issue within North America. The central focus of NCRMD and Insanity defence research is mainly juror attitudes toward the defense. Little attention has been given to potential prejudice towards mental illness. The current study expanded upon NCRMD and Insanity defense research by assessing stigma towards mental illness in juror decision-making.

\section{Legal Context: Juror Decision-Making biases}

Although the criminal justice system assumes jurors can rationally and impartially process information, research has demonstrated that jury decision-making is much more complex. Researchers have found that jurors are influenced by variables such as previous knowledge, the media, and extralegal factors (Finkel \& Sales, 1997). Various theoretical models of juror decision-making have been proposed to offer an explanation as to how jurors process evidence and arrive at their final decision. Tversky and Kahneman (1974) outline three heuristics that individuals employ when making complex judgements and 
Vidmar's $(1997,2002,2003)$ generic prejudice model provides a theoretical basis for juror decision-making that focuses on numerous types of prejudice that can infuse the trial process.

Juror Decision-Making heuristics. Tversky and Kahneman’s (1974) revolutionary research regarding decision-making suggests that people rely on cognitive heuristic principles to quickly and efficiently make judgments. These principles reduce the complexity of making uncertain judgements to simpler judgmental operations. Tversky and Kahneman (1974) described three heuristics that are employed when making uncertain and complex judgments: representativeness, availability, and anchoring-andadjustment. Representativeness is used to evaluate the degree to which an individual or event is similar in essential properties to its parent population. For instance, stereotypical expectations can lead to differences among sanctions. Hill, Harris, and Miller (1985) found that judges and juries adjudicated intraracial homicides of African Americans less seriously than intraracial Caucasian homicides or homicides of Caucasians by African Americans. African Americans reportedly represented social disorganization and were subsequently viewed as having a greater tendency toward violence in their population, thus fitting with the expectations formed by the judges and jurors. Availability is used by jurors to assess the frequency of a group or probability of an event by the ease with which instances or associations come to mind. This can often lead to biases in judgment based on expectations and individual experiences. Stalans' (1993) research on punishment preferences found that an availability heuristic can produce more unstable contextdependent judgements. When individuals were asked to recommend a suitable punishment in abstract cases, they relied on stereotypes as well as their recall of violent 
crimes. Furthermore, participants formed punishment preferences based on their recall of specific crimes and the recall of a crime stereotype. Anchoring-and-adjustment involves making estimates by adjusting the initial value to yield the final answer. However, research shows that individuals have difficulty making adjustments. Robbennolt and Studebaker (1999) found that mock jurors were more likely to increase the size and variability of damage awards in civil cases when monetary caps were set in place. Thus, jurors' judgments are based on initial information provided by the courts and it becomes difficult for jurors to adjust sufficiently from this information.

These rules attempt to make judgements more quick and efficient by reducing the amount of effort and cognitive resources used. Thus, when individuals are overwhelmed by the complexity of the task at hand they are forced to simplify judgemental tasks in order to conserve mental resources (Fiske, 1998). Such rules can make judgments more accurate; however, they can also lead to systematic errors in reasoning. Kahneman and Tversky (1979) contend that rules that lead to systematic errors can support stereotypic thinking, which is believed to be flawed in that it is "unchanging, rigid, overly categorical, undifferentiated, overly simplistic, and inaccurate because variation among individual instances is not taken into account" (Lee, 1989, p. 10).

Given that heuristics are more efficient and require less effort than analytic thinking, they serve as a default mode for decision-making, potentially causing errors in judgments. Individuals are more susceptible to systematic errors when they hold stereotypes, biases, and prejudices (Bigler \& Liben, 1993), which is evident in juror decision-making. According to section 11(d) of the Canadian Charter of Rights and Freedoms (1985), "any person charged with an offence has the right to be presumed 
innocent until proven guilty according to law in a fair and public hearing by an independent and impartial tribunal". This means that jurors are viewed as having an absence of bias, actual or perceived, in relation to the issues and parties in a particular case. However, jurors are regular Canadian citizens who have previous knowledge and experiences. Even though jurors must not allow themselves to be influenced by anything except the evidence presented in court, jurors may unknowingly and unwillingly rely on knowledge fostered by underlying stereotypes, biases, and prejudices (Bornstein \& Rajki, 1994; Rokeach \& Vidmar, 1973). Stereotypical thinking can invoke fear and rejection, leading to biased judgments despite evidence presented in court. Therefore, previous biases increase the likelihood that jurors will make systematic errors, leading to unfair trials.

Juror decision-making research has found that heuristic cues can be inadvertently activated within the courtroom, impacting juror decision-making. Extra-legal factors such as race, physical attractiveness, sex, and socioeconomic status can foster stigmatized opinions, thereby influencing juror verdicts (Bornstein \& Rajki, 1994; Dane \& Wrightsman, 1982; Mazzella \& Feingold, 1994; McGlynn, Megas, \& Benson, 1976; Pozzulo, Dempsey, Maeder, \& Allen, 2010; Rokeach \& Vidmar, 1973; Ugwuegbu, 1979). These biases affect juror decision-making by undermining the standard of proof and the presumption of innocence, increasing the likelihood that the defendant will not obtain a fair trial. If heuristics are inevitable in uncertain and complex situations, the goal should be to reduce stereotypes, biases, and prejudices to reduce the likelihood that they will make systematic errors and increase the likelihood that jurors can make 
impartial judgements. If stereotypic thinking can be reduced, it should increase the likelihood that jurors will make impartial judgements.

Generic prejudice. The generic prejudice model is a theoretical explanation for juror decision-making that focuses on the numerous types of prejudice that can infuse the trial process. Vidmar $(1997,2002,2003)$ proposed that prejudice includes general attitudes, beliefs, and biases that render jurors biased and partial when deciding verdict outcomes. Vidmar (2002) proposed that there are four categories of prejudice that can bias jurors' decision-making: interest, specific, conformity, and generic prejudice. The first category of prejudice, interest prejudice, involves a juror who has a direct or indirect interest in the outcome of the trial. For instance, a person who may possess interest prejudice could be a relative to the victim or the accused in the criminal trial. The second category of prejudice, specific prejudice, occurs when a juror holds attitudes or beliefs that are related to specific issues in the case. Specific prejudice can be related to issues such as the knowledge of a defendant's prior criminal record or an improperly obtained confession. Conformity prejudice, the third category of prejudice, involves how community expectations influence juror verdict decisions. Finally, generic prejudice involves pre-existing prejudicial attitudes, beliefs, or stereotypes regarding the persons involved in the criminal trial or the crime itself. For instance, if a juror holds prejudiced beliefs regarding all offenders who plead that they are NCRMD, they may render all NCRMD cases guilty regardless of the presenting evidence.

Vidmar (1997) tested his generic prejudice model in an experiment that included 25 sexual abuse trials in Canada. In this study, 849 prospective jurors were asked whether they could hear evidence, follow legal instructions, and render a verdict fairly 
and impartially given the circumstances of the case. The sexual abuse cases mostly consisted of male defendants facing charges for sexual assaults against both males and females ranging from 5 years of age to 23 years of age. Vidmar found that on average, $36 \%$ of jurors indicated that they could not decide the case with a fair and impartial mind due to an inherent bias. Some explanations for the lack of impartiality were that participants themselves were victims of sexual abuse, knew a person who had been a victim of sexual abuse, feared that children needed protection from sexual abusers or simply were unable to set aside a presumption of guilt. Thus, research concluded that jurors may be unable to judge sexual assault defendants impartially due to generic prejudice. However, Vidmar (1997) proposes that even though generic prejudice may encompass a jury panel, it is very difficult to identify. Furthermore, sexual assault cases within the NCRMD only account for approximately $4 \%$ of NCRMD cases.

Since this model is rather recent, it has yet to be tested within NCRMD or NGRI trials. However, Wiener and colleagues' (2006) research looks at generic prejudice in sexual assault and homicide trials. The experiment used 82 undergraduate research participants as mock jurors in order to demonstrate that generic prejudice is more likely to be found in sexual assault cases than homicide cases. Participants received 20 criminal scenarios, and were asked to indicate whether the defendant was guilty of the crime for which he was charged and then rate how certain they were of that verdict on a 9-point Likert-type scale $(1=$ very uncertain to $9=$ very certain $)$. Results indicated that there was strong evidence of generic prejudice for the sexual assault cases, but only moderate to weak evidence for homicide cases. These results provide experimental support for generic prejudice in sexual assault trials, which suggests that it may be challenging to 
obtain an impartial jury to try defendants for certain kinds of cases where people harbour bias or stereotypes. Given that the public holds a large degree of prejudice towards the NGRI and NCRMD defence, it is very likely that prejudice could be used when rendering an NGRI or NCRMD verdict. Jurors may harbour prejudice towards mental illness or the defence. Therefore, generic prejudice could account for why jurors are so reluctant to render an NGRI or NCRMD verdict.

\section{Education: Reducing Stigma towards Mental Illness}

Juror partiality in NCRMD trials is a potential issue within the Canadian criminal justice system given that defendants may not be receiving a fair trial. Previous studies in the United States claim that biases toward the NGRI defence are based on myths that reflect inaccurate knowledge (Skeem et al., 2004). Such studies have suggested a need for cost-effective remedies to help overcome media-induced bias towards the defence. My previous studies examined whether educating jurors about the NCRMD defence could reduce bias in decision-making (Maeder \& Fenwick, 2010, 2012). Most recently, analyses revealed that there was no effect of education on attitudes toward the defence or verdict decisions. These results suggest that juror attitudes towards the NCRMD defence may be based on stigma toward mental illness rather than overwhelming NCRMD misconceptions as literature previously concluded.

Given that stigma towards people with mental illness is a prevalent issue in North America, it is no surprise that anti-stigma initiatives have been implemented in an attempt to improve the lives of persons with mental illness (Bell: Let's talk, n.d.; Clark et al., 2013). Strategies that show promising avenues involve educating the public and initiating direct contact with persons who have these disorders (Corrigan et al., 2001; 
Esters, Cooker, \& Ittenbach, 1998; Reinke, Corrigan, Leonhard, Lundin, \& Kubiak, 2004). These approaches seek to replace stigmatizing attitudes with accurate conceptions and challenge attitudes towards mental illness through direct contact. Previous research has found that anti-stigma initiatives can reduce stigma towards persons with mental illness (Chan, Mak, \& Law, 2009; Corrigan, Larson, Sells, Nieseen, \& Watson, 2007; Pinfold et al., 2003; Schmetzer, Lafuz, \& Jack, 2008); however, no such initiatives have been directly tested within trials involving mentally ill offenders.

Education programs are based on the finding that stigma and discrimination are less likely to be endorsed by individuals who are more knowledgeable about mental illness (Brockington et al., 1993; Link, 1987). Both short term and long term education programs have been found to be effective among adolescents ( $\mathrm{Ng} \& \mathrm{Chan}, 2002)$ and adults (Corrigan et al., 2001, 2002) with significant changes in attitudes lasting up to 14 weeks (Morrison \& Teta, 1980). In addition, Mansouri and colleagues (2009) found that short term training programs on mental health improved knowledge and attitudes in community members and health care workers, both immediately after the intervention and for the long term (i.e., two weeks, one year, and two years).

Corrigan and colleagues (2001) examined education and contact effects on attitudes and knowledge structures and found that those assigned to the education condition, which sought to replace myths about mental illness with accurate information, were more willing to agree that persons with mental behaviour disabilities would benefit from medical treatment, and therefore have the potential to recover. Furthermore, the contact condition, which challenged public attitudes about mental illness through direct contact with persons who have disorders, was found to provide positive effects with 
regards to attitudes towards psychiatric disabilities. These contact effects yielded significantly greater reductions in stigma than education, as evidenced by the fact that participants recalled more positive information regarding individuals with mental illness. Thus, contact affected the subsequent processing of social information.

Given that direct contact is most often unfeasible (Stuart, 2006), researchers have examined the impact of indirect video based contact with promising results. Reinke and colleagues (2004) found that indirect video-based contact yields similar attitude improvements when compared to direct contact. As a result, research has shifted towards examining the effect of education and video-based contact. Such studies have found that when a combined approach is used, participants' attitudes and knowledge of mental illness significantly improve immediately after the program (Esters et al.,1998), at one month follow up (Schulze, Richter-Werling, Matschinger, \& Angermeyer, 2003) and at six months follow up (Pinfold et al., 2003). Furthermore, Chan and colleagues (2009) examined the effects of three different stigma reduction programs against mental illness education, education followed by video-based contact, and video-based contact followed by education. Results suggested that large improvements in stigmatizing attitudes could be made only when contact was presented after education. Corrigan and colleagues (2007) examined the impact of education and contact presented via videotape and found that the contact videotape produced consistent positive changes in pity, power, avoidance, and segregation for both the post-test and one week follow up. Lastly, video based education only increased the likelihood that participants would believe people with mental illness are not responsible for their symptoms and disabilities. 
Even though such studies offer support towards the effect of education on attitudes, no studies outside of our earlier research have been conducted to examine the effect of education within NCRMD trials. However, such education strategies used to counter bias in jury decision-making have been tested in sexual abuse trials. Kovera and colleagues (1997) examined whether expert testimony serves as an educational or a persuasive function in juror decision-making. During the trial simulation participants heard numerous testimonies, the most important being a prepared or unprepared victim testimony from an 8-year-old female, and a clinical psychologist who presented expert testimony. Participants were randomly assigned to a control condition that contained no expert testimony or one of three conditions of expert testimony: standard testimony (i.e., a summary of research), repetitive testimony (i.e., standard testimony plus a second summary of the research), or concrete testimony (i.e., standard testimony plus a hypothetical scenario linking the research to the case facts). Kovera and colleagues (1997) found that certain types of expert testimony acted as an educational or persuasive function in juror decision-making and affected verdict outcomes. The results suggested that concrete testimonies sensitized jurors to relevant evidence at trial and repetitive testimonies increased the victim's credibility and conviction rates independent of the child's witness preparation. However, concrete and standard testimonies failed to increase conviction rates independent of the child's preparation. The study suggests that educational information on persons with mental illness could take on an educational or persuasive function in juror decision-making. Even though this study offers relevant information towards education in criminal trials, further research needs to be conducted specifically in NCRMD trials to determine if expert testimonies act as an educational 
function or if anti-stigma programs on mental illness can act as an educational function in NCRMD trials. The current study focused on the latter - i.e., whether mental health education can reduce stigma against persons with mental illness, thus influencing attitudes and verdicts.

\section{Current Study}

Public attitudes toward people with mental illness are particularly negative (Phelan, Link, Stueve, \& Pescosolido, 2000), which intensifies the discrimination that a person with mental illness will face. Although measures such as the NCRMD defence have been implemented within the criminal justice system to ensure that defendants with mental illness are treated fairly, it seems as though prejudiced attitudes toward the NCRMD defence limit the right to a fair trial (Maeder \& Fenwick, 2012). An overwhelming amount of research on the NGRI defence and the NCRMD defence has focused on attitudes towards the defence, which confirms that such attitudes are predominately negative. However, a main criticism of the research to date is the lack of research examining measures to reduce Insanity stigma. In addition, little is known about the consequences that mental illness stigma have on the trial process. This study was the first to examine mental illness stigma within NCRMD trials while also exploring effective interventions to reduce such stigma within the courtroom context. The purpose of this study was to explore juror stigma towards defendants with mental illness and examine the impact of education on juror decision-making in NCRMD cases. Specifically, this study explored whether mental illness and NCRMD education can affect juror attitudes towards mental illness and the NCRMD defence, as well as verdicts. By assessing attitudes and verdict ratings with education, I sought to identify whether 
stigma towards mental illness is of concern in judicial settings while also offering measures to reduce stigma towards mental illness.

\section{Hypotheses}

\section{Hypothesis 1}

There will be a main effect of defendant mental illness on defendant perceptions and mental illness stigma. People with schizophrenia and substance use disorder are more often viewed as unpredictable, violent, and dangerous than people with depression or bipolar disorder (Angermeyer \& Dietrich, 2006). Furthermore, defendants with schizophrenia are more likely to receive harsher sentences in the criminal justice system (Corrigan et al., 2000). Therefore, schizophrenia and substance use disorder will generate more negative defendant perceptions and mental illness stigma in comparison to depression and bipolar disorder.

\section{Hypothesis 2}

There will be a main effect of mental health education on defendant perceptions and mental illness stigma (Mansouri et al., 2009). Specifically, those in the general mental illness education group will report lower levels of mental illness stigma [as measured by the Mental Illness Stigma Scale (MISS; Day et al., 2007)] when compared to the diabetes education group. In addition, those in the general mental illness education group will rate the defendant more favourably when compared to the diabetes education group.

\section{Hypothesis 3}

Mental illness education will produce an effect on verdicts and combined mental illness and NCRMD education will increase the effect on verdicts (Maeder \& Fenwick, 
2012). Maeder and Fenwick (2012) suggest that juror attitudes towards the NCRMD defence may be based on stigma towards mental illness rather than overwhelming NCRMD misconceptions. Furthermore, accurate mental illness education has been shown to positively alter attitudes towards persons with mental illness (Mansouri et al., 2009). Thus, it is hypothesized that mental illness education will independently reduce mental illness stigma and increase NCRMD verdicts. In combination, it is hypothesized that mental illness and NCRMD education will reduce mental illness stigma and NCRMD stigma and increase NCRMD verdicts in comparison to mental illness education exclusively. Given our previous research in this area (Maeder \& Fenwick, 2012), NCRMD education alone is not anticipated to have an effect on verdicts.

\section{Hypothesis 4}

The verdict - mental illness stigma model (figure 1) hypothesizes that a verdict decision is reached as a function of a number of variables. Specifically, defendant mental illness and education will impact on jurors' mental illness attitudes, and these specific attitudes in turn will predict juror verdict decisions. Attitudes towards mental illnesses such as schizophrenia and substance use disorder may be less amenable to education since they are frequently viewed more negatively and harshly than mental illness such as depression and bipolar disorder (Angermeyer \& Dietrich, 2006). Attitudes towards controllability (mental illness avoidant behaviour and personal blame attributed to mental disorders) appear to be less amenable to education for mental illnesses associated with stronger stigma towards mental illness (Corrigan et al., 2001), thus reducing the likelihood of informed NCRMD verdicts. 




Figure 1. The Verdict-Mental Illness Stigma Model

\section{Method}

\section{Participants}

Jury-eligible participants within Canada were recruited through Amazon

Mechanical Turk (MTurk) and Qualtrics Panels. MTurk is a new recruitment method that offers social science researchers access to a large pool of participants while significantly lowering costs. The MTurk subject pool has been found to be similar to that of convenience samples used by other researchers in political science; however, on average, recruits are younger, more liberal, and pay more attention to tasks than the general public (Berinsky, Huber, \& Lenz, 2012). Unfortunately, MTurk did not have a large sample of Canadian participants; therefore, the remainder of participants were recruited through Qualtrics panels. Qualtrics panels distribute surveys out through its panel partners to the 
targeted respondents, inviting respondents to complete the online survey in return for incentives/cash honorarium. In addition, data was collected through Qualtrics, which is a leading provider of Online Survey Software. Ideally, mock juror research simulates a legal trial within a lab setting; however, web based studies have been found to yield similar conclusions when compared to studies completed within the lab (Krantz \& Reeshad, 2000).

A power analysis was conducted to determine the number of participants needed in this study. To achieve power of .80 and a medium sized effect, a sample of 30 participants per condition $(\mathrm{N}=480)$ was required to detect the critical F-Value. In total, 1089 participants took part in this study. A total of 43 participants withdrew from the study, 71 participants did not consent to the use of their data, and 465 participants failed manipulation checks. In addition, 22 individuals were not randomly assigned to a condition; therefore, they were omitted from the study. Four-hundred and eighty-eight participants passed all manipulation checks; however, two participants' scores were omitted from the study (ID number 21 and 149) as the majority of their data was incomplete. If participants failed the NCRMD education, mental illness education, and trial transcript manipulation checks they were diverted to the end of the study. When examining the failed NCRMD education checks $(n=203)$, there were 43 fails for ' $a$ verdict of NCRMD is synonymous with which finding,' 62 fails for 'which of the following dispositions are available in NCRMD cases,' and 73 fails for 'approximately how many individuals are found NCRMD each year.' For those who read the mental illness education $(\mathrm{n}=158)$, there were 48 fails for 'substance use disorders are,' 18 fails for 'individuals with depression,' 56 fails for 'individuals with bipolar disorder who are 
experiencing mania,' 73 fails for 'individuals with schizophrenia,' and 47 fails for 'psychosis is associated to.' For the trial transcript manipulations $(\mathrm{n}=100)$, there were 28 fails for 'during the crime, what happened to Robert Warner, the cashier' and 17 fails for 'where did the crime take place.' Furthermore, a total of 65 participants failed 'what mental illness did the defendant, Mike Smith, have' $(\mathrm{n}=100)$. The breakdown of fails for 'what mental illness did the defendant, Mike Smith, have' per defendant mental illness type can be found in Table 1, below.

Table 1.

Failed Defendant Mental Illness Manipulation Checks per Defendant Mental Illness Type

\begin{tabular}{lcc}
\hline & \# of Failed Manipulation checks & N \\
\hline Schizophrenia & 8 & 19 \\
Depression & 19 & 30 \\
Bipolar & 13 & 23 \\
Substance use & 25 & 28 \\
\hline
\end{tabular}

Thus, a final sample of 486 participants (16 conditions $\mathrm{x}$ an average of 30 participants/condition) was drawn from an online community sample. Participants were $67.3 \%$ female, $32.5 \%$ male, and ranged in age from 18 to $82(M=49.49, S D=14.92)$. The majority of participants identified themselves as Caucasian $(90.3 \%)$, with the remaining participants identifying as Asian (4.1\%), African Canadian (1\%), Aboriginal Canadian (1\%), and 'Other' (2.9\%, mixed race). The educational background was mixed, with $35.2 \%$ of participants holding a Bachelor's degree, $35 \%$ a high school diploma or equivalent, $8.6 \%$ a Master's degree, $2.7 \%$ less than high school, .8\% a PhD, .4\% a Law degree, and $17.3 \%$ 'Other'. In addition, the majority of participants indicated that they 
personally know someone who is mentally ill (56.4\%) and 10\% of participants selfidentified as having a mental illness.

\section{Materials}

Mental illness attitude measure. The Mental Illness Stigma Scale (MISS; Day et al., 2007) was developed to address shortcomings of previous mental illness attitudes measures (see Appendix K). In particular, the scale can be used to measure general mental illness attitudes as well as specific mental illness attitudes. Participants answered 28 specific mental illness statements using a 7-point Likert-type scale, where $1=$ completely disagree and $7=$ completely agree. Examples of these statements include, "there are effective medications for mental illnesses that allow people to return to normal and productive lives," and "there is little that can be done to control the symptoms of mental illness." The MISS scale measures seven subscales of attitudes and beliefs about mental illness: anxiety, relationship disruption, hygiene, visibility, treatability, professional efficacy, and recovery. High scores on treatability, professional efficacy, and recovery indicate positive attitudes, whereas high scores on the other subscales indicate more stigmatized attitudes. Research has found that the MISS scale is internally consistent, with a Cronbach's alpha ranging from .71 to .90 . Similar results of internal consistency have been obtained in an examination of college students by Stone and Merlo (2011; Anxiety: $\alpha=.85$, Relationship disruption: $\alpha=.84$, Hygiene: $\alpha=.87$, Visibility: $\alpha=$ .68 , Treatability: $\alpha=.64$, Professional efficacy: $\alpha=.86$, Recovery: $\alpha=.86$ ).

NCRMD attitude measure. The Insanity Defence Attitudes-Revised scale (Skeem et al., 2004) was revised and used to assess attitudes toward the Canadian NCRMD defence (see Appendix J). The scale contains 22 items answered on a 7-point 
Likert scale $(1=$ strongly disagree, and $7=$ strongly agree $)$. Examples of items in the scale are, "the NCRMD defence returns disturbed, dangerous people to the streets," and "I believe that mental illness can impair people's ability to make logical choices and control themselves." The IDA-R measures two factors: strict liability, and perceived injustice and danger. Strict liability captures the extent to which a juror believes mental illness is relevant to the issue of criminal responsibility, whereas perceived injustice and danger captures how a juror perceives the NCRMD defence itself with regard to misuse and possible threat to public safety. A high score indicates negative attitudes towards the defence. Both strict liability and perceived injustice and danger have been shown to have moderate to good internal consistency ( $\alpha=.68$ for strict liability, $\alpha=.88$ for injustice and danger; Skeem et al., 2004; $\alpha=.84$ for strict liability, $\alpha=.80$ for injustice and danger; Bloech et al., 2007).

Education. There were two mental health education conditions: mental illness and diabetes (control) education (see Appendices $\mathrm{C}$ and $\mathrm{D}$ ), and two defence education conditions: NCRMD and duress (control) education (see Appendices A and B). Each education sheet was approximately two pages, with content derived from current empirical research and case law. Mental illness education included concise information on symptoms, causation theories, treatments, and recovery for schizophrenia, bipolar, depression, and substance use disorder. NCRMD education included information about prevalence and success rates of the defence, as well as potential outcomes of NCRMD verdicts. The diabetes and duress education sheets were similar in content and length to the mental illness and NCRMD education sheets, and served as controls. 
Trial transcripts. The trial transcript included a defendant who is pleading NCRMD to a second degree murder charge, detailed facts in evidence, the defendant's medical record, and statements from both the crown and the defence. To accurately represent the NCRMD process and to ensure reliability for the IDA-R, the trial transcript was based on those used by Shiva (2001) and Skeem (1999). Although the facts in evidence remained the same, the defendant's medical record and statements addressed by the Crown and defence were manipulated according to the mental illness condition. To ensure consistency across all trial transcripts, all defendants were previously diagnosed with a mental illness and had stopped taking medication shortly before the crime in question. Therefore, differences should be a function of the mental illness itself. Furthermore, written transcripts have shown to be equivalent to video, live, or audio-only trial presentations (Bornstein, 1999), and thus should not present problems for this study.

Four mental illnesses were manipulated for the purpose of this study: schizophrenia, bipolar, depression, and substance use disorder. These mental illnesses most frequently occur within NCRMD data and NCRMD remands. NCRMD data suggested that the most prevalent mental illnesses within NCRMD cases are schizophrenia, substance use disorder, mood disorders, and personality disorders (Latimer \& Lawrence, 2006; Livingston et al., 2003; Roesch et al., 1997). Therefore, mental illnesses such as substance use disorder, schizophrenia, depression, and bipolar are the most useful for the purpose of this study as these mental illnesses would provide a realistic NCRMD claim. Furthermore, mental illnesses most likely to be stigmatized within a criminal context are useful for this study to determine whether education can neutralize negative effects of stigmatization such as rejection, fear, and social distance. 
Therefore, mental illnesses associated with a high degree of mental illness stigma, such as substance use disorder and schizophrenia, were chosen for the purpose of this study. Research has shown that attitudes towards substance use disorders and schizophrenia are extremely negative in comparison to other mental illnesses (Angermeyer \& Dietrich, 2006; Day et al., 2007). In addition, substance use disorder and schizophrenia are often labelled as dangerous, unpredictable, and violent, which leads to rejection and social distance from the public (Angermeyer \& Dietrich, 2006; Martin et al., 2000).

Manipulation checks. Following each education sheet, participants were asked to complete a manipulation check without reference to the preceding information to ensure that each education was read and understood. Participants were asked a series of questions on the main points addressed in the education sheet, such as: "approximately how many individuals are found NCRMD each year", and "are substance use disorders considered to be mental disorders?" (See Appendices A, B, C, and D for complete questions). These questions highlighted information that is often misunderstood. In addition, participants completed a manipulation check following the trial transcript. Without reference to the preceding trial transcript, participants were asked to indicate the defendant's mental illness. To ensure that participants were attending to the trial transcript, they also were asked what happened to the victim, and where the crime took place (See Appendix I). Participants who incorrectly answered NCRMD education, mental illness education, and trial transcript manipulation checks were diverted to the end of the study. 
Juror demographics. The juror questionnaire consisted of a range of questions regarding participant demographic information (such as age, gender, race, education, and whether they have had any exposure to a person with mental illness (see Appendix I).

Dichotomous verdict. Participants were asked to issue a verdict of either NCRMD (-1=not criminally responsible on account of mental disorder) or guilty of murder (1=guilty of murder; see Appendix I).

Verdict confidence. On a scale ranging from 1 (not at all confident) to 9 (very confident) participants were asked to indicate the degree of confidence they placed in their verdict (see Appendix I).

Perceptions of the defendant. Participants were asked about their perceptions of the defendant with respect to nine dimensions (i.e., the extent to which the defendant was mentally disordered, appreciated that his actions were wrong, was capable of perceiving alternatives, reasoning logically, acting differently, behaving rationally, could help believing what he did and should be blamed or punished). Answers were indicated on a scale from 1 to 7 (see Appendix I).

\section{Procedure}

Upon recruitment, participants were directed to the online survey software Qualtrics and were asked to read the consent form and indicate whether they consented to participate in the research. Once informed consent was obtained, participants were asked to answer qualification questions, which were included to ensure juror-eligibility (i.e., age, Canadian citizenship, no prior convictions, and a high degree of English literacy). If participants were eligible, they were presented with two randomly assigned education pages (mental illness or diabetes education, and NCRMD or duress education). Following 
education, participants were asked to complete a manipulation check to ensure that each education sheet was read and understood. Participants then read a brief trial transcript, which described a second-degree murder committed by a defendant whose mental illness was manipulated. Following the trial transcript, participants were asked to render a verdict (guilty/NCMRD), and provide a confidence rating regarding their verdict. In addition, participants were asked to complete a trial transcript manipulation check to ensure that they correctly identified the defendant's mental illness and certain facts in evidence. Finally, participants completed the juror questionnaire, the MISS scale, and the Canadian revised IDA-R scale. The last two scales were counterbalanced. For the purpose of this study, participants answered the MISS scale with regards to the particular mental illness type that they were assigned. Thus, specific mental illness attitudes were measured according to mental illness manipulation.

\section{Design}

A 2 [Mental Health education: mental illness, diabetes], x 2 [Defence education: NCRMD, duress], x 4 [Defendant mental illness: schizophrenia, bipolar, depression, substance use disorder], between-subjects factorial design was used to examine attitudes and verdict decisions. A control condition (no-mental illness) was not used as the defence must establish a claim of mental disorder in NCRMD trials. Thus, it would be unnecessary to include a defendant who was not suffering from a disease of the mind and who is not eligible to use the NCRMD defence.

Creation of variables. To obtain a sensitive measure of guilt, a continuous variable of verdict rating was created by multiplying dichotomous verdict $(-1=$ NCRMD, $1=$ Guilty $)$ by verdict confidence $(1=$ completely unconfident to $9=$ completely 
confident). The variable ranged from -9 (very confident that the defendant was NCRMD) to 9 (very confident that the defendant was guilty). The continuous verdict score is widely accepted and commonly calculated in jury research (e.g., Cohn, Bucolo, Pride, \& Sommers, 2009; Sommers \& Ellsworth, 2001). Scales for defence credibility, Crown credibility, and perceptions of the defendant were made (rated 1 to 9), with some items needing to be reverse-coded. To analyze defendant perception scores, three items were reverse coded and mean scores were combined to yield the best reliability. Therefore, lower scores indicate more positive defendant impressions. All scales were checked for adequate reliability and were found to have good reliability with Cronbach alpha's above .80. Before combining scores for the Mental Illness Stigma Scale, three items were reverse coded for analysis, so that higher scores represented more negative attitudes. After combining scores, total mean scores $(\alpha=.87)$ were computed with higher scores representing more stigmatized attitudes. To analyze Insanity Defence Attitudes with the IDA-R scale, five items were reverse coded, such that higher scores represent negative attitudes towards the NCRMD defence. Total mean scores were computed for the total IDA-R $(\alpha=.92)$, the Strict liability subscale $(\alpha=.81)$ and the Perceived Injustice and Danger subscale $(\alpha=.92)$. All were found to have adequate reliability.

\section{Results}

Prior to analysis, the data were examined for potential assumption violations. First, data were screened for univariate and multivariate outliers. One participant was identified as a univariate outlier (ID number 3 ) on the IDA-R variable, with a z-score of 3.56. This IDA-R attitude score was corrected by recalculating the score to within 3.29 standard deviations from the mean, as per Cohen, Cohen, West, and Aiken's (2003) 
recommended remedial measures. Three participants (ID numbers: 131, 58, 342) were identified as potentially problematic multivariate outliers as their Maholonbis distance fell outside the normal distribution (Maholonobis values 16.01, 13.70, 13.19). One value exceeded the critical $\chi^{2}$ value of 13.82 (Cohen et al., 2003), suggesting that remedial measures were needed. Furthermore, examination of DFIT values suggested that there were two (ID number: 131,342$)$ potentially problematic multivariate outliers $(.05, .05 ; \mathrm{k}$ $=1 / \mathrm{n}$ ), which were identified by the Maholonobis distance assessment. Out of the three potential multivariate outliers, two participants ranged from the lowest and/or highest scores on predictor variables (i.e. mental illness attitudes, Insanity defence attitudes, defendant perceptions); however, one participant rendered particularly high scores on all predictor variables. Given that this participant had exceptionally high scores across all measures, it is possible that this participant has a high degree of punitiveness. However, even if this is the case, he or she is still of interest to the current study. Thus, remedial measures were needed. Multivariate outliers were corrected by Windsorizing the data and replacing extreme values within the $95^{\text {th }}$ percentile of the data.

Finally, assumptions of independence, homogeneity of variance, and normality were examined. Independence and homogeneity of variance were met; however, upon examination of histograms, skewness and kurtosis statistics, it was determined that normality for dichotomous verdict and continuous verdict were slightly violated. Since regression and ANOVA are considered robust against normality deviations (Lorenzen \& Anderson, 1993; Van Belle, 2002), normality was deemed adequate to proceed with analysis. Furthermore, the data obtained is based on valid data-points.

\section{Dichotomous Verdict}


A stepwise binary logistic regression was conducted to examine our hypothesis that mental illness education will produce an effect on verdict, and that combined mental illness education and NCRMD education will increase the effect on verdict. Three separate models were tested across three blocks. The first block included defence education $($ coded as $0=$ duress, $1=$ NCRMD), mental health education (coded as $0=$ diabetes, $1=$ mental illness), three mental illness type variables contrast coded with substance abuse as the comparison group (schizophrenia vs substance use [coded as $0=$ substance use disorder, $1=$ schizophrenia], bipolar vs substance use [coded as $0=$ substance use disorder, $1=$ bipolar], and depression vs substance use [coded as $0=$ substance use disorder, $1=$ depression]) as the predictor variables and dichotomous verdict (coded as $0=$ guilty, $1=\mathrm{NCRMD}$ ) as the criterion variable. The second block included all the previous predictors, but included all possible two way interactions between these variables. The final block included all previous predictors in addition to three way interactions between these variables.

A test of the first block model was statistically significant compared to the null model, $\chi^{2}=48.28, p<.001$, with a Nagelkerke's $\mathrm{R}^{2}$ of .13 . However, the Hosmer and Lemeshow test was not statistically significant $\left(\chi^{2}=16.62, p=.02\right)$, indicating that the model was not a good fit. The second model was also statistically significantly compared to the first block, $\chi^{2}=15.75, p<.03$, with a Nagelkerke's $\mathrm{R}^{2}$ of .17 and a Hosmer and Lemeshow's $\chi^{2}$ of 5.62, $p=.47$. Finally, the last block's model was statistically significant compared to the first two blocks, $\chi^{2}=16.10, p<.001$, with a Nagelkerke's $\mathrm{R}^{2}$ of .21 and a Hosmer and Lemeshow's $\chi^{2}$ of $0, p=1$. Thus, the product terms significantly improved the model fit. The results from the logistic regression are presented in Table 2. 
Table 2

Summary of Logistic Regression Analysis Predicting Verdict Selections $(N=486)$

\begin{tabular}{|c|c|c|c|c|c|c|}
\hline Variable & B & $\mathrm{SE}$ & OR & $95 \% \mathrm{CI}$ & $\begin{array}{c}\text { Wald } \\
\text { Statistic }\end{array}$ & $P$ \\
\hline \multicolumn{7}{|l|}{ Defence education } \\
\hline NCRMD & -1.47 & .51 & .23 & {$[.09, .62]$} & 8.39 & .004 \\
\hline Duress $^{a}$ & $0 *$ & & & & & \\
\hline \multicolumn{7}{|l|}{$\begin{array}{l}\text { Mental health } \\
\text { education }\end{array}$} \\
\hline Mental illness & -.66 & .45 & .52 & {$[.22,1.25]$} & 2.16 & .142 \\
\hline Diabetes $^{\mathrm{a}}$ & $0 *$ & & & & & \\
\hline \multicolumn{7}{|l|}{ Mental Illness type } \\
\hline Schizophrenia & 1.11 & 1.15 & 3.03 & {$[.32,28.81]$} & 1.02 & .335 \\
\hline Bipolar & -.07 & .46 & .95 & {$[.38,2.29]$} & .93 & .879 \\
\hline Depression & -.01 & .45 & .99 & {$[.41,2.41]$} & .02 & .984 \\
\hline Substance $^{\mathrm{a}}$ & $0 *$ & & & & & \\
\hline \multicolumn{7}{|l|}{ Interactions $^{b}$} \\
\hline MH ed.by D ed. & 1.25 & .73 & 3.49 & {$[.84,14.46]$} & .00 & .085 \\
\hline D ed.by MI(1) & 1.18 & 1.29 & 3.25 & {$[.25,41.05]$} & 2.96 & .362 \\
\hline D ed. by MI(2) & 2.09 & .74 & 8.11 & {$[1.92,34.20]$} & .83 & .004 \\
\hline D ed. by MI (3) & 2.22 & .74 & 9.21 & {$[2.17,39.08]$} & 8.12 & .003 \\
\hline MH ed. by MI (1) & .70 & 1.29 & 2.01 & {$[.16,25.04]$} & 9.07 & .588 \\
\hline MH ed. by MI (2) & .45 & .70 & 1.57 & {$[.40,6.21]$} & .29 & .522 \\
\hline MH ed. by MI (3) & 2.99 & .93 & 19.92 & $\begin{array}{l}{[3.19,} \\
124.27]\end{array}$ & .41 & .001 \\
\hline $\begin{array}{l}\text { D ed. x MH ed. by } \\
\text { MI(1) }\end{array}$ & -25 & 1.64 & 1.29 & {$[.05,31.91]$} & .02 & .878 \\
\hline $\begin{array}{l}\text { D ed. by MH ed. by } \\
\operatorname{MI}(2)\end{array}$ & -4.32 & 1.07 & .38 & {$[.05,3.11]$} & .81 & .369 \\
\hline $\begin{array}{l}\text { D ed. by MH ed. by } \\
\text { MI(3) }\end{array}$ & .28 & 1.22 & .01 & {$[.00, .15]$} & 12.45 & .001 \\
\hline
\end{tabular}


Note. Verdict coded as $0=$ guilty, $1=\mathrm{NCRMD}$. $\mathrm{CI}=$ Confidence interval for odds ratio (OR). $\mathrm{SE}=$ Standard Error. OR=Odds Ratio.

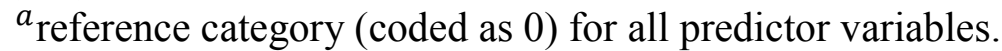

${ }^{b}$ Mental Illness type $=$ MI $(1=$ Schizophrenia vs substance use, $2=$ Bipolar vs substance use, $3=$ Depression vs substance use). Defence Education $=\mathrm{D}$ ed. Mental Health Education $=\mathrm{MH}$ ed

*This parameter is set to zero because it is redundant

Overall, prediction success was 68.5\% (89.7\% for NCRMD and 33.7\% for guilty). An examination of the predictors revealed that defence education significantly contributed to the model. The odds ratio for defence education indicates that, holding all other variables constant, jurors were .23 times more likely to select a guilty verdict when they received NCRMD education than duress education.

In addition, there was a significant interaction between defence education and the variable contrasting bipolar disorder to substance use disorder, $\mathrm{B}=2.09, p<.01$. Crosstabulation and Chi-Squared Tests of Independence were used to examine the condition effects of verdict for defence education and bipolar vs substance use. Verdict ratings for bipolar disorder and substance use disorder were split into separate 2 x 2 (Mental illness: bipolar vs. substance use x Verdict: NCRMD vs guilty) categories (Table 3). A contingency Chi-Squared Test indicated that the relationship between verdict and the variable contrasting bipolar disorder to substance use disorder was not significant for participants who received duress education, $\chi^{2}(1, \mathrm{~N}=145)=.04, p=.85$. However, the ChiSquared Test of Independence indicated that the relationship between verdict and the variable contrasting bipolar to substance use disorder was significant for those who received NCRMD education, $\chi^{2}(1, \mathrm{~N}=122)=20.49, p<.001$. Jurors who received NCRMD education were almost three times more likely to select an NCRMD verdict when the defendant was diagnosed with bipolar disorder (71\%) than substance use disorder (29\%; 
$p<.01)$. Furthermore, jurors were less likely to select a guilty verdict when the defendant was diagnosed with bipolar disorder (30\%) than substance use disorder $(70 \% ; p<.01)$. In addition, jurors who received NCRMD education were more likely to issue an NCRMD verdict $(70 \%)$ than a guilty verdict $(30 \%)$ when the defendant was diagnosed with bipolar disorder $(p<.01)$. However, jurors were more likely to select a guilty verdict $(70 \%)$ than an NCRMD verdict (30\%) when the defendant was diagnosed with substance use disorder $(p<.01)$.

Table 3

Percentage of Verdicts as a Function of Defence Education and Bipolar vs Substance Use

\begin{tabular}{|c|c|c|}
\hline \multirow[b]{2}{*}{ Verdict } & \multicolumn{2}{|c|}{ Defence education } \\
\hline & Duress education & NCRMD education \\
\hline \multicolumn{3}{|l|}{ Substance use disorder } \\
\hline \multirow{2}{*}{ Guilty } & 44 & 43 \\
\hline & $49 \%$ & $70 \%$ \\
\hline \multirow[t]{2}{*}{ NCRMD } & 46 & 18 \\
\hline & $51 \%$ & $30 \%$ \\
\hline \multicolumn{3}{|l|}{ Bipolar } \\
\hline \multirow[t]{2}{*}{ Guilty } & 26 & 18 \\
\hline & $47 \%$ & $30 \%$ \\
\hline \multirow[t]{2}{*}{ NCRMD } & 29 & 43 \\
\hline & $53 \%$ & $70 \%$ \\
\hline
\end{tabular}

In addition, there was a significant interaction between defence education and the variable contrasting depression to substance use disorder, $\mathrm{B}=2.22, p<.001$. Crosstabulation and Chi-Squared Tests of Independence were used to examine the condition effects of verdict for defence education and depression vs substance use. Verdict ratings 
for depression and substance use disorder were split into separate 2 x 2 (Mental illness: depression vs. substance use x Verdict: NCRMD vs guilty) categories (Table 4). The Chi-Squared Test of Independence for NCRMD education was significant, $\chi^{2}(1$, $\mathrm{N}=123)=16.52, p<.001$, indicating that there was a significant relationship between verdict and the variable contrasting depression to substance use disorder for those who received NCRMD education. Jurors who received NCRMD education were about two times more likely to select an NCRMD verdict when the defendant was diagnosed with depression $(69 \%)$ as compared to substance use disorder $(31 \% ; p<.01)$. Furthermore, jurors were less likely to select a guilty verdict when the defendant was diagnosed with depression (33\%) as opposed to substance use disorder $(67 \% ; p<.01)$. In addition, jurors who received NCRMD education were more likely to select an NCRMD verdict (66\%) than a guilty verdict (34\%) when the defendant was diagnosed with depression $(p<.02)$.

Moreover, the Chi-Squared Test of Independence for duress education was significant, $\chi^{2}(1, \mathrm{~N}=149)=8.20, p<.01$, indicating that there was a significant relationship between verdict and the variable contrasting depression and substance use disorder for those who received duress education. Jurors who received duress education were no more likely to select an NCRMD verdict (49\%) for defendants diagnosed with depression than for those diagnosed with substance use disorder $(51 \% ; p=.92)$. However, jurors were less likely to select a guilty verdict when the defendant was diagnosed with bipolar disorder $(32 \%)$ rather than substance use disorder $(68 \% ; p<.01)$. In addition, jurors who received duress education were more likely to select an NCRMD verdict (75\%) than a guilty verdict (25\%) when the defendant was diagnosed with depression $(p<.01)$. 
However, jurors were no more likely to select a guilty verdict (49\%) than an NCRMD verdict $(51 \%)$ when the defendant was diagnosed with substance use disorder $(p=.92)$.

Table 4

Percentage of Verdicts as a Function of Defence Education and Depression vs Substance Use

\begin{tabular}{|c|c|c|}
\hline \multirow[b]{2}{*}{ Verdict } & \multicolumn{2}{|c|}{ Defence education } \\
\hline & Duress education & NCRMD education \\
\hline \multicolumn{3}{|l|}{ Substance use disorder } \\
\hline \multirow{2}{*}{ Guilty } & 44 & 43 \\
\hline & $49 \%$ & $70 \%$ \\
\hline \multirow[t]{2}{*}{ NCRMD } & 46 & 18 \\
\hline & $51 \%$ & $30 \%$ \\
\hline \multicolumn{3}{|l|}{ Depression } \\
\hline \multirow[t]{2}{*}{ Guilty } & 15 & 21 \\
\hline & $25 \%$ & $34 \%$ \\
\hline \multirow[t]{2}{*}{ NCRMD } & 44 & 41 \\
\hline & $75 \%$ & $66 \%$ \\
\hline
\end{tabular}

Similar to findings of defence education for depression as compared to substance use, there was a significant interaction between mental health education and the variable contrasting depression to substance use disorder, $\mathrm{B}=2.99, p<.01$. It was expected that jurors who received mental illness education would be more likely to render an NCRMD verdict. Cross-tabulation and Chi-Squared Tests of Independence were used to examine the condition effects of verdict for mental health education and depression vs substance use. Verdict ratings for depression and substance use disorder were split into separate $2 \mathrm{x}$ 2 (Mental illness: depression vs substance use disorder x Verdict: NCRMD vs guilty) categories (Table 5). A contingency Chi-Squared Test indicated that the relationship 
between verdict and the variable contrasting depression to substance use disorder was significant for participants who received mental illness education, $\chi^{2}(1, N=120)=16.92$, $p<.01$. Jurors who received mental illness education were more likely to select an NCRMD verdict for defendants with depression (64\%) than substance use disorder $(35 \%$; $p<.03$ ). Jurors also were less likely to select a guilty verdict when the defendant was diagnosed with depression $(26 \%)$ than substance use disorder $(74 \% ; p<.01)$. Furthermore, jurors were more likely to issue an NCRMD verdict (75\%) than a guilty verdict $(25 \%)$ when the defendant was diagnosed with depression $(p<.01)$. In addition, jurors who received mental illness education were more likely to select a guilty verdict $(62 \%)$ than an NCRMD verdict (38\%) when the defendant was diagnosed with substance use disorder; however, this effect was marginally significant $(p=.08)$.

Furthermore, the Chi-Squared Test of Independence for diabetes education was significant, $\chi^{2}(1, \mathrm{~N}=152)=6.07, p<.01$, indicating that the relationship between verdict and the variable contrasting depression to substance use disorder was significant for participants who received diabetes education. Jurors who received diabetes education were no more likely to select an NCRMD verdict for a defendant with depression (51\%) than substance use disorder $(49 \% ; p=.91)$. However, jurors were more likely to select a guilty verdict for defendants with substance use disorder (69\%) than depression $(31 \%$; $p<.01)$. Furthermore, jurors were more likely to issue an NCRMD verdict (66\%) than a guilty verdict (34\%) for defendants with depression when they received diabetes education $(p<.02)$. However, jurors who received diabetes education were no more likely to issue an NCRMD verdict (55\%) than a guilty verdict (45\%) for defendants with substance use disorder $(p=.46)$. 
Table 5

Percentage of Verdicts as a Function of Mental Health Education and Depression vs Substance Use

Mental health education

\begin{tabular}{|c|c|c|}
\hline Verdict & Diabetes educating & Mental illness education \\
\hline \multicolumn{3}{|l|}{ Substance use disorder } \\
\hline \multirow[t]{2}{*}{ Guilty } & 48 & 39 \\
\hline & $55 \%$ & $62 \%$ \\
\hline \multirow[t]{2}{*}{ NCRMD } & 40 & 24 \\
\hline & $45 \%$ & $38 \%$ \\
\hline \multicolumn{3}{|l|}{ Depression } \\
\hline \multirow[t]{2}{*}{ Guilty } & 22 & 14 \\
\hline & $34 \%$ & $25 \%$ \\
\hline \multirow[t]{2}{*}{ NCRMD } & 42 & 43 \\
\hline & $66 \%$ & $75 \%$ \\
\hline
\end{tabular}

Lastly, there was a significant three way interaction between defence education, mental health education, and the variable contrasting depression to substance use disorder, $\mathrm{B}=.28, p<.01$. Cross-tabulation and Chi-Squared tests of independence were used to examine the condition effects of defence education, mental health education, and depression vs substance use on verdict. Verdict ratings for depression disorder and substance use disorder were split into separate 2 x 2 (Mental illness: depression vs. substance use disorder x verdict: NCRMD vs guilty) categories (Table 6). Surprisingly, the Chi-Squared Test indicated that there was not a significant relationship between NCRMD education, mental illness education, and the variable contrasting depression to substance use disorder, $\chi^{2}(1, \mathrm{~N}=59)=2.78, p=.10$. In addition, there was not a significant 
relationship between duress education, diabetes education, and the variable contrasting depression to substance use disorder, $\chi^{2}(1, \mathrm{~N}=88)=0, p=98$. However, there was a significant relationship between NCRMD education, diabetes education, and the variable contrasting depression to substance use disorder, $\chi^{2}(1, \mathrm{~N}=64)=16.06, p<.01$. Jurors who received NCRMD education and diabetes education were more likely to select an NCRMD verdict for a defendant with depression (78\%) than substance use disorder $(22 \% ; p<.01)$. In addition, jurors were more likely to select a guilty verdict for defendants with substance use disorder $(72 \%)$ than depression $(28 \% ; p<.02)$. Furthermore, jurors who received NCRMD education and diabetes education were more likely to select an NCRMD verdict (74\%) than a guilty verdict (26\%) for defendants with depression $(p<.01)$. However, jurors were less likely to select an NCRMD verdict $(23 \%)$ than a guilty verdict (77\%) for defendants with substance use disorder $(p<.01)$.

In addition, the Chi-Squared test indicated that there was a significant relationship between duress education, mental illness education, and the variable contrasting depression to substance use disorder, $\chi^{2}(1, \mathrm{~N}=61)=18.60, p<.001$. Jurors who received duress education and mental illness education were more likely to select an NCRMD verdict for a defendant with depression $(68 \%)$ than substance use disorder $(32 \% ; p<.04)$. In addition, jurors were more likely to select a guilty verdict for defendants with substance use disorder $(90 \%)$ than depression $(10 \% ; p<.01)$. Furthermore, jurors who received duress education and mental illness education were more likely to issue an NCRMD verdict (93\%) than a guilty verdict (7\%) for defendants with depression $(p<.01)$. However, jurors were no more likely to issue an NCRMD verdict (41\%) than a guilty verdict $(59 \%)$ for defendants with substance use disorder $(p=.38)$. 
Table 6

Percentage of Verdicts as a Function of Defence education, Mental Health Education and Depression vs Substance Use

\begin{tabular}{ccccc}
\hline & \multicolumn{4}{c}{ Education } \\
\cline { 2 - 5 } Verdict & \multicolumn{2}{c}{ Duress education } & \multicolumn{2}{c}{ NCRMD education } \\
\cline { 2 - 5 } Substance use disorder & Diabetes & Mental illness & Diabetes & Mental illness \\
Guilty & 25 & 19 & 23 & 20 \\
NCRMD & $43 \%$ & $59 \%$ & $77 \%$ & $65 \%$ \\
Depression & 33 & 13 & 7 & 11 \\
Guilty & $59 \%$ & $41 \%$ & $23 \%$ & $35 \%$ \\
& 13 & 2 & & 12 \\
NCRMD & $43 \%$ & $7 \%$ & 9 & $43 \%$ \\
& 17 & 27 & $26 \%$ & 16 \\
& $57 \%$ & $93 \%$ & $74 \%$ & $57 \%$ \\
\hline
\end{tabular}

\section{Continuous Ratings}

A series of Analyses of Variance (4 mental illness x 2 mental health education x 2 defence education) were conducted on the dependent variables (defendant perceptions, mental illness attitudes, NCRMD attitudes, continuous verdict) to address Hypotheses 1, 2 , and 3.

Defendant perceptions. First, to determine the effects of mental illness type, mental health education, and defence education on defendant perceptions, a $4 \times 2 \times 2$ ANOVA was conducted using defendant perceptions as the dependent variable. Results showed that there was a main effect of mental illness type, $F(1,470)=11.20, p<.01$, $\eta \mathrm{p}^{2}=.07$. Post hoc comparisons using a Bonferroni test were conducted to analyze the 
differences among mean defendant perception scores as a function of mental illness type. Comparisons indicated that perceptions toward defendants with schizophrenia $(M=3.26$, $S D=1.58)$ were significantly more positive $(p<.05)$ than perceptions of defendants with bipolar disorder $(M=4.11, S D=1.73)$, depression $(M=4.12, S D=2.10)$, and substance use disorder $(M=4.73, S D=1.83)$. Furthermore, mean defendant perception scores for defendants with substance use disorder $(M=4.73, S D=1.83)$ were significantly more negative $(p<.05)$ than those for defendants with schizophrenia $(M=3.26, S D=1.58)$, depression $(M=4.12, S D=2.09)$, and bipolar disorder $(M=4.11, S D=1.73)$. The effects of mental illness on defendant perceptions are displayed in Figure 2.

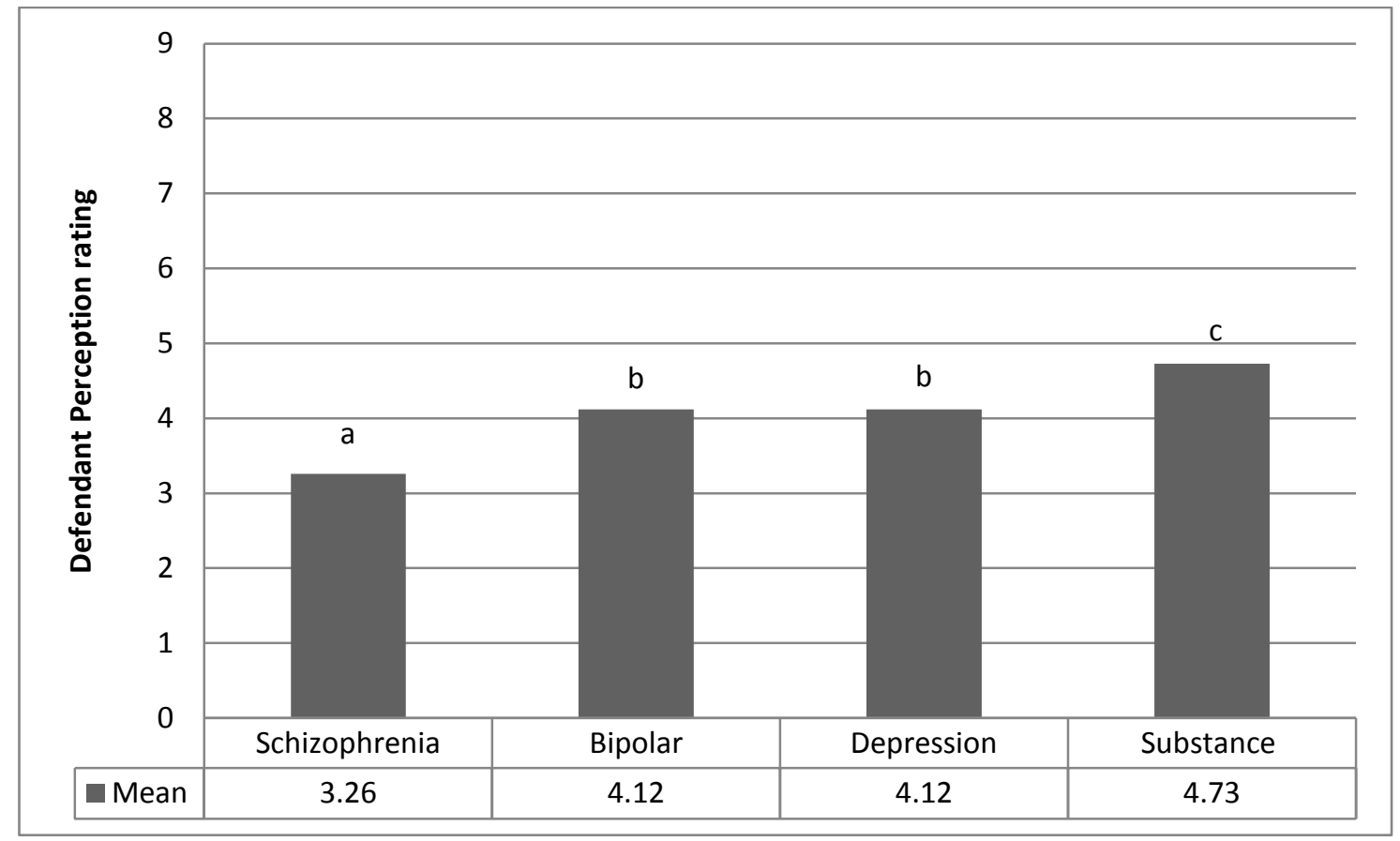

Figure 2. Main effect of mental illness on defendant perceptions. Lower scores indicate more positive impressions. Bars that share a letter are not significantly different; bars with different letters are significantly different. 
There were no significant main effects of defence education, $F(1,470)=2.23$, $p=.14, \eta p^{2}=.01$, or mental health education, $F(1,470)=2.63, p=.11, \eta p^{2}=.01$, on defendant perceptions. However, there was a significant three way interaction between defence education, mental health education, and mental illness type, $F(1,470)=3.90, p=.01$, $\eta p^{2}=.02$. A series of simple effects tests were conducted to tease apart this interaction.

For those who received NCRMD education, the main effect of mental health education, $F(3,238)=1.56, p=.21, \eta p^{2}=.01$, and the interaction between mental health education and mental illness type, $F(2,238)=1.19, p=.31, \eta p^{2}=.02$, were nonsignificant. However, there was a main effect of mental illness type, $F(3,238)=11.19, p<.001$, $\eta \mathrm{p}^{2}=.12$. Post hoc comparisons using a Bonferroni test indicated that perceptions toward defendants with schizophrenia $(M=3.29, S D=1.56)$ were significantly more positive than perceptions of defendants with depression $(M=4.33, S D=1.97)$ and substance use disorder $(M=5.08, S D=1.73)$. In addition, mean defendant perception scores for defendants with substance use disorder $(M=5.08, S D=1.73)$ were significantly harsher than those for defendants with schizophrenia $(M=3.29, S D=1.56)$ and bipolar disorder $(M=4.03$, $S D=1.76)$. The effect of mental illness type on defendant perceptions for participants who received NCRMD education is displayed in Figure 3. 


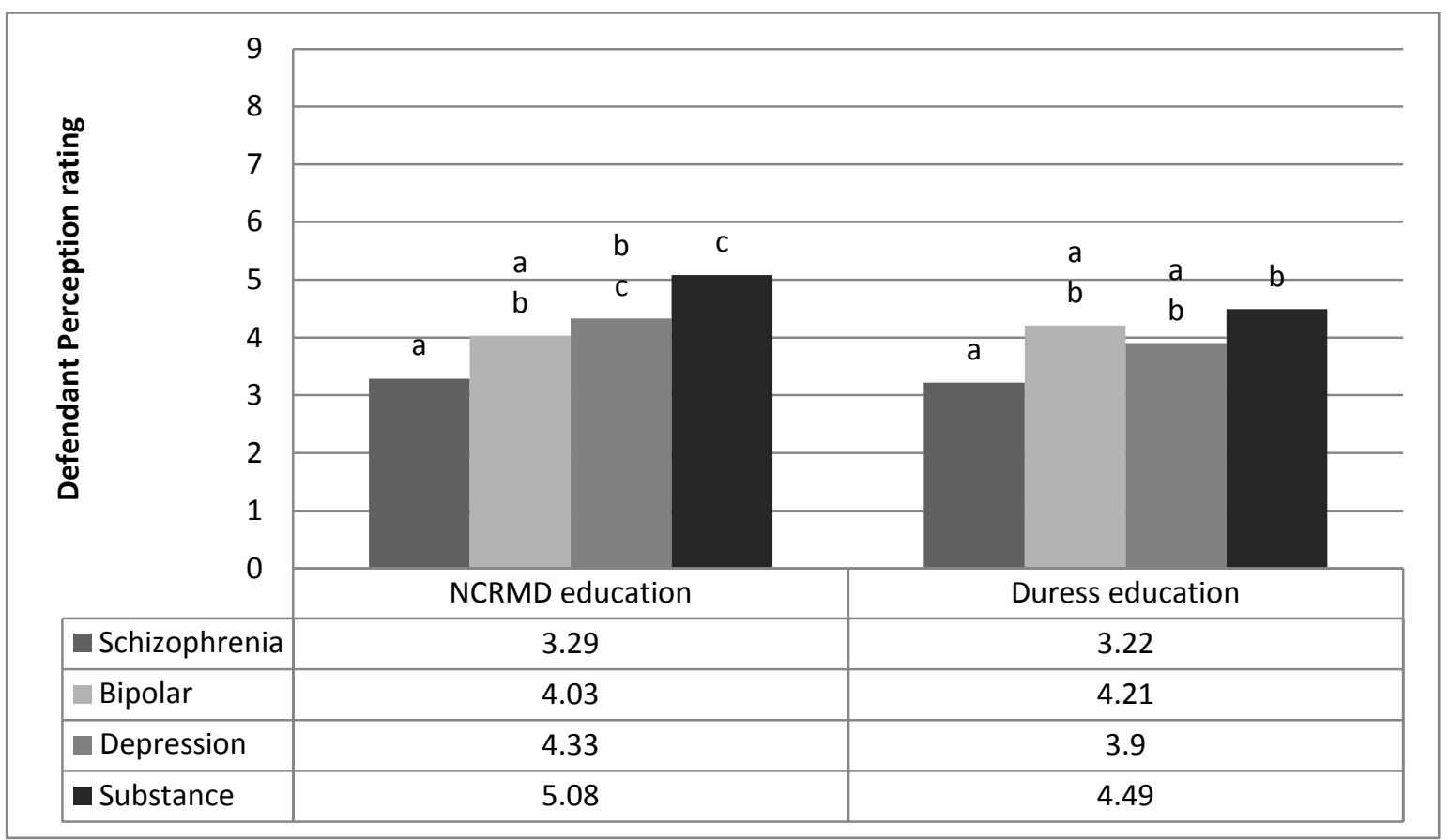

Figure 3. Simple effects of mental illness type on defendant perceptions for defence education. Lower scores indicate more positive impressions. Within each education, bars that share a letter are not significantly different; bars with different letters are significantly different.

To examine the interaction in another way, separate t-tests with defence education as the independent variable were conducted for the different mental illness types. The effect of defence education was not significant for schizophrenia, $t(96)=.213, p=.83$, bipolar, $t(114)=-.548, p=.59$, or depression, $t(119)=1.12, p=.30$. However, the effect of defence education was moderately significant for substance use disorder, $t(149)=1.92$, $p=.05$. Jurors who read about a defendant with substance use disorder perceived the defendant significantly more negatively when they received NCRMD education $(M=5.08, S D=1.73)$ than duress education $(M=4.49, S D=1.84)$. 
For those who received duress education, the main effect of mental health education was nonsignificant, $F(2,232)=1.16, p=.24, \eta p^{2}=.01$. However, there was a main effect of mental illness type, $F(3,232)=3.45, p=.02, \eta p^{2}=.04$. Post hoc comparisons indicated that defendant perceptions were significantly more positive for defendants with schizophrenia $(M=3.22, S D=1.64)$ than defendants with substance use disorder $(M=4.49$, $S D=1.84)$. However, bipolar disorder $(M=4.21, S D=1.71)$ and depression $(M=3.90$, $S D=2.21$ ) did not differ significantly from the other mental illness types. The effect of mental illness type on defendant perceptions for duress education is displayed in Figure 3.

Furthermore, the two way interaction between mental health education and mental illness type was statistically significant, $F(3,232)=3.28, p<.02, \eta \mathrm{p}^{2}=.04$. To tease apart this interaction, separate one-way ANOVAs with mental illness type as the independent variable were conducted for those who received mental illness education and those who received diabetes education. For those who received diabetes education, the effect of mental illness type was not significant, $F(3,118)=1.48, p=.22, \eta p^{2}=.04$. However, for those who received mental illness education, the effect of mental illness type was significant, $F(3,114)=5.22, p<.01, \eta p^{2}=.12$. Post hoc analysis using a Bonferroni test revealed that perceptions toward defendants with schizophrenia were significantly more positive $(M=3.29, S D=1.61)$ when compared to defendants with substance use disorder $(M=4.49, S D=1.76)$. Furthermore, perceptions towards defendants with substance use disorder $(M=4.49, S D=1.76)$ were more negative in comparison to defendants with schizophrenia $(M=3.29, S D=1.56)$ and depression $(M=3.03, S D=1.65)$. However, perceptions toward defendants with bipolar disorder $(M=4.17, S D=1.64)$ did not differ 
significantly from the other mental illness types. The effect of mental illness type on defendant perceptions for those participants who received duress and mental health education are displayed in Figure 4.

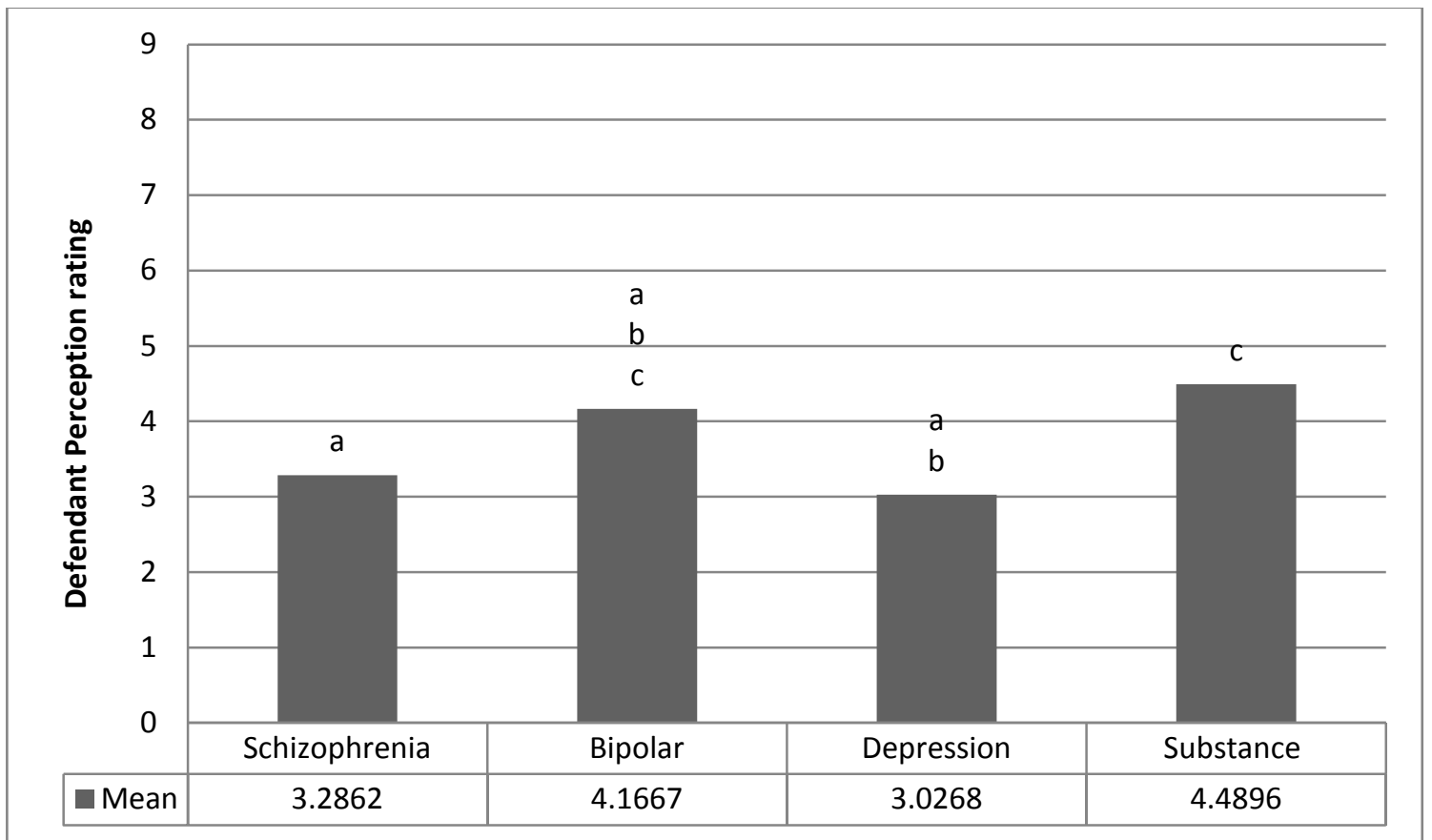

Figure 4. Simple main effects of mental illness type on defendant perceptions for duress education and mental illness education. Lower scores indicate more positive impressions. Bars that share a letter are not significantly different; bars with different letters are significantly different.

Attitudes toward mental illness. Mental illness type, defence education, and mental illness education were also examined against mental illness attitudes by conducting another $4 \times 2 \times 2$ ANOVA with mental illness stigma (MISS) as the dependent variable. For the purpose of this study, participants' answered the MISS scale with regards to the specific mental illness type that they were assigned. Results showed that there was a main effect of mental illness type on MISS scores, $F(1,469)=22.71, p<.01$, 
$\eta \mathrm{p}^{2}=.13$. Post hoc comparisons using a Bonferroni test revealed that attitudes toward substance use disorder $(M=3.80, S D=.92)$ were significantly more negative in comparison to schizophrenia $(M=3.24, S D=.86)$, bipolar $(M=3.04, S D=.84)$ and depression $(M=3.04, S D=.87)$. However, bipolar $(M=3.04, S D=.84)$ and depression $(M=3.04, S D=.87)$ did not differ significantly from one another. The effect of mental illness type on Mental Illness Stigma is displayed in Figure 5. None of the other main effects or interactions in this analysis reached statistical significance.

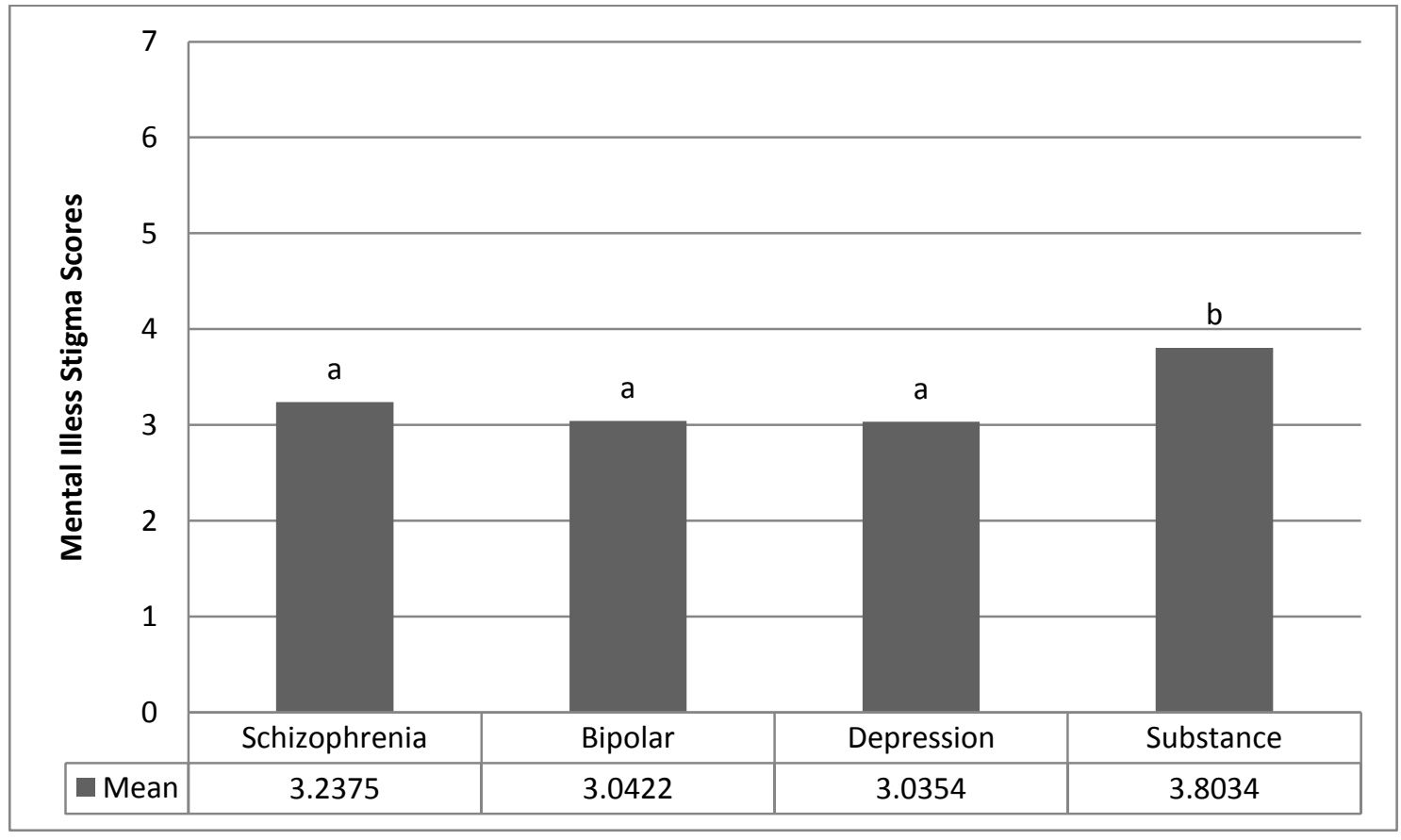

Figure 5. Main effect of mental illness type on mental illness attitudes. Higher scores indicate more negative attitudes. Bars that share a letter are not significantly different; bars with different letters are significantly different.

Attitudes toward the NCRMD defence. Similarly, another 4x2x2 ANOVA was conducted with Insanity defence attitudes (IDA-R) as the dependent variable. Results indicate that there was a main effect of mental illness type on the total IDA-R mean, $F(1$, 
$470)=4.10, p<.01, \eta p^{2}=.03$. Post hoc comparisons using the Bonferroni test revealed that NCRMD defence attitudes for those who read about a defendant with substance use disorder $(M=4.13, S D=.87)$ were significantly more negative than those who read about a defendant with schizophrenia $(M=3.76, S D=.82)$. However, bipolar $(M=3.99, S D=.85)$ and depression $M=3.99, S D=.79$ ) did not differ from the other mental illness types. The effects of mental illness type on NCRMD attitudes are displayed in Figure 6.

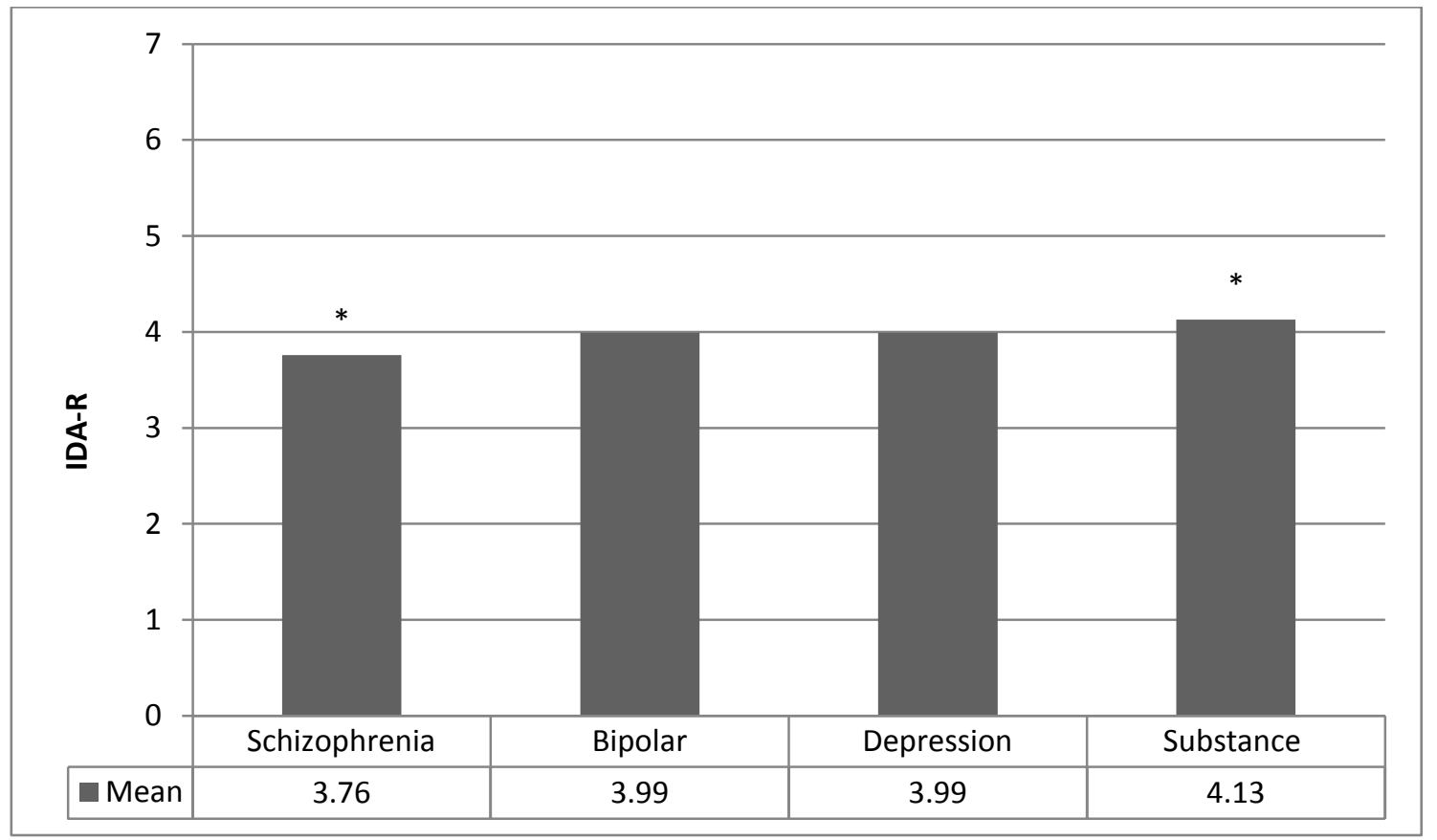

Figure 6. Main effect of mental illness type on NCRMD defence attitudes. Higher scores indicate more negative attitudes. Bars marked with an asterisk * are significantly different

In addition, there was a significant two way interaction between defence education and mental health education, $F(1,470)=5.43, p<.02, \eta p^{2}=.01$. A series of independent-samples t-tests were conducted to tease apart this interaction. 
For those who received duress education, the effect of mental illness education was nonsignificant, $t(238)=3.00, p<.01$. However, there was a significant effect of mental health education for those who received NCRMD education, $t(244)=3.00, p<.01$. Comparisons revealed that NCRMD attitudes were significantly more positive when participants received mental illness education $(M=3.83, S D=.78)$ than diabetes education $(M=4.14, S D=.82), t(244)=2.999, p<.01$. The effects of mental health education on NCRMD attitudes for those who received NCRMD and duress education are displayed in Figure 7.



Figure 7. Simple main effects of mental health education on NCRMD attitudes for defence education. Higher scores indicate more negative attitudes. Within each block, bars marked with an asterisk* are significantly different.

Furthermore, there was a significant two way interaction between defence education and mental illness type, $F(1,470)=2.95, p=.03, \eta p^{2}=.02$. To tease apart this interaction, separate one-way ANOVA's with mental illness type as the independent 
variable were conducted for those who received NCRMD education and those who received duress education. For those who received NCRMD education, the effect of mental illness was nonsignificant, $F(3,242)=2.12, p=.09, \eta p^{2}=.03$. However, for those who received duress education, the effect of mental illness type was significant, $F(3$, $236)=4.46, p<.01, \eta p^{2}=.05$. Post hoc comparisons indicated that NCRMD attitudes were significantly more positive for defendants with schizophrenia $(M=3.64, S D=6.79)$ than defendants with substance use disorder $(M=4.18, S D=.88)$. However, bipolar $(M=4.07$, $S D=.89)$ and depression $(M=3.81, S D=.85)$ did not differ significantly from the other mental illness types. The effect of mental illness type on NCRMD attitudes for those who received duress education is displayed in Figure 8.

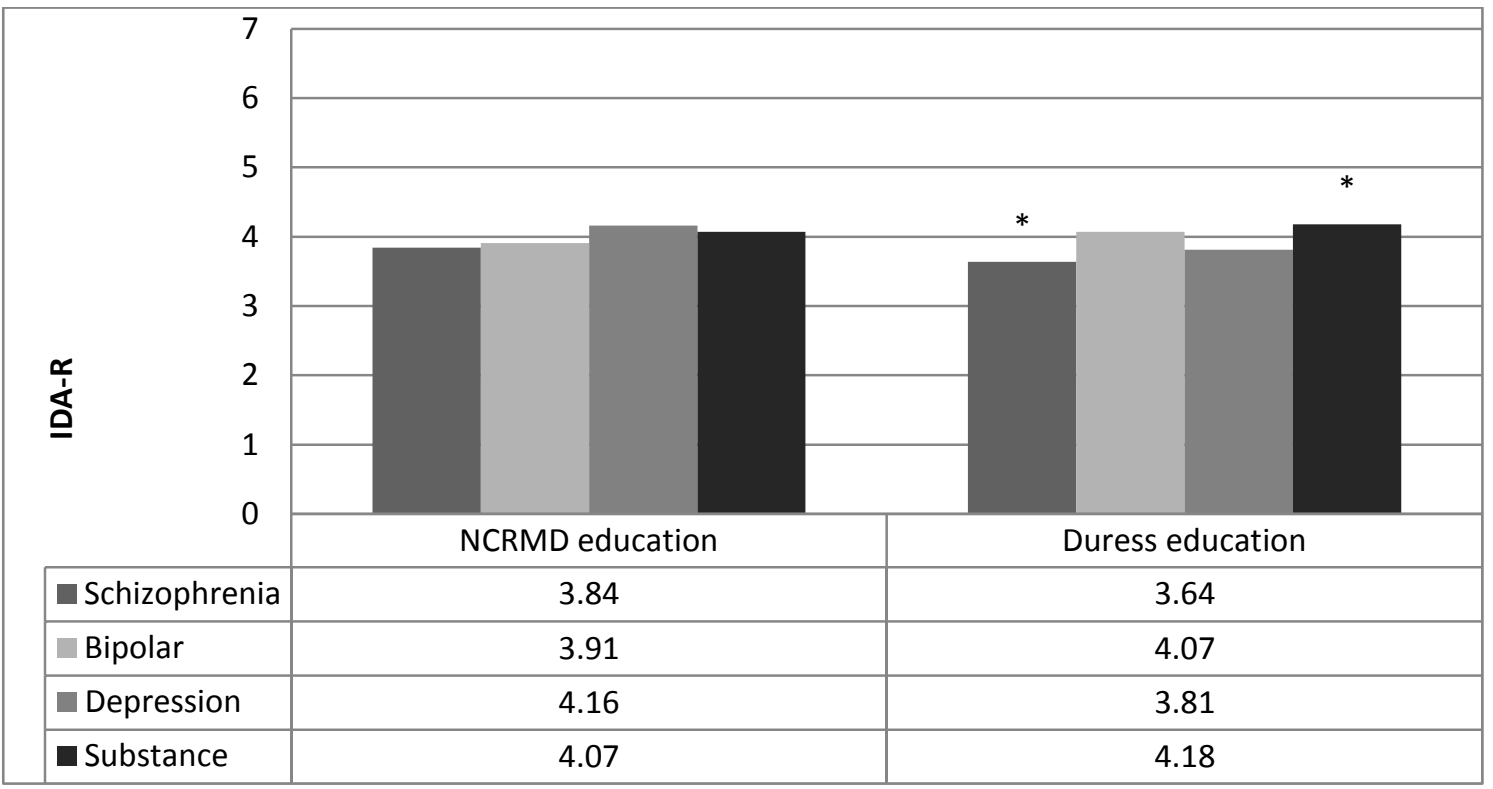

Figure 8. Simple main effects of mental illness type on NCRMD attitudes for duress education. Higher scores indicate more negative attitudes. Within each education type, bars marked with an asterisk * are significantly different.

Verdict decisions. Finally, to explain the effects of mental illness type, defence education, and mental health education on participants' certainty that the defendant was 
guilty or NCRMD, a 4x2x2 ANOVA was conducted using continuous verdict as the dependent variable. Results showed that there was a main effect of mental illness type, $F(3,470)=18.23, p<.001, \eta p^{2}=.10$. Post hoc analyses using a Bonferroni test indicated that jurors were significantly more certain in an NCRMD verdict rating for defendants with schizophrenia $(M=-5.02, S D=5.56)$ than for those with bipolar $(M=-1.62$, $S D=7.18)$, depression $(M=-2.65, S D=6.52)$, and substance use disorder $(M=1.25$, $S D=6.80)$. In addition, participants were more certain that the defendant was guilty when he had substance use disorder, as compared to the other mental illness types. However, there were no differences in verdict ratings between bipolar and depression. The main effect of mental illness type on continuous verdict is displayed in Figure 9.



Figure 9. Main effects of mental illness type on continuous verdict. Positive scores indicate guilty ratings; negative scores indicate NCRMD ratings. Bars that share a letter are not significantly different; bars with different letters are significantly different. 
In addition, a significant interaction between defence education and mental illness type on continuous verdict was observed, $F(3,470)=3.50, p<.02, \eta p^{2}=.02$. To tease apart this interaction, separate one-way ANOVA's with mental illness type as the independent variable were conducted for those who received NCRMD education and those who received duress education. For those who received NCRMD education, the effect of mental illness type was significant, $F(3,242)=18.83, p<.001, \eta p^{2}=.190$. Post hoc analysis using a Bonferroni test revealed that jurors were significantly more confident that the defendant was NCRMD when he was diagnosed with schizophrenia $(M=-5.27, S D=5.35)$ than depression $(M=-2.05, S D=6.52)$ and substance use disorder $(M=3.13, S D=6.37)$. In addition, jurors were significantly more confident that the defendant was guilty when he was diagnosed with substance use disorder $(M=3.13, S D=6.37)$ than schizophrenia $(M=-$ 5.27, $S D=5.35)$, bipolar $(M=-2.64, S D=7.05)$ and depression $(M=-2.05, S D=6.52)$.

For those who received duress education, the effect of mental illness type was significant, $F(3,236)=5.71, p<.001, \eta p^{2}=.07$. Post hoc analysis using a Bonferroni test revealed that jurors were significantly more confident in an NCRMD verdict for defendants with schizophrenia $(M=-4.58, S D=5.95)$ than for those with bipolar $(M=-.49$, $S D=7.23)$ and substance use disorder $(M=-.033, S D=6.815)$. In addition, jurors were significantly more confident in a guilty verdict rating for defendants with substance use disorder $(M=-.03, S D=6.82)$ than for those with schizophrenia $(M=-4.58, S D=5.95)$ and depression $(M=-3.27, S D=6.51)$.

To examine the interaction in another way, separate t-tests with defence education as the independent variable were conducted for different mental illness types. The effect of defence education was not significant for schizophrenia, $t(96)=-.591, p=.56$, bipolar, 
$t(114)=-1.60 p=.11$, or depression, $t(119)=1.3, p=.30$. However, the effect of defence education was significant for substance use disorder, $t(149)=1.87, p<.01$. Jurors who read about a defendant with substance use disorder were significantly less confident in an NCRMD verdict when they received NCRMD education $(M=3.13, S D=6.37)$ than duress education $(M=-.03, S D=6.81)$. The effect of defence education on continuous verdict for each mental illness type is displayed in Figure 10.

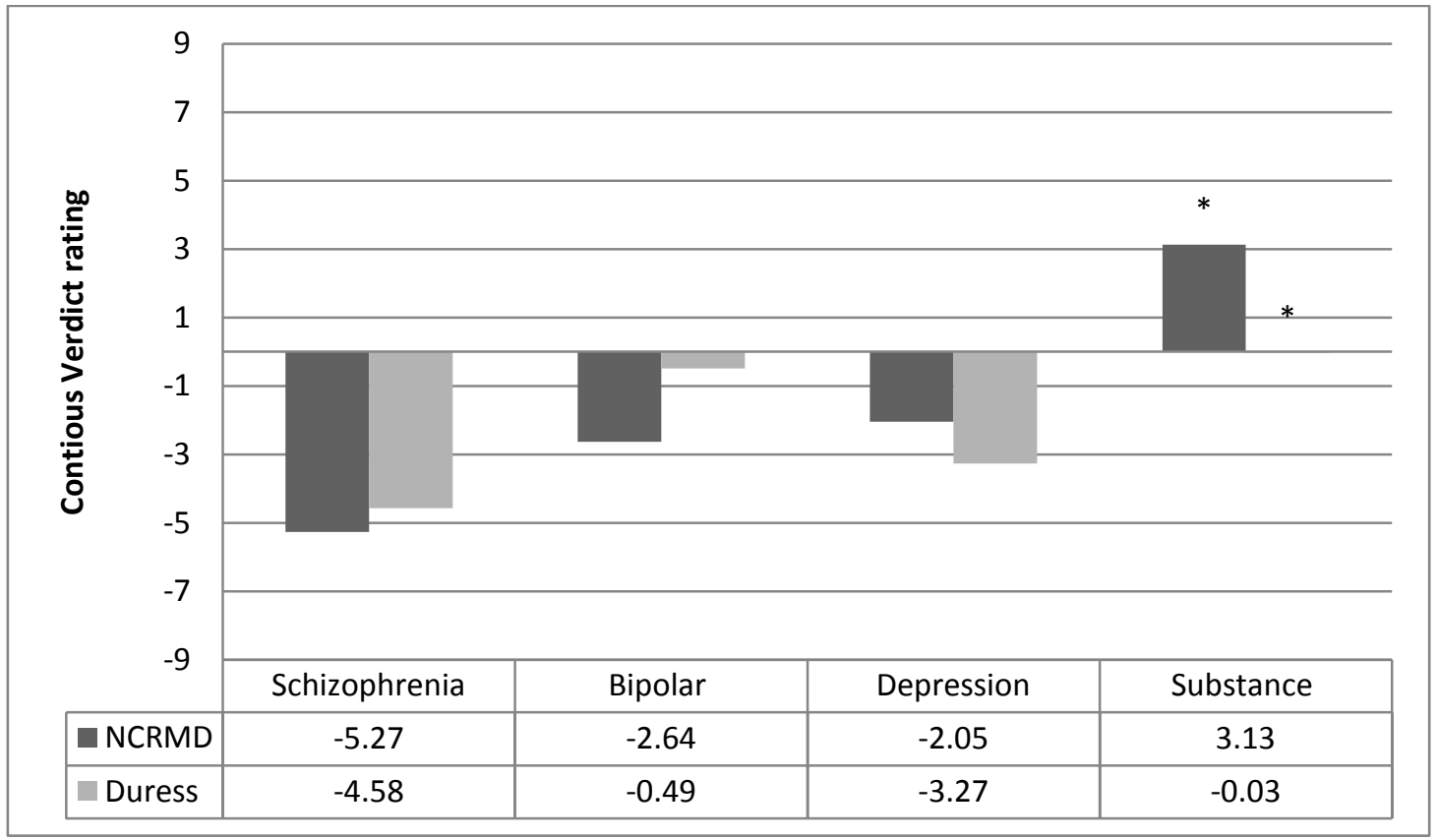

Figure 10. Simple main effects of defence education on continuous verdict for each mental illness type. Positive scores indicate guilty ratings; negative scores indicate NCRMD ratings. Within each mental illness type, bars marked with an asterisk * are significantly different.

Furthermore, there was a significant three way interaction between defence education, mental health education, and mental illness type, $F(3,470)=5.54, p<.001$, $\eta p^{2}=.03$. A series of simple effects tests were conducted to tease apart this interaction. 
For those who received NCRMD education, the main effect of mental health education, $F(3,238)=.92, p=.34, \eta p^{2}=.004$, and the interaction between mental health education and mental illness type, $F(3,238)=1.44, p=.23, \eta \mathrm{p}^{2}=.02$, were nonsignificant. However, there was a main effect of mental illness type, $F(3,242)=18.83, p<.001$, $\eta p^{2}=.19$, as described earlier and depicted in Figure 10 .

For those who received duress education, the main effect of mental health education was nonsignificant, $F(3,232)=.31, p=.58, \eta p^{2}=.001$. However, there was a main effect of mental illness type, $F(3,236)=5.71, p<.001, \eta p^{2}=.067$, as described above and displayed in Figure 10.

Furthermore, for those who received duress education, the two way interaction between mental health education and mental illness type was statistically significant, $F(3$, $232)=5.24, p=.002, \eta p^{2}=.06$. To tease apart this interaction, separate one-way ANOVAs with mental illness type as the independent variable were conducted for those in the duress education conditions who received mental illness education and those who received diabetes education. For those who received diabetes education, the effect of mental illness type was not significant, $F(3,118)=.71, p=.55, \eta p^{2}=.02$. However, for those who received mental illness education, the effect of mental illness type was significant, $F(3,114)=11.59, p<.001, \eta p^{2}=.23$. Post hoc comparisons using a Bonferroni test indicated that jurors were significantly more confident in an NCRMD verdict for defendants with schizophrenia $(M=-4.48, S D=6.14)$ than for those with bipolar $(M=.00$, $S D=7.07)$ and substance use disorder $(M=1.41, S D=6.19)$. In addition, jurors were significantly more confident in an NCRMD verdict for defendants with depression than for those with bipolar $(M=-6.45, S D=3.97)$ and substance use disorder $(M=1.41$, 
$S D=6.19)$. The effect of mental illness type on continuous verdict for those participants who received duress education and mental illness education are displayed in Figure 11.

To examine the interaction in another way, separate t-tests were conducted on those who received duress education with mental health education as the independent variable was conducted for different mental illness types. The effect of mental health education was not significant for schizophrenia, $t(34)=.246, p=.81$, bipolar, $t(53)=.473$, $p=.64$, or substance use disorder, $t(88)=1.50, p=.14$. However, the effect of mental health education was significant for depression, $t(57)=-4.17, p<.001$. Jurors who read about a defendant with depression were significantly more confident in an NCRMD verdict when they received mental illness education $(M=-6.45, S D=3.97)$ than diabetes education $(M=$ $.20, S D=7.05)$.

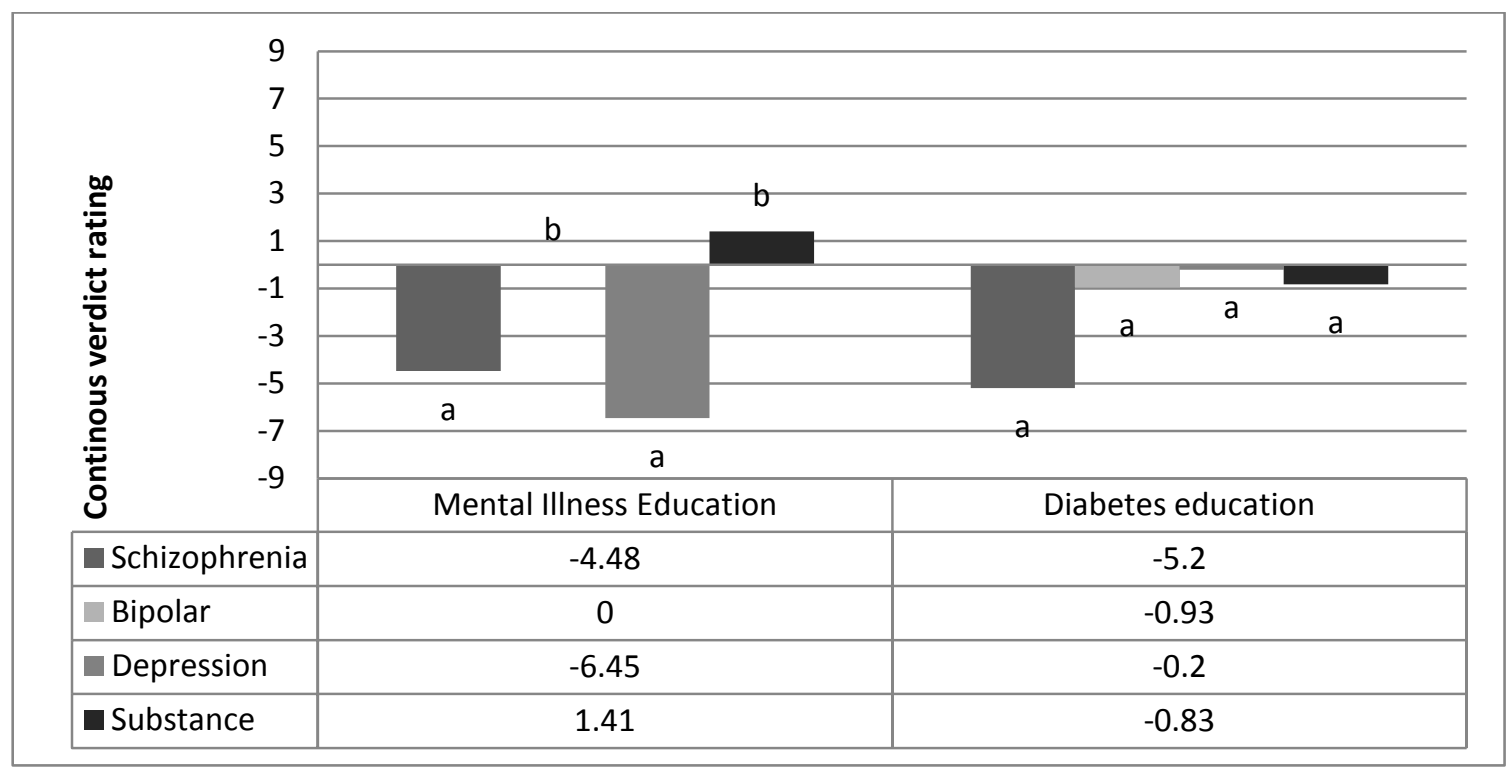

Figure 11. Simple main effects of mental illness type on continuous verdict for duress and mental health education. Positive scores indicate guilty ratings. Within each education type, bars that share a letter are not significantly different; bars with different letters are significantly different. 


\section{Path analysis}

The verdict - mental illness stigma model (Figure 1) proposes that defendant mental illness, defence education, and mental health education impacts on jurors' mental illness attitudes, NCRMD attitudes, and perceptions of the defendant, which ultimately predict juror verdict decisions in an NCRMD case. To obtain a complete picture of these connections and to estimate the magnitude and significance of these relationships, a path analysis was conducted using Mplus version 7.11 software (Muthen \& Muthen, 19982013). Coefficients were obtained through maximum likelihood procedures. In this path analysis, mental illness type conditions were dummy coded and conditions were compared against substance use disorder.

In the first step, 5 regressions were conducted using defendant mental illness type schizophrenia vs. substance use (schizophrenia $=1$, substance use disorder $=0$ ), bipolar vs. substance use (bipolar $=1$, substance use disorder $=0$ ), depression vs. substance use (depression $=1$, substance use disorder $=0)$, defence education $(\mathrm{NCRMD}=1$, duress $=0$ ), and mental health education (mental illness $=1$, diabetes $=0$ ) as the predictor variables and defendant perceptions, mental illness stigma, and NCRMD attitudes as the criterion variables. The second step was conducted through the analysis of the aforementioned variables as predictors, with continuous verdict as the criterion variable.

To test the fit of the model, the Comparative Fit Index (CFI) and the Root Mean Square Error of Approximation (RMSEA) were examined. The Comparative Fit Index (CFI) for the model was equal to .778 , indicating that the model was not an acceptable fit. An acceptable model fit is indicated by a CFI value of .90 or greater ( $\mathrm{Hu} \&$ Bentler, 1999). Furthermore, the Root Mean Square Error of Approximation (RMSEA) was equal 
to .376; whereas, an acceptable model fit is indicated by an RMSEA value of .05 or less (Hu \& Bentler, 1999). Given that the model did not provide an acceptable fit, modification indices were run to evaluate the change in Chi Squared if fixed parameters were freed. Modification indices suggested that model fit would improve by correlating defendant perceptions with NCRMD attitudes, mental illness attitudes with NCRMD attitudes, and mental illness attitudes with defendant perceptions.

Correlation analyses were conducted to examine the relationship between the aforementioned variables. Indeed, analysis indicated that defendant perceptions were positively related to mental illness attitudes $(\mathrm{r}=.184 ; p<.001)$. Thus, negative defendant perception ratings were significantly related to negative mental illness attitudes. Given that defendant perceptions and mental illness attitudes examined specific questions in regards to the defendants' mental illness type, it can be expected that defendant perceptions would correlate with mental illness attitudes. Similar results have been found in an examination of defendants with Post Traumatic Stress Disorder (PTSD; Kelly, 2011). The study, an unpublished Master's thesis, found that jurors who tended to blame defendants with PTSD less had more positive attitudes towards mentally ill people. In addition, Roberts and Golding (1991) found that jurors' perceptions of the defendant's mental state and blameworthiness were strongly related to verdicts rendered. Furthermore, jurors' perceptions of blameworthiness were more strongly related to verdicts rendered than manipulation of case facts, such as premeditation (Roberts \& Golding, 1991).

Furthermore, defendant perceptions were significantly and positively related to NCRMD attitudes $(r=.49 ; p<.001)$. Thus, negative ratings of defendant perceptions were 
related to negative NCRMD attitudes. Previous literature indicates that defendant perceptions are strongly correlated with Insanity defence attitudes (Roberts \& Golding, 1991). In addition, mental illness attitudes were moderately and positively related to NCRMD attitudes $(r=.42, p<.001)$. These findings indicate that negative ratings of mental illness attitudes were related to more negative NCRMD attitudes (Skeem et al., 2004). Skeem and colleagues (2004) found that the IDA-R measure is strongly correlated with community mental health attitudes, locus of responsibility for mental illness, and beliefs that the rights of mentally ill individuals should be restricted to protect the public. Thus, suggested modification statements were added into the redefined saturated model. However, model fit indices were not evaluated as they are not available for fully saturated models. Figure 12 illustrates all significant paths in the fully saturated model; standardized regression weights are provided.



Figure 12. Fully-saturated Verdict-Mental Illness Stigma Model 
Within this model, the variable contrasting schizophrenia to substance use disorder was significantly correlated with NCRMD attitudes (jurors reported more positive NCRMD attitudes when evaluating defendants with schizophrenia as compared to those with substance use disorder), mental illness attitudes (such that jurors reported more positive mental illness attitudes when questioned with regards to schizophrenia rather than substance use disorder), and defendant perceptions (perceptions towards defendants with schizophrenia were more positive in comparison to defendants with substance use disorder). In addition, the variable contrasting schizophrenia to substance use disorder had a direct relationship with continuous verdict, such that jurors were more certain in an NCRMD verdict rating for defendants with schizophrenia compared to those with substance use disorder.

Similarly, the variable contrasting bipolar disorder to substance use disorder significantly correlated with mental illness attitudes (such that jurors held more positive mental illness attitudes when asked about bipolar disorder as compared to substance use disorder) and defendant perceptions (perceptions towards defendants with bipolar disorder were more positive in comparison to defendants with substance use disorder). Furthermore, the variable contrasting bipolar disorder to substance use disorder had a direct relationship with continuous verdict, such that jurors were more certain in an NCRMD verdict rating for defendants with bipolar than for those with substance use disorder.

In addition, the variable contrasting depression to substance use disorder significantly correlated with mental illness attitudes (such that jurors held more positive mental illness attitudes when asked about depression as compared to substance use 
disorder) and defendant perceptions (perceptions towards defendants with depression were more positive in comparison to defendants with substance use disorder). The variable contrasting depression to substance use disorder also had a direct relationship with continuous verdict, such that jurors were more certain in an NCRMD verdict rating for defendants with depression than for those with substance use disorder. Furthermore, mental illness education significantly correlated with NCRMD attitudes, such that jurors held more positive NCRMD attitudes when they received mental illness education rather than diabetes education.

Finally, in addition to the variables contrasting schizophrenia, bipolar, and depression to substance use disorder, continuous verdict was related to mental illness stigma (those who endorsed mental illness stigma were less certain of the defendant's guilt) and defendant perceptions (those who perceived the defendant positively were less certain of the defendant's guilt). These findings suggest that education did not directly or indirectly affect jurors' verdict certainty as was hypothesized. However, mental illness type was directly and indirectly related to verdicts via mental illness attitudes and perceptions of the defendant.

\section{Discussion}

Overall, results exemplify the verdict differences between varying mental illnesses and the prevalence of mental illness stigma among mock jurors. Results indicate that there was a direct effect of defendant mental illness type on defendant perceptions, mental illness stigma, and decision-making in NCRMD trials. Contrary to previous research (Angermeyer \& Dietrich, 2006), defendants with schizophrenia were perceived much more positively in comparison to defendants with bipolar disorder, 
depression, and substance use disorder. Furthermore, defendants with schizophrenia were more likely to receive an NCRMD verdict than were defendants with other mental illness types. Previous research indicated that schizophrenia is perceived negatively and is associated with a high degree of dangerousness (Angermeyer \& Dietrich, 2006) and a low degree of recovery (Day et al., 2007); therefore, it was hypothesized that perceptions towards those defendants would be negative. Although there is a high degree of stigma surrounding schizophrenia in general, jurors associated a low degree of blame and culpability to the defendant's actions when the defendant was diagnosed with schizophrenia. As predicted, defendants with substance use disorder were consistently viewed negatively in comparison to defendants with schizophrenia, bipolar disorder, and depression. Jurors attributed a high degree of blame to defendants with substance use disorder. Furthermore, defendants with substance use disorder were less likely to be found NCRMD in comparison to defendants with schizophrenia, bipolar, and depression.

Weiner's (1986) attribution-affect-help judgment model can help explain why jurors' defendant perceptions were more positive towards schizophrenia, bipolar, and depression than substance use disorder, despite schizophrenia's association with a high degree of stigmatized attitudes. This model proposes that achievement-related behaviour is a result of perceived causality and emotion. Weiner believed that people direct anger towards those whom they perceive to be responsible for the cause in question, and they direct pity towards those whom they do not perceive to be responsible for the cause in question. Thus, these emotions mediate our thoughts and behaviours towards that individual. As a result, our ultimate behaviour can be explained through our attributions (cause is controllable) and affect (less pity and more anger). If the cause is perceived as 
controllable, we are less likely to react with pity and more likely to react with anger. More anger decreases the likelihood of helping behaviour. Menec and Perry (1998) tested the attribution-affect-help judgment model in the context of stigmas towards cancer, blindness, and AIDS. They found that as perceived controllability of the onset of the stigma increased, respondents reported more anger and less pity. Furthermore, help judgments were associated with greater pity; however, anger was only moderately associated with help judgments.

In the context of the current research, a significant number of jurors indicated that defendants with schizophrenia, bipolar, and depression were unable to appreciate the nature of their actions due to their disorder, and therefore, should not be blamed for their actions. It is likely that individuals with these disorders were viewed with more sympathy and pity as the onset of the disorders is thought to be brought on by chemical imbalances in the brain, and therefore completely out of the individual's control. Thus, a defendant with one of these disorders could also be perceived as a victim, compelling jurors to 'help' the defendant by seeking a treatment oriented outcome (NCRMD) rather than a crime control oriented outcome (guilty). Given that substance use disorder has an extra element of consciously ingesting a substance, jurors may believe that the onset of substance use disorder is highly controllable, even if the compulsive element is related to genetics. Previous research indicates that individuals often associate the onset of substance use issues with a high degree of controllability, which increases rejection behaviour (Martin et al., 2000). If jurors believe that the onset of the mental illness or the illness itself was controllable, they may be more likely to believe that the act in question could have been prevented, leading to negative defendant perceptions and a greater 
certainty in a guilty verdict. Therefore, if helping behaviour is determined by pity, then sympathy and empathy may also be a driving factor for verdicts rendered in mental health cases, a theory that should be examined further.

In reviewing educational hypotheses, results revealed similarities and differences with previous research. Although there were no main effects of defence education on NCRMD attitudes, there was an interaction between defence education and mental illness type. Specifically, those who received duress education reported different NCRMD attitudes as a function of mental illness type, but the effect of NCRMD education was not significantly different among the various mental illness types. Thus, educating people about the defence appears to equalize NCRMD attitudes among defendant mental illness types. However, this does not indicate that NCRMD attitudes significantly improved due to education. Rather, it suggests that NCRMD attitudes did not significantly vary among the different mental illness types when participants received NCRMD education. These results suggest that although negative misconceptions toward the NCRMD defence may affect negative attitudes toward the defence, they may not be the main cause of the negative attitudes toward the defence. Rather, a variety of negative attitudes may be responsible for the misconceptions surrounding the NCRMD defence. Therefore, such negative attitudes may be difficult to overcome.

Contrary to our hypotheses, continuous results revealed that mental illness education and NCRMD education did not have a combined effect on defendant perceptions, mental illness stigma, or decision-making in NCRMD cases. Interestingly, regardless of mental illness education, NCRMD education had the opposite effect as was predicted for people who were assigned to evaluate a defendant with substance use 
disorder. When participants received NCRMD education, jurors' certainty in a guilty verdict increased for defendants with substance use disorder. These findings indicate that NCRMD education may act as an anchor for negative attitudes towards substance use disorder. As indicated by the continuous analyses, jurors tend to associate a higher degree of controllability and blame to individuals with substance use disorder. As a result, participants may disagree that substance use disorder is a mental illness that hinders an individual's ability to appreciate the nature and quality of his or her actions and precludes him or her from criminal responsibility. Thus, educating participants on the definition of NCRMD, the prevalence rate of NCRMD cases, and the dispositions available to an NCRMD offender could make participants less likely to find the defendant with substance use disorder NCRMD given their perceived lack of fit between substance use disorder and a mental disorder that precludes criminal responsibility. Furthermore, dispositions may not be perceived as sufficient punishment for a defendant with substance use disorder. Thus, jurors may feel more compelled to punish the defendant with substance use disorder through criminal sanction rather than rehabilitative efforts.

Although NCRMD education may act as an anchor for NCRMD attitudes, path analyses suggest that such attitudes do not have a direct effect on decision-making in NCRMD cases. Rather, defendant perceptions and mental illness stigma attitudes appear to have the greatest impact on decision-making. However, education had a limited effect on defendant perceptions, attitudes, and verdict decisions, which lends support to the notion that mental illness attitudes are deeply ingrained in social and cultural norms and are less amenable to change despite education. This lack of an effect may suggest that 
other variables, such as perceived mental illness controllability, have a strong relationship with mental illness attitudes, defendant perceptions, and decision-making in NCRMD cases. Furthermore, these results lend further support to Weiner's (1986) attributionaffect-help judgment model, which posits that variables such as mental illness controllability and pity may mediate the relationship between mental illness and helping judgments. However, Corrigan and colleagues (2001) found that attitudes towards controllability (mental illness avoidant behaviour and personal blame attributed to mental disorders) appear to be less amenable to education for mental illnesses associated with stronger stigma. This could also explain why education did not have a large impact on verdicts rendered.

In addition, mental illness education influenced NCRMD attitudes; however, NCRMD attitudes did not have a significant effect on verdict selection. These results diverge from previous studies, which suggested that NCRMD attitudes have a large influence on verdicts rendered in NCRMD cases (Roberts \& Golding, 1991; Skeem et al., 2004). The lack of an effect of NCRMD attitudes on verdicts could be attributed to interactive effects between trial manipulation and attitudes scales. Specifically, reading about different mental illnesses in the trial affected how jurors felt about the NCRMD defence. Therefore, attitudes toward the NCRMD defence may have been influenced by factors such as defendant mental illness type and perceived mental illness controllability. For instance, participants may agree that the defendant was mentally ill and incapable of discerning his actions; however, they may disagree that a certain mental disorder, such as substance use disorder, precludes one from criminal responsibility due to perceived mental illness controllability. Therefore, participants' perceptions toward the NCRMD 
defence and criminal responsibility depended on individual interpretations of mental illness, an issue that will be further discussed within the limitation section.

Furthermore, these results seem to contradict previous literature, which suggests that mental illness attitudes are amenable to change. Previous research indicates that anti-stigma initiatives can reduce stigma towards persons with mental illness (Chan et al., 2009; Corrigan et al., 2001; Pinfold et al., 2003; Schemetzer et al., 2008). Furthermore, research suggests that educational information within criminal trials can act as a persuasive function in verdicts rendered (Kovera et al., 1997); thus, it was hypothesized that mental illness education would have an effect on NCRMD verdicts. Refuting this prediction, mental illness education did not have a significant effect on mental illness attitudes. However, mental illness attitudes had a significant effect on verdict selection. Such results suggest that the mental illness education used for this study may not be a reliable tool to reduce mental illness stigma in juror decision-making in NCRMD trials. As a result, mental illness stigma and defendant perceptions can present themselves in NCRMD judgments, affecting jurors' ability to impartially apply legal standards. Therefore, a mentally ill offender's right to a fair trial may be reduced. However, it should be noted that participants read the equivalent of a 2-page educational report, whereas other successful education pieces, such as Corrigan and colleagues (2001) provided a 10-minute education presentation conducted in person followed by a 5 -minute discussion. Perhaps the education used for this study did not have an effect as it was too short. In addition, the education was read passively and did not involve a discussion where participants could engage in critical thinking. 
These findings also lend support for the generic prejudice model (Vidmar, 1997, 2002, 2003), whereby prejudice infuses the trial process, rendering jurors biased and partial when deciding verdict outcomes. Such inconsistencies in attitudinal responses among defendant mental illness type could imply that jurors hold a number of generic prejudices in regards to specific mental illnesses. For instance, participants may hold prejudicial attitudes and beliefs regarding substance use disorder, causing them to disagree that individuals with substance use disorders are mentally ill. Therefore, participants may render a guilty verdict despite research or education which that suggests substance use disorder is a mental illness. This could mean that jurors hold prejudice towards the defendant's mental illness rather than the NCRMD defence specifically, as indicated by previous research (Finkel, 1995; Skeem et al., 2004). In addition, jurors may utilize conformity prejudice as the juror may feel pressure from the media and the community to render a guilty verdict for defendants with substance use disorder. Given that the media consistently endorses stigmatized attitudes about mental illness and dangerous criminal behaviours (Brockington et al., 1993; Hamre et al., 1994), jurors may feel compelled to render a guilty verdict in order to please the community and to avoid external reactions of anger, hostility, and defensive indifference towards the juror.

\section{Implications}

The current research has implications for the prediction of verdicts rendered in NCRMD cases. Furthermore, this study contributes to the limited research regarding Canadian mental illness attitudes. Previous research examining the impact of labelling on public attitudes towards people with schizophrenia and major depression in Germany found that people with schizophrenia are associated with fear and increased social 
distance, while labelling persons with major depression had no effect on public attitudes (Angermeyer \& Matschinger, 2003). However, when individuals perceived persons with schizophrenia as being in need of help, participants' preference for social distance was mixed. In addition, research within the United States indicates that adults with schizophrenia are perceived to be a danger to themselves and others in comparison to individuals with depression (Anglin, Alberti, Link \& Phelan, 2006; Link, Phelan et al., 1999; Martin et al., 2000). Conversely, current results indicate that attitudes towards schizophrenia were no more negative than attitudes towards bipolar disorder and depression. Similar to Angermeyer and Matschinger (2003), attitudes toward schizophrenia were both positive and negative, suggesting that defendants with schizophrenia may have been perceived to be in need of help or treatment. Furthermore, perceptions towards defendants with schizophrenia were significantly more positive in comparison to defendants with bipolar disorder, depression, and substance use disorder. Thus, stigma towards schizophrenia was less pronounced in comparison to attitudes established in the United States (Anglin et al., 2006; Link et al., 1999; Martin et al., 2000) and Germany (Angermeyer \& Matschinger, 2003).

Although Angermeyer and Matschinger (2003) found that labelling persons with major depression had no effect on public attitudes in Germany, research within the United States has found that adults with major depression are perceived to be a danger to themselves (Pescosolido et al., 2010). Yet, Angermeyer and Dietrich's (2006) examination of 33 national studies within Europe found that stigma towards depression and bipolar disorder are relatively less pronounced in comparison to other mental illnesses, as participants are more sympathetic towards individuals with depression and 
bipolar disorder. Similarly, current results indicate that attitudes toward defendants with depression and bipolar were more positive in comparison to attitudes toward defendants with substance use disorder. However, previous research within the United States has found that attitudes towards depression and bipolar disorder were no more positive than attitudes toward schizophrenia (Anglin et al., 2006; Link et al., 1999; Martin et al., 2000). In this study, perceptions towards individuals with depression and bipolar were significantly more negative in comparison to schizophrenia.

Furthermore, research conducted within the United States and Europe indicate that individuals with substance use disorders are consistently associated with rejection, dangerousness, and increased social distance (Angermeyer \& Dietrich, 2006; Anglin et al., 2006; Link et al., 1999; Martin et al., 2000). Indeed, current results indicate that attitudes towards substance use disorder were more negative than those regarding schizophrenia, bipolar disorder, and depression. Furthermore, jurors' perceptions towards defendants with substance use disorder were significantly more negative in comparison to defendants with schizophrenia, bipolar disorder, and depression. These results offer an updated review on mental illness attitudes; however, continuous research is needed to examine the evolution of mental illness attitudes. In addition, mental illness findings in this study highlight the differing perceptions of mental illness stigma in NCRMD cases and in comparison to mental illness attitudes established in the United States and Europe.

Furthermore, this study addresses concerns regarding biased verdicts in NCRMD cases while offering potential solutions. Despite previous research, results indicate that attitudes towards the NCRMD defence do not necessarily exert considerable influence on 
mock jurors' verdicts. Rather, attitudes toward mental illness and defendant perceptions are highly influential upon verdicts. As a result, voir dire examinations in the United States pertaining to Insanity attitudes may not identify potentially biased verdicts as researchers previously thought (Culter et al., 1992). Within the United States, the voir dire procedure allows attorneys to pre-emptively evaluate prospective jurors through a number of model jury selection questions so that reasons for any appropriate challenges for cause can be identified. For instance, jurors are questioned on biographical information, such as the type of work they do, education history, and television shows they watch (Carchman, 2007). In addition, jurors are questioned on their ability to be a fair and impartial juror (Carchman, 2007). Therefore, attorneys can identify and reject jurors with potential biases, ensuring a fair trial.

In addition, this study provides a better understanding of when and why prejudice is likely to occur in NCRMD trials. Therefore, this study has significant implications for policies and practices that can reduce the likelihood of jury bias. Currently, Canadian courts have a number of avenues to safeguard against potential injustices, two of which are the peremptory challenge and the challenge for cause. These challenges are components of jury selection. A peremptory challenge allows attorneys to reject and replace a potential juror without explanation (Heinz, 1993; Vidmar \& Melnitzer, 1984). This process takes place during initial jury selection; therefore, attorneys receive limited information on prospective jurors. Conversely, a challenge for cause allows attorneys to reject jurors based on a presumption of juror partiality, which must be proven (Rose, 2001). The Crown and the defence have an unlimited amount of challenges for cause (Brown, 2000; Vidmar \& Melnitzer, 1984). However, the trial judge has the authority to 
reject the challenge, and the challenge may be subject of an appeal (Rose, 2001). Therefore, limited resources are available to the defence to ensure that their defendant receives a fair trial. Cutler and colleagues (1992) argued that extended voir dires (jury selection procedures) in Insanity trials could increase a mentally ill defendant's chance of a fair trial. Although voir dire procedures are not typically permitted in Canada, a judge in a trial may permit a challenge for cause question on a case-by-case basis (Juries Act, 1998; R. v. Parks, 1993; R. v. Williams, 1998). As an example, two precedential cases (R. v. Parks, 1993; R. v. Williams, 1998) have permitted challenge for cause for a minority defendant where widespread racial prejudice was apparent. However, the defence must provide that such general prejudice exists. Current results suggest that a mental illness stigma challenge for cause should be allowed, and that jury panels should be pre-emptively examined with regards to their attitudes toward mental illness in order to prevent skewed verdicts. Given that anti-NCRMD attitudes may not be very predictive of verdict decisions in Canada, jury questioning should instead examine attitudes towards mental illness, and perceptions of mental illness controllability and blameworthiness. Without additional precautions, a defendant's right to a fair trial may be limited.

However, one may argue that this research is not practically significant as public policy seems to be moving in the opposite direction. On November 25, 2013 the Government of Canada enacted Bill C-14 (2013), the Not Criminally Responsible Reform Act, legislation aimed at making it more difficult to release mentally ill offenders from custody in order to increase public safety. The reform was based on three main components: putting public safety first, creating a high-risk designation, and enhancing victims' rights (Department of Justice, 2013). However, the reform exaggerates violence 
among the mentally ill while undervaluing rehabilitation efforts. Therefore, the reform contributes to mental illness stigmatization. This reform seems to be in opposition to defendant rights, which only gives more reason to study this area. Future studies should examine how the Not Criminally Responsible Reform Act affects individuals' perceptions toward mental illness and if jurors' guilt ratings increase as a result. Ideally, amendments should be made to the Not Criminally Responsible Reform Act, which supports victims without enabling the stigma and discrimination of mental illness.

\section{Limitations and Future Directions}

Although this study has many strong points, it is not without potential limitations. The ecological validity is a potential concern for the current study given the use of written trial transcripts. However, research regarding the trial presentation medium on jurors' judgments of culpability suggests that similar results have been obtained through written transcripts and video trial transcripts. Bornstein's (1999) assessment of 11 published studies that varied on trial presentation medium found that only 6 studies specifically compared trial video with trial transcript; none of these studies found a main effect of trial presentation medium on mock jury outcomes. Similar results have also been found in more recent research studies. For example, Pezdek and colleagues (2010) examined whether jurors' perceptions of eyewitness expert testimony varied as a function of trial presentation medium - video or transcript. However, no significant interactions of trial presentation medium and expert condition were found, indicating that trial transcripts are externally valid. Therefore, written trial transcripts may not differ in the quality or nature of data from that of video trials (Bornstein, 1999; Pezdek et al., 2010). Furthermore, Forsterlee and colleagues (2000) found that written expert testimony is 
sometimes preferred, as it improves mock jurors' comprehension of complex expert testimony.

In addition, the present study focused on juror decision-making rather than jury decision-making, which may limit ecological validity as well as construct validly. Although this study sought to examine the individual processes that each juror takes when rendering a verdict decision, this does not simulate a real courtroom trial. In real trials, jury members must agree upon a final verdict decision rather than rendering an individual verdict. However, research has suggested that juror verdicts can reliably predict jury decisions rendered within a group (Diamond, 1997). Follow-up studies should examine if there is a difference between group decision-making and individual decision-making within NCRMD trials and if education effects can be replicated with group decision-making. Given the amount of negative attention towards the NCRMD defence, group decisions may provide pressures to conform in instances of disagreement, which may affect deliberations. However, previous research regarding sentencing decisions for defendants with mental illness indicated that mock jurors' sentences in group conditions did not differ from individual conditions (Sabbagh, 2011). Furthermore, mock jurors' sentences were slightly more lenient toward defendants with schizophrenia than defendants with no mental disorder (Sabbagh, 2011).

Mock trials have also been criticized for lack of realism as judgment consequences are vastly different for mock jurors than real jurors. Real jurors must accept that their judgment will have impact on the people involved in the case as well as the larger community, a task that mock jurors do not face. Although this may limit the generalizability of results, Canadian jury research is limited to mock trials as it is an 
offence for a juror to disclose any information relating to the proceedings of the jury if the information was absent from the courtroom and was not subsequently disclosed in open court (Criminal Code, 1985; R. v. Pan, 2001; R. v. Sawyer, 2001).

Another concern to the current study's external validity is the use of online studies. Despite potential external validity concerns, research suggests that online studies produce comparable results to that of in-lab research (Birnbaum, 2000; Buchanan \& Smith, 1999; Riva, Teruzzi, \& Anolli, 2003; Smith \& Leigh, 1997). Furthermore, there are limitations to both online studies and in lab studies since both lack elements of experimental realism. However, manipulation checks have been implemented to safeguard the validity of the data collection. Furthermore, limited information pertaining to the Qualtrics panel subject pool was available, limiting the generalizibility of results. Qualtrics panels assist researchers to reach a target demographic, launch the study, and monitor the project (Qualtrics Panels, n.d). The panel offers a high-quality sample, convenient launch process, and reputable past customers (Qualtrics Panels, n.d). However, to date, no case studies have been completed on the quality of data Qualtrics panels produces. Therefore, the generalizability is of the current results may be limited. Notably, however, demographic information obtained for the purpose of this study indicates that participants varied in age and education.

In addition, the imbalance of participants' gender causes concern regarding the generalizability of results. Literature suggests that females are more lenient in their verdict decisions in Insanity cases (Breheney, Groscup, \& Galietta, 2007). Female participants were more likely to attribute the defendant's actions to an impulse caused by a mental illness and were more likely to find the defendant to be less responsible for his 
actions (Breheney et al., 2007). In that study, women were more willing to issue NGRI verdicts than were men. In the current study, a greater proportion of female responses were collected. Therefore, results may display an increased amount of NCRMD verdicts, limiting the generalizability of results. Future studies should whether female Canadian jurors are also more lenient in their verdict decisions in NCRMD cases.

Furthermore, predictor variables were measured after exposure to the independent variables, as we did not want to alert participants of the true nature of the study. However, this could be a potential limitation to the current study. As such, the lack of educational results could be attributed to interactive effects between trial manipulation and attitude scales. Specifically, reading about different mental illnesses in the trial may have affected participants' attitudes toward mental illness and the NCRMD defence. Indeed, results did demonstrate an effect of defendant mental illness type on NCRMD attitudes, suggesting that the specific mental illness type that participants read about affected how they felt about the Insanity defence. However, previous research suggests that mental illness attitudes are robust and deeply ingrained in social and cultural norms (Madianos et al., 2012). In addition, these attitudes have been found to be relatively stable over time (Distefano \& Pryer, 1979; Klama \& Egan, 2011; Olmsted \& Durham, 1976; O’Mahoney, 1979; Schwartz, 1978). However, participants answered the MISS scale with regards to the specific mental illness type that they were assigned. Given the previous research indicating that attitudes toward schizophrenia, substance abuse disorder, bipolar disorder, and depression may differ (Angermeyer \& Dietrich, 2006; Angermeyer \& Matschinger, 2003; Link \& Phelan, 2006; Link et al., 1999; Martin et al., 2000), it was hypothesized that mental illness attitudes would differ due to defendant 
mental illness. Therefore, the order of presentation is not as large of a concern for mental illness attitudes.

In addition, research suggests that Insanity defence attitudes are stable over time (Louden \& Skeem, 2007; Skeem \& Golding, 2001; Skeem et al., 2004) and less likely to change, despite education and persuasive messages. Moreover, some researchers have debated that such attitudes are relatively stable intuitive conceptions of Insanity (Hans \& Slater, 1984). However, this study's results indicate that the specific mental illness type that participants read about affected participants' attitudes toward the NCRMD defence. Therefore, future studies should administer attitude scales prior to exposure to the trial transcript to ensure that attitudes do not vary as a function of trial exposure, or counterbalance the order of attitude scales and the trial transcript to determine if attitudes varied as a function of trial exposure.

As previously stated, the lack of education results could be attributed to interactive effects between trial manipulation and attitude scales. However, the lack of education results could also be attributed of the material within the education. Specifically, the mental illness education indicated that causes of schizophrenia, bipolar, and depression can be related to chemical changes in the brain and genetics; however, the substance use disorder education provided less physiological causes and more psychological causes, such as psychosocial problems (e.g. loss of job, family problems, and relationship problems). Therefore, the onset of substance use disorder could be perceived as controllable by reading our education. In addition, by reading about all disorders, participants may have generated the option that substance use disorder was 'less' of a disorder in comparison to the other mental illness. Furthermore, education 
provided an element on psychosis and how psychosis can affect all mental illnesses. However, the connection between psychosis and substance use disorder was not construed as strongly as the other mental illness types. As a result, participants may not have been able to make the connection between substance use disorder and psychosis when reading the trial transcript, making the substance use disorder trial less believable. Inconsistencies between the trial transcripts could also limit our ability to make comparisons between all mental illnesses. Specially, the schizophrenia, depression, and bipolar trial transcripts depicted within this study indicated that the defendant's illness was due to a number of factors, such as family history, chemical imbalances in the brain, and a major life event. As a result, the onset of the defendants' disorder could be construed as uncontrollable, causing jurors to feel more pity and empathy for the defendant. However, the substance use disorder trial transcript did not construe the same level of family history, chemical imbalance in the brain, or major life event as the other trial transcripts. Thus, jurors may perceive the onset of the disorder as more controllable in comparison to the other disorders. In addition, the other trial transcripts indicated that the defendant stopped taking his medication due to reasons related to the disorder itself (e.g., he believed that he was better), yet the substance use disorder trial indicated that the defendant could no longer afford counselling. Although this may be outside of the defendant's control, this could also add negative stigmas regarding social economic status. Therefore, the large effect of substance use disorder could have been attributed to the differences between the trial manipulations. Furthermore, the substance use disorder trial briefly made mention that the defendant was in possession of a firearm. Although the firearm was not used, this could generate negative attitudes in regards to gun 
violence, which could be further attributed to the defendant. Therefore, comparisons across the mental illness types should be cautioned.

In addition, the large number of manipulation check failures causes concern for the current study. Such failures could be attributed to the fact that participants were asked to complete a series of manipulation checks highlighting information that is often misunderstood after each piece of education and trial transcript. These results signify the fact that people are unable to identity a number of mental illnesses even if the mental illness was salient. In addition, results suggest that people know little about mental illness despite receiving direct education. Furthermore, rather than failing to attend to the materials, participants may have answered questions based on their own stereotypes and misconceptions. For instance, some participants may have continued to hold the belief that substance use disorder is not a mental illness despite receiving education. Therefore, they may have disregard education and answered manipulation checks based on their previous beliefs. Although these results are concerning, their removal ensures that participants used for the purpose of this study displayed a high degree of comprehension, and that therefore, current results cannot be attributed to a lack of comprehension or memory of the educational material.

In addition, future studies should examine whether results replicate over a variety of mental illness types, such as organic disorder. Due to the size and the complexity of the current design, the most prevalent mental illnesses used in NCRMD trials were examined. However, future studies should examine verdict differences across a variety of other mental disorders. For instance, perhaps jurors would be more sympathetic toward defendants with an organic disorder and therefore would be more likely to find a 
defendant with an organic disorder NCRMD. Furthermore, such studies should examine differences between sentencing/dispositions for a variety of mental disorders. Although jurors may be more willing to find a defendant with an organic disorder NCRMD, it is possible that jurors may select harsher dispositions for defendants with an organic disorder as prospects for disorder recovery are reduced in comparison to other mental disorders.

Factors such as mental health history should also be examined, as this could impact jurors' perceptions towards the defendant, affecting jurors' emotions and the likelihood that they would find the defendant NCRMD. Within the current study, the criminal act in question was the first psychotic break for the defendant across all conditions. However, the stability of the defendant's mental illness may impact how jurors perceive the mentally ill defendant. For example, a person with a long history of schizophrenia who has committed a violent act may be viewed differently in comparison to a person who develops a delusional disorder and commits a violent act. The person with a long history of schizophrenia may be viewed more positively because his or her disorder is seen to be more stable in comparison to an individual who had no previous mental illness history and committed a violent act during his first psychotic break. In addition, participants may associate failure to take medication with instability, causing participants to react with more anger and less pity. Thus, future studies should examine and manipulate defendant mental history to see if this has a large impact on verdicts rendered in NCRMD cases.

Furthermore, individual perceptions toward NCRMD dispositions should be examined. Specifically, studies should examine whether jurors perceive psychiatric 
treatment as insufficient, punishment, rehabilitative, or a deterrent. Although NCRMD attitudes did not predict verdicts rendered in NCRMD trials, attitudes toward dispositions may relate to defendant perceptions, thus indirectly affecting guilt ratings. In addition, follow up studies should examine Weiner's (1986) attribution-affect-help judgment model to determine if perceptions of mental illness controllability have an impact on jurors' mental illness attitudes, perceptions of the defendant, and emotions such as sympathy and anger towards the mentally ill defendant. Previous research has found that mental illnesses associated with higher ratings of controllability were linked to greater anger and less pity (Menec \& Perry, 1998). Furthermore, greater pity was predictive of greater willingness to help (Menec \& Perry, 1998). Thus, follow up studies should examine if perceived controllability of the onset of mental illness, history of mental illness, and stability of illness impacts jurors' mental illness attitudes, perceptions of the defendant, and emotions, which ultimately predict juror verdict decisions in an NCRMD case. These results could help explain why jurors are reluctant to find certain mentally ill defendants NCRMD.

\section{Conclusion}

Despite potential shortcomings, the present study provided relevant knowledge on juror decision-making in NCRMD trials. Previous studies have shown that jurors are inherently biased against the NCRMD defence and such bias affects their ability to impartially apply legal standards. However, the present study suggests that NCRMD attitudes do not significantly influence verdicts rendered in NCRMD trials. Rather, defendant mental illness, attitudes toward mental illness, and perceptions of the defendant appear to have the greatest impact on decision-making. Furthermore, this research sheds 
light on the perceptions of varying mental illnesses and the prevalence of mental illness stigma among mock jurors. Furthermore, it has become more apparent that stigmatized attitudes toward mental illness have daunting effects on mentally ill individuals. Education strategies attempted to enhance juror impartiality and fairness within the criminal justice system; however, education had a limited effect on defendant perceptions, attitudes, and verdicts in NCRMD cases. This lends support to the notion that mental illness attitudes are deeply ingrained in social and cultural norms and are not amenable to change despite education. As a result, mental illness attitudes and defendant perceptions may present themselves in NCRMD judgments. However, differences among education conditions did not imply that jurors held extremely biased attitudes. Therefore, inferences that attitudes affected jurors' ability to impartially apply legal standards cannot be made with certainty.

However, results imply that defendant mental illness affected jurors' perceptions of the defendant, attitudes toward mental illness, and judgments in NCRMD trials. Furthermore, current results suggest that other factors, such as perceived mental illness controllability and emotions, may influence verdict decisions. Therefore, future studies should examine Weiner's (1986) attribution-affect-help judgment model to determine if jurors' perceptions of mental illness controllability impacts on jurors' emotions, mental illness attitudes, and perceptions of the defendant, which ultimately predict juror verdict decisions in an NCRMD case. Overall, results suggest that the Canadian legal system may be in need of potential strategies to safeguard against injustice and prejudice as a function of mental illness stigma in NCRMD trials. 


\section{References}

Adams, K. \& Ferrandino, J. (2008). Managing mentally ill inmates in prisons. Criminal Justice and Behaviour, 35(8), 913-927. doi: 10.1177/0093854808318624

Administrative Office of the Courts State of New Jersey. (2007, May 16). Jury selection - Model voir dire questions promulgated by directive \#21-06-Revised procedures and question. Retrieved from http://www.judiciary.state.nj.us/directive/2007/dir_04_07.pdf

Ajzen, I. \& Gilbert Cote, N. (2008). Attitudes and the prediction of behavior. In W. D. Crano \& R. Prislin (Eds.), Attitudes and Attitude Change (pp. 289-311). New York: Psychology Press.

American Psychiatric Association (2000). Diagnostic and statistical manual of mental disorders. ( $4^{\text {th }}$ ed. Text revision). doi:10.1179/appi.books.9780890423349

Angermeyer, M.C. \& Dietrich, S. (2006). Public beliefs about and attitudes towards people with mental illness: A review of population studies. Acta Psychiatrica Scandinavica, 113(3), 163-179. doi: 10.1111/j.1600-0447.2005.00699.x

Angermeyer, M.C. \& Matschinger, H. (2003). The stigma of mental illness: Effects of labelling on public attitudes towards people with mental disorder. Acta Psychiatrica Scandinavica, 108, 304-309. doi: 10.1034/j.16000447.2003.00150.x

Anglin, D.M., Link, B.G., \& Phelan, J.C. (2006). Racial differences in stigmatizing attitudes toward people with mental illness. Psychiatric Services, 57(6), 857-862. doi:10.1176/appi.ps.57.6.857. 
Appelbaum, P.S. (2006). Violence and mental disorders: Data and public policy. The American Journal of Psychiatry, 163, 1319-1321.doi:10.1176/appi.ajp.163.8.1319

Bargh, J.A. (1999). The cognitive monster: The case against the controllability of automatic stereotype effects. In S. Chaiken \& Y.Trope (Eds.), Dual process theories in social psychology (pp.361-382). New York: Guilford.

Bargh, J.A., Chen, M., \& Burrows, L. (1996). Automaticity of social behavior: Direct effects of trait construct and stereotype activation on action. Journal of Personality and Social Psychology, 17(2), 230-244. doi: 10.1037/00223514.71 .2 .230

Bell: Let's talk (n.d.). Retrieved on March 9, 2012, from Bell Canada Website, http://letstalk.bell.ca/en/our-initiatives/

Berinsky, A.J., Huber, G.A., \& Lenz, G.S. (2012). Evaluating online labour markets for experimental research: Amazon.com's mechanical turk. Political Analysis, 20, 351-368. doi:10.1093/pan/mpr057

Bigler, R. S. \& Liben, L. S. (1993). A cognitive-developmental approach to racial stereotyping and reconstructive memory in Euro-American children. Child Development, 64(5), 1507-1518. doi: 10.1111/j.1467-8624.1993.tb02967.x

Bipolar Disorder - Fact Sheet (n.d.) Retrieved on October 14, 2011, from Treatment Advocacy center website, http://www.treatmentadvocacycenter.org/resources/briefing-papers-and-factsheets/159/46

Billings, J. (1874). Josh Billings' Wit and Humor. London: G. Routledge and Sons. Birnbaum, M.H. (Ed.). (2000). Psychological experiments on the Internet. San Diego: 
Academic Press.

Bland, R.C., Newman, S.C., Dyck, R.J., \& Orn, H. (1990). Prevalence of psychiatric disorders and suicide attempts in a prison population. Canadian Journal of Psychiatry, 35(5), 407-413.

Bloechl, A.L., Vitacco, M.J., Neumann, C.S., \& Erickson, S.E. (2007). An empirical investigation of Insanity defense attitudes: Exploring factors related to bias. International Journal of Law and Psychiatry, 30(2), 153-161. doi:10.1016/j.ijlp.2006.03.007

Bonta, J., Law, M., \& Hanson, K. (1998). The prediction of criminal and violent recidivism among mentally disordered offenders: A meta-analysis. Psychological Bulletin, 123(2), 123-142. doi: 10.1037/0033-2909.123.2.123

Bonta, J., Rugge, T., \& Dauvergne, M. (2003). The reconviction rate of federal offenders - User Report 2003-02. Retrieved from http://www.publicsafety.gc.ca/cnt/rsrcs/pblctns/rcvd-fdffndr/index-eng.aspx Bornstein, A.B. (1992). Public attitudes towards persons with mental illness. Health Affairs, 3, 186-196. doi: 10.1377/hlthaff.11.3.186

Bornstein, B.H. (1999). The ecological validity of jury simulations: Is the jury still out? Law and Human Behaviour, 23(1), 75-91.

Bornstein, B.H. \& Rajki, M. (1994). Extra-legal factors and product liability: The influence of mock jurors' demographic characteristics and intuitions about the cause of injury. Behavioral Sciences and the Law, 12, 127-147.

doi:10.1002/bsl.2370120204 
Breheney, C., Groscup, J., \& Galietta, M. (2007). Gender matters in the insanity defense. Law and Psychology Review, 31, 93-123.

Brockington, I. F., Hall, P., Levings, J., \& Murphy, C. (1993). The community's tolerance of the mentally ill. British Journal of Psychiatry, 162, 93-99. doi:10.1192/bjp.162.1.93

Brown, R. B. (2000). Challenges for cause, stand-asides, and peremptory challenges in the nineteenth century. Osgoode Hall Law Journal, 38(3), 453-494

Buchanan, T., \& Smith, J.L. (1999). Using the Internet for psychological research: Personality testing on the World-Wide Web. British Journal of Psychology, 90, 125-144. doi: 10.1348/000712699161189

Butler, B. (2006). NGRI revisited: Venirepersons' attitudes towards the insanity defence. Journal of Applied Social Psychology, 38(8), 1833-1847. doi: 10.1111/j.00219029.2006.00084.x

Callahan, L.A., Steadman, H.J, McGreevy, M.A., \& Robins, P.C. (1991). The volume and characteristics of insanity defense pleas: An eight-state study. The Bulletin of the American Academy of Psychiatry and the Law, 19, 331-338.

Canadian Charter of Rights and Freedoms, PART I OF THE CONSTITUTION ACT, 1982.

Canadian Institute for Health Information (2008). Improving the Health of Canadians: Mental Health, Delinquency and Criminal Activity. Retrieved from https://secure.cihi.ca/free products/mh crime full report apr11 08 e.pdf 
Canadian Mental Health Association (2004, April 30). Backgrounder: Justice and mental health. Retrieved from http://www.cmha.ca/public_policy/justicebackgrounder/\#.U3VdltJdWa8

Canadian Psychiatric Association. (2011, November 23). Position Statement: The treatment of mental illness in correctional settings. Retrieved from $\underline{\text { http://publications.cpa-apc.org/media.php?mid=1249 }}$

Case, B., Steadman, H.J., Dupuis, S.A., \& Morris, L.S. (2009). Who succeeds in jail diversion programs for persons with mental illness? A multi-site study. Behavioral Sciences and the Law, 27, 661-674. doi: 10.1002/bsl.883

Chan, J.Y.N., Mak, W.W.S., \& Law, L.S.C. (2009). Combining education and videobased contact to reduce stigma of mental illness: "The same or not the same" anti-stigma program for secondary schools in Hong Kong. Social Science \& Medicine, 68, 1521-1526. doi:10.1016/j.socscimed.2009.02.016

Cirincione, C., Steadman, H.J., Clark-Robbins, P.C., \& Monahan, J. (1992). Schizophrenia as a contingent risk factor for criminal violence. International Journal of Law and Psychiatry, 15, 347-358.

Clark, W., Welch, S.N., Berry, S.H., Collentine, A.M., Collins, R., Lebron, D., \& Shearer, A.L. (2013). California's historic effort to reduce the stigma of mental illness: The mental health services act. American Journal of Public Health, 103(5), 786-794. doi: 10.2105/AJPH.2013.301225.

Clausell, E., \& Fiske, S.T. (2005). When do subgroup parts add up to the stereotypic whole? Mixed stereotype content for gay male subgroups explains overall ratings. Social Cognition, 23, 161-181. doi:10.1521/soco.23.2.161.65626 
Cohen, J., Cohen, P., West, S.G. \& Aiken, L.S. (2003). Applied Multiple Regression/Correlation Analysis for the Behavioral Sciences ( $3^{\text {rd }}$ ed.). New Jersey: Lawrence Erbaum Associates.

Cohn, E. S., Bucolo, D., Pride, M., \& Sommers, S. R. (2009). Reducing White juror bias: The role of race salience and racial attitudes. Journal of Applied Social Psychology, 39(8), 1953-1973. doi: 10.1111/j.1559-1816.2009.00511.x

Collins, J. Edward (2012). Chapter 12: Criminal Law, Procedure, and Administration. Annual Survey of Massachusetts Law, 1958 (16).

Colverdale, J., Nairn, R., \& Classen, D. (2002). Depictions of mental illness in print media: A prospective national sample. Australian and New Zealand Journal of Psychiatry, 36(5), 697-700. doi: 10.1046/j.1440-1614.2002.00998.x

Correctional Service of Canada. (2007). CSC launches a comprehensive mental health strategy. E-journal of Let's Talk, 32(1). Retrieved from http://www.cscscc.gc.ca/text/pblct/lt- en/2007/32-1/index-eng.shtml

Correctional Service of Canada. (2009). Mental health strategy: For corrections in Canada. Retrieved from http://www.csc-scc.gc.ca/health/092/MH-strategyeng.pdf

Corrigan, P.W., Larson, J., Sells, M., Nieseen, N., \& Watson, A.C. (2007). Will filmed presentations of education and contact diminish mental illness stigma? Community Mental Health Journal, 42(2), 171-181. doi: 10.1007/s10597-0069061-8 
Corrigan, P.W., Markowitz, F.E., Watson, A., Rowan, D., \& Kubiak, M.A. (2003). An attribution model of public discrimination towards persons with mental illness. Journal of Health and Social Behavour, 44(2), 162-179. doi: 10.2307/1519806 Corrigan, P.W., River, L.P., Lundin, R. K., Penn, D.L, Uphoff-Wasowski, K., Campion, J., Mathisen, J., Gagnon, C., Bergman, M. Goldstein, H., \& Kubiak, M.A. (2001). Three strategies for changing attributions about severe mental illness. Schizophrenia Bulletin, 27(2), 187- 195.

Corrigan, P.W., River, L.P., Lundin, R.K., Uphoff Wasowski, K., Campion, J., Mathisen, J., Goldstein, H., Bergman, M., Gagnon, C., \& Kubiak, M.A. (2000). Stigmatizing attributions about mental illness. Journal of Community Psychology, 28(1), 91102. doi: 0.1002/(SICI)1520-6629(200001)28:1<91::AID-JCOP9>3.0.CO;2-M

Corrigan, P.W. \& Watson. A.C. (2005). Findings from the National comorbidity survey n the frequency of violent behavior in individuals with psychiatric disorders. Psychiatry Research. 136(2-3), 153-162.

Criminal Code of Canada. R.S., 1985, c. C-46, s. 16; R.S., 1985, c. 27 (1st Supp.), s. 185(F); 1991, c. 43, s. 2.

Criminal Code, S.C. (1892), Chap. 29, s.11

Crocker, A.G., Seto, M.C., Nicholls, T.L., \& Coté, G. (2013, March). Description and processing of individuals found not criminally responsible on account of mental disorder accused of serious violent offences. Retrieved from https://ntpptn.org/NCRMD-SVO-NTPteam_March_2013.pdf 
Dane, F.C., \& Wrightsman, L.S. (1982). Effects of defendants' and victims' characteristics on jurors' verdicts. In N. L. Kerr \& R. M. Bray (Eds.), The psychology of the courtroom (pp. 83-118). New York, NY: Academic Press.

Day, E.N., Edgren, K., \& Eshelman, A. (2007). Measuring stigma toward mental illness: Development and application of the mental illness stigma scale. Journal of Applied Social Psychology, 37(10), 2191-2219. doi: 10.1111/j.15591816.2007.00255.x

Diabetes Fact Sheet. (2011). Retrieved September 20, 2011, from Canadian Diabetes Association website, http://www.diabetes.ca/files/Diabetes_Fact_Sheet.pdf

Diamond, S.S. (1997). Illuminations and shadows from jury simulations. Law and Human Behavior, 21(5), 561-571. doi: 10.1023/A:1024831908377

Diefenbach, D.L. \& West, M.D. (2007). Television and attittudes toward mental health issues: Cultivation analysis and the third-person effect. Journal of Community Psychology, 35(2), 181-195. doi: 10.1002/jcop.20142

Dietrich, S., Heider, D., Matschinger, H. \& Angermeyer, M.C. (2006). Influence of newspaper reporting on adolescents' attitudes towards people with mental illness. Social Psychiatry Psychiatric Epidemiology, 41(1), 318-322. doi: $10.1007 / \mathrm{s} 00127-005-0026-\mathrm{y}$

Distefano, M.K., Pryer, M. W. (1979). Follow-up mental health attitudes of psychiatric aids after training. Psychological Reports, 45(3), 801-802.

Department of Justice Canada. (2006). The review board systems in Canada: An overview of results from the mentally disorderd accused data collection study. 
Retrieved from http://dsp-psd.pwgsc.gc.ca/collection_2009/justice/J3-2-2006-11E.pdf

Department of Justice Canada. (2013). Backgrounder: Not criminally responsible reform act. Retrieved from http://www.justice.gc.ca/eng/news-nouv/nrcp/2013/doc_33001.html

Douglas, M. \& Zaentz, S. (Producer), \& Forman, M. (Director). (21 November 1975). One Flew over the Cuckoo's Nest [Motion picture]. USA: United Artists Corporation.

Durham v. United States, 214 F.2d 862

Esters, I. G., Cooker, P. G., \& Ittenbach, R. F. (1998). Effects of a unit of instruction in mental health on rural adolescents' conceptions of mental illness and attitudes about seeking help. Adolescence, 33, 469-476.

Evaluation of criminal responsibility. In A. M. Goldstein, S. J. Morse, D. L. Shapiro, \& I. B. Weiner (Ed.), Handbook of Psychology: Forensic Psychology (Vol. 11, pp. 390). Hoboken, New Jersey, United States: John Wiley \& Sons, Inc.

Evans, J. S. (1984). Heuristics and analytic processes in reasoning. British Journal of Psychology, 75, 451-468. doi: 10.1111/j.2044-8295.1984.tb01915.x

Fazio, R.H. (1990). Multiple processes by which attitudes guide behavior: The MODE model as an integrative framework. In M. P. Zanna (Ed.), Advances in experimental social psychology (Vol. 23, pp. 75-109). New York: Academic Press.

Fazio, R. H. (1995). Attitudes as object-evaluation associations: Determinants, consequences, and correlates of attitude accessibility. In R. E. Petty J. A. 
Krosnick (Eds.), Attitude strength: Antecedents and consequences (pp. 247-282). Hillsdale, NJ: Erlbaum.

Fazio, R.H. \& Williams, C.J. (1986). Attitude accessibility as a moderator of the attitudeperception and attitude-behavior relations: An investigation of the 1984 presidential election. Journal of Personality and Social Psychology, 51(3), 505514.

Finkel, N. J. (1988). Insanity on trial. New York: Plenum Press.

Finkel, N.J. (1989). The insanity defense reform act of 1984: Much ado about nothing. Behavioural Sciences and the Law, 7, 403-419.

Finkel, N.J. (1991). The insanity defense: A comparison of verdict schemas. Law and Human Behavior, 15(5), 533-554. doi:10.1007/BF01650293

Finke, N.J. (1995). Commonsense justice: Jurors notions of the law. Cambridge, MA: Harvard University Press.

Finkel, N.J. (1997). Commonsense justice, psychology, and the law: Prototypes that are common, senseful, and not. Psychology, Public Policy, and Law, 3(2/3), 461-489. doi: 10.1037/1076-8971.3.2-3.461

Finkel, N.J. (2000). But it's not fair! Commonsense notions of unfairness. Psychology, Public Policy, and Law, 6(4), 898-952. doi: 10.1037///1076-8971.6.4.898.

Finkel, N.J. \& Groscup, J.L. (1997). Crime prototypes, objective versus subject responsibility, and a commonsense balance. Law and Human Behavior, 21(2), 209-224.

Finkel, N.J. \& Sales, B.D. (1997). Commonsense justice: Old roots, germinant ground, and new shoots. Psychology, Public Policy, and Law, 3(2/3), 227-241. 
Fishbein, M., \& Ajzen, I. (1975). Belief, attitude, intention and behavior. Reading, Massachusetts: Addison-Wesley Publishing Company.

Fiske, S.T. (1998). Stereotyping, prejudice, and discrimination. In D.T. Gilbert, S.T. Fiske, \& G. Lindzey (Eds.), The handbook of social psychology $\left(4^{\text {th }} \mathrm{ed}\right.$. Vol. 2, pp.357-411). New York: McGraw Hill.

ForsterLee, L., Horowitz, I., Athaide-Victor, E., \& Brown, N. (2000). The bottom line: The effect of written expert witness statements on juror verdict and information processing. Law and Human Behavior, 24(2), 259-270. doi:

10.1023/A:1005415104323\% T

Francis, C., Pirkis, J. Blood, R.W., Dunt, D., Borley, B., \& Stewart, A. (2005). Portrayal of depression and other mental illnesses in Australian nonfiction media. Journal of Community Psychology, 33(3), 283-297. doi: 10.1002/jcop.20050

Glick, P. \& Fiske, S.T. (2001). An ambivalent alliance: Hostile and benevolent sexism as complementary justifications of gender inequality. American Psychologist, 56, 109-118. doi: 10.1037/0003-066X.56.2.109

Goffman, E. (1963). Stigma: Notes on the management of spoiled identity. New York: Simon \& Schuster Inc.

Government of Canada (2006). The human face of mental health and mental illness in Canada. Retrieved from http://www.phac-aspc.gc.ca/cd-mc/mi-mm/indexeng.php

Hamre, P., Dahl, A.A., \& Malt, U.F. (1994). Public attitudes to the quality of psychiatric treatment, psychiatric patients, and prevalence of mental disorders. Nordic Journal of Psychiatry, 48(4), 275-281. 
Hans, V. (1986). An analysis of public attitudes toward the insanity defence.

Criminology, 24(2), 393-414. doi: 10.1111/j.1745-9125.1986.tb05102.x

Hans, V. \& Slater, D. (1984). Plain crazy: Lay definitions of legal insanity. International Journal of Law \& Psychiatry, 7, 105 -114

Health Canada. (2002). Best Practices- Concurrent Mental Health and Substance Use

Disorders. Retrieved from http://www.hc-sc.gc.ca/hc-ps/alt formats/hecs$\underline{\text { sesc/pdf/pubs/adp-apd/bp disorder- }}$ $\underline{\mathrm{mp} \_ \text {concomitants/bp_concurrent_mental_health-eng.pdf }}$

Health Canada, Health Canada Editorial Board Mental Illnesses in Canada. (2002). A report on mental illnesses in Canada. Retrieved from http://www.phacaspc.gc.ca/publicat/miic-mmac/pdf/men ill e.pdf

Health Promotion and Programs Branch Health Canada. (1996). Mental illness and violence: Proof or stereotype? Retrieved from http://www.phac-aspc.gc.ca/mhsm/pubs/mental illness/index-eng.php\#tc

Heinz, J. (1993). Peremptory challenges in criminal cases: A comparison of regulation in the United States, England, and Canada. Loyal of Los Angeles International and Comparative law Review, 16(1). Retrieved from http://digitalcommons.lmu.edu/ilr/vol16/iss1/6

Heyman, G. (2009). Addiction: A Disorder of Choice. Cambridge, MA: Harvard University Press.

Hill, G.D, Harris, A.R., \& Miller, J.L. (1985). The etiology of bias: Social heuristics and rational decision making in deviance processing. Journal of Research in Crime and Delinquency, 22, 135-162. doi: 10.1177/0022427885022002003 
Hosch, H.M., Culhane, S.E., Tubb, V.A. \& Granillo, E.A. (2011). Town vs. gown: A direct comparison of community residents and student mock jurors. Behavioral sciences and the law. Advance online publication. doi: 10.1002/bsl.970

Hu, L.T. \& Bentler, P.M. (1999). Cutoff criteria for fit indexes in covariance structure analysis: Conventional criteria versus new alternatives. Structural Equation Modeling, 6(1), 1-55. doi: 10.1080/10705519909540118

Huntely, J. \& Costanzo, M. (2003). Sexual harassment stories: Testing a story-mediated model of juror decision making in civil litigation. Law and Human Behavior, 27(1), 29-51. doi:10.1023/A:102167811225

Hyler, S.E., Gabbard, G.O., \& Schneider, I. (1991). Homicidal maniacs and narcissistic parasites: Stigmatization of mentally ill persons in the movies. Hospital and Community Psychiatry, 42, 1044-1048.

Jellinek, E. M. (1960). The Disease Concept of Alcoholism. New Haven: Hillhouse. Insanity Defence Reform Act of 1984. Pub, L 98-476, title II, ch. IV (§ 401 seq.), October 12, 1984, 98 Stat. 2057 (18 U.S.C. 4241 et seq.)

Jones, E. E., Farina, A., Hastorf, A. H., Markus, H., Miller, D. T., \& Scott, R. A. (1984). Social stigma: The psychology of marked relationships. New York: Freeman. Juries Act. 1998, c. 16, s. 1.

Kahneman, D. \& Tversky, A. (1979). Prospect theory: An analysis of decision under risk. Econometrica, 47(2), 263-291. doi: 10.2307/1914185

Kelly, J. O. (2011). Veterans on trial: Juror attitudes and behaviors toward veterans with posttraumatic stress disorder (Master's thesis). Retrieved from ProQuest dissertations and Theses database. (UMI No. 14956270) 
Klama, E.K. \& Egan, V. (2011). The big-five, sense of control, mental health and fear of crime as contributory factors to attitudes towards punishment. Personality and Individual Differences, 51(1), 613-617. doi: 10.1016/j.paid.2011.05.028

Kovera, M.B., Gresham, A.W., Borgida, E., Gray, E. \& Regan, P.C. (1997). Does expert psychological testimony inform or influence juror decision making? A social cognitive analysis. Journal of Applied Psychology, 82(1), 178-191. doi:10.1037/0021-9010.82.1.178

Krantz, J.H. \& Reeshad, D. (2000). Validity of web-based psychological research. Psychological Experiments on the Internet. Birnbaum, M.H. (ed.), Academic Press: San Diego.

Kutys, J. \& Esterman, J. (2009, November). GBMI vs. NGRI: An Annotated Bibliography. The Jury Expert. Retrieved from http:/www.thejuryexpert.com/wpcontent/uploads/KutysTJENov2009.pdf

Latimer, J. \& A. Lawrence. (2006). The Review Board Systems in Canada: An Overview of Results from the Mentally Disordered Accused Data Collection Study.

Retrieved from http://www.justice.gc.ca/eng/rp-pr/csj-sjc/jspsjp/rr06_1/index.html

LeBlanc, S.M. (2007). Cruelty to the mentally ill: An eighth amendment challenge to the abolition of the insanity defense. American University Law Review, 56(5), 12811328.

Lee, J.S. (1989). Thinking about higher order thinking: Abstraction and stereotype thinking in education. DeKalb, IL: Social Science Research Institute, Northern Illinois University. 
Leshner, A. (1997). Addiction is a Brain Disease, and it Matters. Science, 278, 45-47. doi: 10.1126/scient.278.5335.45

Lieberman, J. D., \& Krauss, D. A. (Eds.). (2009). Jury psychology: Social aspects of trial processes (Vol. 1). Farnham, Surrey, England: Ashgate Publishing Limited.

Link, B.G. (1987). Understanding labeling effects in the area of mental disorders: An assessment of the effects of expectations of rejection. American Sociological Review, 52, 96-112.

Link, B.G., Andrews, H., \& Cullen, F.T. (1992). The violent and illegal behavior of mental patients reconsiders. American Sociological Review, 57, 275-292.

Link, B. \& Phelan, J. (2001). Conceptualizing stigma. Annual Review of Sociology, 27(3), 363-385. doi: 10.1146/annurev.soc.27.1.363

Link, B. G., Phelan, J., Bresnahan, M., Stueve, A., \& Pescosolido, B. (1999). Public conceptions of mental illness: Labels, causes, dangerousness, and social distance. American Journal of Public Health, 89, 1328-1333. doi: 10.2105/AJPH.89.9.1328

Livingston, J.D., Wilson, D., Tien, G., \& Bond, L. (2003). A follow-up study of persons found not criminally responsible on account of mental disorder in British Columbia. Canadian Journal of Psychiatry, 48(6).

Lorenzen, T.J. \& Anderson, V.L. (1993). Design of experiments: A no-name approach. New York, Marcel Dekker.

Louden, J, \& Skeem, J. (2007). Constructing insanity: Jurors’ prototypes, attitudes, and legal decision-making. Behavioural Sciences and the Law, 25(4), 449-470. doi: $10.1002 / \mathrm{bs} 1.760$ 
MacLaury, R. (1991). Prototypes revisited. Annual Review of Anthropology, 20, 55-74. doi: 10.1146/annurev.an.20.100191.000415

Madianos, M., Economou, M., Peppou, L.E., Kallergis, G., Rogakou, E., \& Alevizopoulos, G. (2012). Measuring public attitudes to severe mental illness in Greece: Development of a new scale. The European Journal of Psychiatry, 26(1). doi: 10.4321/S0213-61632012000100006

Maeder, E.M. \& Fenwick, K.L. (2010, November). The more you know: Educating jurors about the not criminally responsible by reason of mental disorder (NCRMD) defence. Poster presentation at the Carleton University Forensic Psychology Research Centre Conference, Ottawa, ON.

Maeder, E.M. \& Fenwick, K.L. (2011, June). Investigating attitudes toward the not criminally responsible by reason of mental disorder (NCRMD) defence. Poster presentation at the North American Correctional and Criminal Justice Psychology/Canadian Psychological Association Conference, Toronto, ON. Maeder, E.M. \& Fenwick, K.L. (2011, June). The more you know: Educating jurors about the not criminally responsible by reason of mental disorder (NCRMD) defence. Poster presentation at the North American Correctional and Criminal Justice Psychology/Canadian Psychological Association Conference, Toronto, ON.

Maeder, E.M. \& Fenwick, K.L. (2012, March). Educating Canadian jurors about the not criminally responsible by reason of mental disorder defence. Poster presentation at the American Psychology-Law Society conference, San Juan, Puerto Rico. 
Mansouri, N., Gharaee, B., Shariat, S.V., Bolhari, J., Nooraie, R.Y., Rahimi Movaghar, A., et al. (2009). The change in attitude and knowledge of health care personnel and general population following trainings provided during integration of mental health in Primary Health Care in Iran: A systematic review. International Journal of Mental Health Systems, 3(15). doi: 10.1186/1752-4485-3-15

Martin, J.K., Pescosolido, B.A., \& Tuch, S.A. (2000). Of fear and loathing: The role of 'disturbing behavior,' labels, and causal attributions in shaping public attitudes toward people with mental illness. Journal of Health and Social Behavior, 41(2), 208-223.

Mazzella, R., \& Feingold A. (1994). The effects of physical attractiveness, race, socioeconomic status, and gender of defendants and victims on judgments of mock jurors: A meta-analyses. Journal of Applied Social Psychology, 24(15), 131 5-1 344. doi: 10.1111/j.1559-1816.1994.tb01552.x

McGlynn, R. R., Megas, J. C., \& Benson, D. H. (1976). Sex and race as factors affecting the attribution of Insanity at a murder trial. The Journal of Psychology, 93, 93-99. doi: $10.1080 / 00223980.1976 .9921378$

Menec, V. H. \& Perry, R. P. (1998). Reactions to stigmas among canadian students: Testing attribution-affect-help judgment model. The Journal of Social Psychology, 138(4), 443-453. doi: 10.1080/00224549809

Miller, H.T. (1985). Recent changes in criminal law: The federal insanity defence. Louisiana Law Review, 46(2).

Monahan, J. (1992). Mental Disorder and violent behavior: Perceptions and evidence. The American Psychologist, 47(4), 511-521. doi: 10.1037//0003-066X.47.4.511 
Monahan, J., Steadman, H.J., Silver, E., Applebaum. P., Mulvey, et al. (2001). Rethinking risk assessment: The MacArther study of mental disorder and violence. New York: Oxford University Press.

Morgan, R.D., Flora, D.B., Kroner, D.G., Mills, J.F., Varghese, F., \& Steffan, J.S. (2012). Treating offenders with mental illness: A research synthesis. Law and Human Behaviour, 36(1), 37-50. doi: 10.1037/h0093964.

Morrison, J.K. \& Teta, D.C. (1980). Reducing students' fear of mental illness by means of seminar-induced belief change. Journal of Clinical Psychology, 36(1), 275276. doi: $10.1002 / 1097-4679$

Muthén, L.K. and Muthén, B.O. (1998-2012). Mplus User's Guide. Seventh Edition. Los Angeles, CA: Muthén \& Muthén

National Commission on the Insanity Defense (United States); National Mental Health Association. (1983). Myths and realities: A report of the National Commission on the Insanity defense. Arlington, VA: The Association.

National Diabetes Information Clearinghouse (November 2008). Diabetes overview. Retrieved from http://diabetes.niddk.nih.gov/dm/pubs/overview/DiabetesOverview_508.pdf

Nelson, T. D. (Ed.). (2009). Handbook of prejudice, stereotyping, and discrimination (1st Edition ed.). Psychology Press.

New South Wales Mental Health Sentinel Review Committee. (2003). Tracking Tragedy: A systemic look at suicides and homicides amongst mental health inpatients. NSW: Centre for Mental Health, Department of Health. 
Neville, K. (2010). The insanity defense: A comparative analysis (Unpublished honors thesis). Retrieved from Eastern Michigan University Digital Commons, http://commons.emich.edu/cgi/viewcontent.cgi?article=1219\&context=honors

Ng, P., \& Chan, K.F. (2002). Attitudes toward people with mental illness: Effects of a training program for secondary school students. International Journal of Adolescent Medical Health, 14(3), 215-224. doi:10.1515/IJAMH.2002.14.3.215

Office of the Correctional Investigator (2012). Annual report of the Office of the Correctional Investigator 2012-2013. Retrieved from http://www.ocibec.gc.ca/cnt/rpt/annrpt/annrpt20122013-eng.aspx

Olley, M. C., Nicholls, T. L. \& Brink, J. (2009). Mentally ill individuals in limbo: Obstacles and opportunities for providing psychiatric services to corrections inmates with mental illness. Behavioral Sciences \& Law, 27(5), 811-831. doi: $10.1002 / \mathrm{bsl} .899$

Olmsted, D.W. \& Durham, K. (1976). Stability of mental health attitudes: A semantic differential study. Journal of Health and Social Behavior, 17(1), 35-44

Pennington, N., \& Hastie, R. (1986). Evidence evaluation in complex decision making. Journal of Personality and Social Psychology: Learning, Memory, and Cognition, 51, 521-533. doi: 10.1037/0022-3514.51.2.242

Pennington, N. \& Hastie, R. (1988). Explanation based decision making: Effects of memory on judgment. Journal of Experimental Psychology: Learning, Memory, and Cognition, 14(3), 521-533. doi:10.1037/0278-7393.14.3.521 
Pennington, N. \& Hastie, R. (1992). Explaining the evidence: Tests of the story model for juror decision making. Journal of Personality and Social Psychology, 62(2), 189206. doi: 10.1037/0022-3514.62.2.189.

Pescosolido, B.A., Martin, J.K., Long, J.S., Medina, T.R., Phelan, J.C., \& Link, B.G. (2010). "A disease like any other'? A decade of change in public reactions to schizophrenia, depression, and alcohol dependence. The American Journal of Psychiatry, 167(11), 1321-1330. doi:10.1176/appi.ajp.2010.09121743.

Pezdek, K. Avila-Mora, E., \& Sperry, K. (2010). Does trial presentation medium matter in jury simulation research? Evaluating the effectiveness of eyewitness expert testimony. Applied Cognitive Psychology, 24(5), 673-690. doi: 10.1002/acp.1578

Phelan, J.C., Link, B.G., Stueve, A., \& Pescosolido, B.A. (2000). Public conceptions of mental illness in 1950 and 1996: What is mental illness and is it to be feared? Journal of Health and Social Behavior, 41(2), 188-207. doi: 10.2307/2676305

Pilon, M. (1999, October 5). Mental disorder and canadian criminal law. Retrieved from http://dsp-psd.pwgsc.gc.ca/Collection-R/LoPBdP/BP/prb9922-e.htm

Pinfold, V., Toulmin, H., Thornicroft, G., Huxley, P., Farmer, P., \& Graham, T. (2003). Reducing psychiatric stigma and discrimination: Evaluation of educational interventions in UK secondary schools. British Journal of Psychiatry, 182, 342346. doi: 10.1192/bjp.02.375

Psychology works fact sheets. (2009). Retrieved October 22, 2011, from Canadian Psychological Associations website, http://www.cpa.ca/psychologyfactsheets/ 
Pozzulo, J.D., Dempsey, J. Maeder, E., \& Allen, L. (2010). The effects of defendant gender, defendant age, and victim gender on juror decision making. Criminal Justice and Behavior, 37(1), 47-63. doi: 10.1177/0093854809344173

Priest, R., Vize, C. Roberts, A., Roberts, M., \& Tylee. R. (1996). Lay people's attitutdes to treatment of depression: results of opinion poll for defeat depression campaign just before its launch. British Medical Journal, 313 (7061), 858-859. doi:

10.1136/bmj.313.7061.858

Prins, S. (2011). Does traninstitutionalization explain the overrepresentation of people with serious mental illnesses in the criminal justice system. Community Mental Health Journal, 47(6), 716

Qualtrics Panels (n.d.) Retrieved February 3, 2012, from Qualtrics website, https://www.qualtrics.com/panel-management/

Queen v. M’Naghten. 8 Eng. Rep. 718 (1843).

Reinke, R. R., Corrigan, P. W., Leonhard, C., Lundin, R. K., \& Kubiak, M. A. (2004). Examining two aspects of contact on the stigma of mental illness. Journal of Social and Clinical Psychology, 23(3), 377-389. doi:10.1521/jscp.23.3.377.35457

Regina v. Parks (1993) 15 O.R. (3d) 324 (C.A.).

Regina v. Williams (1998) 1 S.C.R. 1128, S.C.J. 49.

Riva, G., Truzzi, T., \& Anolli, L (2003). The use of the internet in psychological research:Comparison of online and offline questionnaires. Cyber Psychology and Behavior, 6(1),73-80. doi: 10.1089/109493103321167983. 
Robbennolt, J.K. \& Studebaker, C.A. (1999). Anchoring in the courtroom: The effects of caps on punitive damages. Law and Human Behavior, 23(3), 353-373. doi: 10.1023/A:1022312716354

Roberts, C. \& Golding, S. (1991). The social construction of criminal responsibility and Insanity. Law and Human Behavior, 15(4), 349-376. doi: 10.1007/BF02074076

Roberts, C., Golding, S., \& Fincham, F. (1987). Implicit theories of criminal responsibility: Decision making and the Insanity defence. Law and Human Behavior, 11(3), 207-232. doi: 10.1007/BF01044643

Roesch, R., Ogloff, J.R.P, Hart, S.H., Dempster, R.J., Zapf, P.A., \& Whittemore, K.E. (1997). The impact of Canadian criminal code changes on remands and assessments of fitness to stand trial and criminal responsibility in British Columbia. Canadian Journal of Psychiatry, 42(5), 509-514.

Rokeach, M., \& Vidmar, N. (1973). Testimony concerning possible jury bias in a black panther murder trial. Journal of Applied Social Psychology, 3, 19-29. doi: 10.1111/j.1559-1816.1973.tb01291.x

Rosche, E. (1975). Cognitive representations of semantic categories. Journal of Experimental Psychology, 104, 192-232. doi:10.1037/0096-3445.104.3.192

Rosche, E. \& Mervis, C. (1997). Family resemblances: Studies in the internal structure of categories. Cognitive Psychology, 7, 573-605. doi:10.1016/0010-0285(75)900249

Rose, G.V. (2001). An introduction to law and the Canadian legal system. In R.A. Schuller\& J.R.P. Ogloff (Eds.). Introduction to Psychology and Law, 2, 29-56. Toronto, Ontario: University of Toronto Press. 
Rusch, N., Angermeyer, M.C., \& Corrigan, P. W. (2005). Mental illness stigma:

Concepts, consequences, and initiatives to reduce stigma. European Psychiatry, 20(8), 529-539. doi: 10.1016/j.eurpsy.2005.04.004

R. v. Byrne (1960) 2 QB 396

R. v. Pan; R. v. Sawyer, (2001) 2 S.C.R. 344, 2001 SCC 42

R. v. Swain, (1991) 1 S.C.R. 933

Sabbagh, M. (2011). Direct and indirect influence of defendant mental illness on jury decision making. The University of Central Florida Undergraduate Research Journal, 5(2), 86-96.

S.C. Code Ann 17-24-20(A)

Schmetzer, A. D., Lafuze, J.E., \& Jack, M.E. (2008). Overcoming stigma: Involving families in medical student and psychiatric residency education. Academic Psychiatry, 32(2), 127-131. doi: 10.1176/appi.ap.32.2.127

S.C. Code Ann. § 17-24-20 (Law. Co-op. Supp. 2003)

Schulze, B., Richter-Werling, M., Matschinger, H., \& Angermeyer, M. C. (2003). Crazy? So what! Effects of a school project on student's attitudes towards people with schizophrenia. Acta Psychiatrica Scandinavica, 107, 142-150. doi:

10.1034/j.1600-0447.2003.0244.x

Schwartz, S.H. (1978). Temporal instability as a moderator of the attitude-behaviour relationship. Journal of Personality and Social Psychology, 36, 715-724. doi: $10.1037 / 0022-3514.36 .7 .715$

Sheth, H.C. (2009). Dinstituionalization or disowning responsibility. International Journal of Psychosocial Rehabilitation, 13(2), 11-20. 
Shipley, S.L. \& Borynski, M.L. (2013). Mental illness and violence: A misunderstood relationship. In Helfgott, J.B (Eds.), Criminal Psychology (pp 63-96). Santa Barbara, CA.

Shiva, A.A. (2001). The effect of prior exposure to mental illness on juridical decisionmaking in legal cases involving the Insanity defense. (Doctorial dissertation). Retrieved from ProQuest Dissertations and Theses database. (AAI3028586)

Silver, E., Cirincione, C., \& Steadman, H.J. (1994). Demythologizing inaccurate perceptions of the Insanity defense. Law and Human Behavior, 18(1), 63-70. doi: 10.1007/BF01499144

Skeem J. (1999). Understanding juror decision making and bias in Insanity defence cases: The role of lay conceptions and case-relevant attitudes. (Doctoral dissertation). Retrieved from ProQuest Dissertations and Theses database. (AAT 9948543)

Skeem, J. \& Golding, S. (2001). Describing jurors' personal conceptions of Insanity and their relationship to case judgments. Psychology, Public Policy, and Law, 7(3), 561-621. doi: 10.1037//1076-8971.7.3.561

Skeem, J., Louden, J., \& Evans, J. (2004). Venirepersons's attitudes toward the Insanity defense: Developing, refining, and validating a scale. Law and Human Behavior, 28(6), 623-688. doi: 10.1007/s10979-004-0487-7.

Sloat, L. M., \& Frierson, R. L. (2005). Juror knowledge and attitudes regarding mental illness verdicts. Journal of the American Academy of Psychiatry and the Law Online, 33(2), 208-213.

Smith, M.A., \& Leigh, B. (1997). Virtual subjects: Using the Internet as an alternative 
source of subjects and research environment. Behavior Research Methods, Instruments \& Computers, 29, 496-505. doi: 10.3758/BF03210601

Smith, V.L (1991). Prototype in the courtroom: Lay representations of legal concepts. Journal of Personality and Social Psychology, 61(6), 857-72. doi:10.1037/00223514.61

Smith, V.L. (1993). When prior knowledge and law collide: Helping jurors use the law. Law and Human Behavior, 17(5), 507-36. doi: 10.1007/BF01045071

Smith, V.L. \& Studebaker, C. (1996). What do you expect?: The influence of people's prior knowledge of crime categories on fact-finding. Law and Human Behavior, 20, 519-532. doi:10.1007/BF01499039

Sommers, S. R., \& Ellsworth, P. C. (2001). White juror bias: An investigation of prejudice against Black defendants in the American courtroom. Psychology, Public Policy, and Law, 7, 201-229. doi: 10.1037/1076-8971.7.1.201

Stalans, L.J. (1993). Citizens' crime stereotypes, biased recall, and punishment preferences in abstract cases: The educative role of interpersonal sources. Law and Human Behavior, 17(4), 451-470. doi: 10.1007/BF01044378

Stall, N.S. (2013). Imprisoning the mentally ill. CMAJ, 183(3), 201-202. doi: 10.1503/cmaj.109-4390

Steblay, N., Hosch, H.M., Culhane, S.E., \& McWethy, A. (2006). The impact on juror verdicts of judicial instruction to disregard inadmissible evidence: A metaanalysis. Law and Human Behavior, 30, 469-492. doi: 1031007/s10979-0069039-7 
Stone, A.M. \& Merlo, L.J. (2011). Attitudes of college students toward mental illness stigma and the misuse of psychiatric medications. Journal of Clinical Psychiatry, 72(2), 134-139. doi: 10.4088/JCP.09m05254ecr

Stuart, H., Arboleda-Florez, J. (2001). A public health perspective on violent offenses among persons with mental illness. Psychiatric Service, 52(5), 654-659. doi: 10.1176/appi.ps.52.5.654

Stuart, H. (2003). Violence and mental illness: An overview. World Psychiatry, 2(2), 121-124.

Stuart, H. (2006). Reaching out to high school youth: the effectiveness of a video based anti-stigma program. Canadian Journal of Psychiatry, 51(10), 647-653.

Swanson, J.W., Holzer, C.E., Ganju, V.K., \& Jono, R.T. (1990). Violence and psychiatric disorder in the community: Evidence from the epidemiologic catchment area surveys. Hospital and Community Psychiatry, 41, 761-770.

Swanson, J.W., Swartz, M.S., Van Dorn, R.A., Elbogen, E.B., Wagner, H.R., Rosenheck, R.A., et al. (2006). National study of violent behavior in persons with schizophrenia. Archives of General Psychiatry, 63(5), 490-499. doi: 1 0.1001/archpsyc.63.5.490

Teplin, L.A. (1984). Criminalizing mental disorder: The comparative arrest rate of the mentally ill. American Psychologist, 36, 784-803.

The Canadian Press. (2010, November 15). Mom guilty of murder for drowning daugthers. $C B C$ News. Retrieved from http://www.cbc.ca/canada/toronto/story/2010/11/15/campioneguilty.html?ref=rss 
The Canadian Press. (2010, December 14). Mentally ill offenders failed by justice system: Report. CTV News. Retrieved from http://www.ctv.ca/CTVNews/Canada/20101214/mentally-ill-offenders-101214/

The Correctional Investigator Canada. (2011, June 29). Annual Report of the Office of the Correctional Investigator 2010-2011. Retrieved from http://www.ocibec.gc.ca/rpt/annrpt/annrpt20102011-eng.aspx\#ss 1a

The Globe and Mail. (5 November 2005). Mentally ill inmates being left untreated, ombudsman says. The Globe and Mail. Retrieved from http://www.theglobeandmail.com/news/national/mentally-ill-inmates-being-leftuntreated-ombudsman-says/article358553/

The Montreal Gazette . (2007, March 14). Prison is no cure: Number of mentally ill offenders in prison has doubled in 10 years. The Montreal Gazette. Retrieved from http://www.canada.com/montrealgazette/columnists/story.html?id=d0812639$5436-4 \mathrm{~b} 82-95 \mathrm{af}-4 \mathrm{ca} 320 \mathrm{f} 51 \mathrm{~b} 36$

The Not Criminally Responsible Reform Act. (2013). $1^{\text {st }}$ Reading November 25, 2013, $41^{\text {st }}$ Parliament, $2^{\text {nd }}$ session.

Torrey, E.F. (1994). Violent behavior by individuals with serious mental illness. Hospital and Community Psychiatry, 45(7), 653-662.

Torrey, E.F. (1998). Violent behavior by individuals with serious mental illness: The role of treatment compliance and insight. In Amador, X.F. \& David, A.S. (Eds.), In Insight and psychosis. New York, NY, US: Oxford University Press. 
Tversky, A. \& Kahneman, D. (1974). Judgment under uncertainty: Heuristics and biases. Science, 185(4157), 1124-1131.

Ugwuegbu, D. C. E. (1979). Racial and evidential factors in juror attribution of legal responsibility. Journal of Experimental Social Psychology, 15, 133-146. doi: $10.1016 / 0022-1031(79) 90025-8$

U.S. v. Brawner, 471 F.2d 969 (1972)

Van Belle G. (2002). Statistical Rules of Thumb. New York, John Wiley \& Sons.

Vidmar, N. (1997). Generic prejudice and the presumption of guilt in sex abuse trials. Law and Human Behavior, 21(1), 5-25. doi: 10.1023/A:10248695699

Vidmar, N. (2002). Case studies of pre- and midtrial prejudice in criminal and civil litigation. Law and Human Behavior, 26(1), 73-105. doi: 0147-7307/02/0200$0073 / 1$

Vidmar, N. (2003). When all of us are victims: Juror prejudice and "terrorist" trials. Chicago-Kent Law Review, 78, 1143-1178.

Vidmar, N. \& Melnitzer, J. (1984). Juror prejudice: An empirical study of a challenge for cause. Osgoode Hall Law Journal, 22(3), 487-511.

Vincent, G.M. (1999). Criminal responsibility after Bill C-30: Factors predicting acquttal and lengths of confinement in British Columbia (Master's thesis). Retrieved from ProQuest dissertations and Theses database. (UMI No. MQ51494)

Vitacco, M.J, Malesky, L.A, Erickson, S.K., Leslie, W., Croysdale, A., \& Bloechl, A. (2009). Measuring attitudes toward the Insanity defense in venirepersons: Refining the IDA-R in the evaluation of juror bias. International Journal of Forensic Mental Health, 8, 62-70. doi: 10.1080/14999010903014754 
Weiner, B. (1986). An attributional theory of motivation and emotion. New York: Springer-Verlag.

Weiner, B., Perry., R.P., \& Magnusson, J. (1988). An attributional analysis of reactions to stigmas. Journal of Personality and Social Psychology, 55, 738-748. doi: $10.1037 / 0022-3514.55 .5 .738$

Weiner, I. B., Freedheim, D. K., Goldstein, A. M., Borum, R., Packer, I. K., Eeing, C. P., et al. (2003). Evaluation of criminal responsibility. In A. M. Goldstein, S. J. Morse, D. L. Shapiro, \& I. B. Weiner (Ed.), Handbook of Psychology: Forensic Psychology (Vol. 11, pp. 390). Hoboken, New Jersey, United States: John Wiley \& Sons, Inc.

Wheeler, S.C. \& Petty, R.E. (2001). The effects of stereotypes activation on behavior: A review of possible mechanisms. Psychological Bulletin, 127(6), 797-826. doi: $10.1037 / 0033-2909.127 .6 .797$

Wiener, R., Arnot, L., Winter, R., \& Redmond, B. (2006). Generic prejudice in the law: sexual assault and homicide. Basic and Applied Social Psychology, 28(2), 145 155. doi: 10.1207/s15324834basp2802_4

Winko v. British Columbia (Forensic Psychiatric Institute), 2 S.C.R. 625 (1999). Wolkenstein, L. \& Meyer, T.D. (2008). Attitudes of young people towards depression and mania. Psychology and Psychotherapy: Theory, Research and Practice, 81(1), 15-31. doi: 10.1348/147608307X2182 


\section{Appendix A}

Not Criminally Responsible on account of Mental Disorder Education

Mental disorder is defined in the Canadian Criminal Code as a disease of the mind. An individual charged with a criminal offence who has been found to suffer from a mental disorder by a mental health professional, however, is not necessarily exempt from criminal responsibility. The Canadian Criminal Code claims that criminal responsibility is appropriate only when the actor is a discerning moral agent, capable of making choices between right and wrong. Such a determination is based upon a strict legal test administered by a judge. Many accused who suffer from a mental disorder are therefore tried and convicted within the criminal justice system. These individuals can be found not criminally responsible on account of mental disorder (NCRMD).

A verdict of NCRMD is not synonymous with a finding of guilt or a conviction. Rather, the verdict means that the court has ruled that the accused was not criminally responsible for his or her actions at the time the offence was committed.

However, an accused or an accused counsel may decide that raising issues of mental illness during a criminal process may not be in their best interests. Raising a mental health issue may avoid a criminal conviction; however, it can also lead to indeterminate involvement with the system responsible for managing mentally disordered accused. For instance, an offender who committed a violent crime could be convicted of murder and sentenced to 7 years of prison, whereas an offender who committed a violent crime who is found not criminally responsible could be sentenced to permanent hospitalization or permanently placed in a half way house. There is the potential that a defendant who is not criminally responsible could spend longer "terms" than what they would if they were to have plead guilty. Thus, only a small group of accused actually raise the issue of mental illness. Of those, the number of individuals found not criminally responsible was less than $1 \%$ in $2006 / 2007$.

After a verdict of NCRMD, the court may either give a disposition or defer the action to a Review Board. However, if either the prosecutor or the accused apply for the court to give the disposition itself, and if the court is able to do so, it must comply. The court may give the following dispositions:

- Detention in-hospital;

- Conditional discharge; and,

- Absolute discharge.

In cases where no disposition is made by the court, the accused person is referred to the provincial or territorial Review Board, where the Board will give a disposition within 45 days of the verdict. Dispositions given by the court, with the exception of absolute discharge, are reviewed by a Review Board within 90 days and may be altered at that juncture.

For accused who receive dispositions for detention in-hospital, they are not required to submit to treatment while in-hospital. The disposition is intended to detain the accused in an environment where appropriate medical and psychiatric care is available to them. 
However, in cases where the accused refuses treatment that may be necessary to maintain good mental health, treatment may be deemed necessary. In these cases, treatment is administered in accordance with respective provincial/territorial mental health acts.

A verdict of NCRMD is synonymous with which finding?
a) Not Guilty
b) Not criminally responsible
c) Guilty

Which of the following dispositions is available in NCRMD cases?
a) 10 years in prison
b) Life imprisonment
c) Conditional discharge

Approximately how many individuals are found NCRMD each year?
a) Less than $1 \%$
b) $10 \%$
c) $30 \%$ 


\title{
Appendix B
}

\section{Duress Education}

\author{
Duress
}

The Canadian Criminal Justice System attempts to keep order and protect innocent Canadian citizens by punishing individuals who break the law. In doing so it aims to be fair, equal, and protect individual rights. Those accused of a criminal offence are protected by basic rights. For instance, during criminal proceedings the burden of proof lays with the prosecution - that is, the prosecution must prove that the defendant is guilty beyond a reasonable doubt. Thus, the defendant is innocent until proven guilty. In most cases, the prosecution must prove that the defendant committed the act and that the defendant had criminal intent to commit the crime. However, there are incidents when individuals do not have criminal intent. Individuals may commit an offence when under extreme pressure. The Criminal Code attempts to accommodate those who commit crimes due to threats or difficult circumstances. One defence is known as duress.

Duress is partially outlined in section 17 of the Criminal Code of Canada as, "A person who commits an offence under compulsion by threats of immediate death or bodily harm from a person who is present when the offence is committed is excused, if he believes that the threats will be carried out and if the person is not a party to a conspiracy or association whereby the person is subject to compulsion, but this section does not apply where the offence that is committed is high treason, murder, piracy, attempted murder, sexual assault, sexual assault with a weapon, threats to a third party or causing bodily harm, aggravated sexual assault, forcible abduction, hostage taking, robbery, assault with a weapon or causing bodily harm, aggravated assault, unlawfully causing bodily harm, arson or an offence under 280 to 283 (abduction and detention of young persons)."

Section 17 of the Criminal Code suggests that duress can only be applied to principle parties, those who actually commit the offence and that duress does not apply to serious crimes. However, in common law (case law) judges have extended the defence of duress to apply when someone is forced to commit an act because of harm or threat to a third party. Furthermore, duress has been broadened to serious violent offences such as murder if there was no way out of the situation other than to commit the offence. In addition, it was ruled that 'immediate death or bodily harm' violated section 7 of the Canadian Charter of Rights and Freedoms. Thus, the defence of duress is available to an accused even when they were not under immediate threat of bodily harm at the time the offence was committed.

Therefore, an individual is said to act under duress if:

1. If an individual threatened to cause serious bodily harm or to kill the person(s) in question unless a specific act was committed; and

2. If the person (s) in question believed that this threat would be carried out; and

3. If the person (s) in question did not have a safe way to avoid the harm threatened; and 
4. If the individual's threat caused the person (s) in question to commit the specified act

The person in question is not required to prove that $\mathrm{s} /$ he acted under duress. The Crown must prove beyond a reasonable doubt that $\mathrm{s} /$ he did not act under duress. Unless the Crown proves beyond a reasonable doubt that at least one of these conditions for duress was absent, the person in question must be acquitted of the charge.

An individual may use duress as a defence in what circumstance?

a) Compulsion by threats

b) Self defence

c) Ignorance of the law

In duress individuals did not:

a) have Actus Reus.

b) have criminal intent.

c) commit a criminal act.

The defence of duress can not apply to what offence?

a) Aggravated assault

b) Murder

c) It can apply to both of the above 


\section{Appendix C}

\section{Mental Illness Education What is Substance Use Disorder?}

Substance use disorder is the misuse of one or more substances over an extended period, followed with various behavioural, physical, and psychological symptoms. Substances can include alcohol, non-prescription and prescription drugs, illicit drugs, and solvents. There are two categories of substance use disorders: Substance dependence and substance abuse. Substance dependence refers to a person with a problematic pattern of substance use, involving three of the following features: tolerance, withdrawal, lack of success in cutting down or controlling the substance, spending a lot of time trying to get a hold of the substance or recovering from its effects, and giving up various activities because of the substance use. Substance abuse is similar to substance dependence; however, the impairment experienced by the person is more marked. For instance, as a result of substance abuse, the person is unable to meet obligations, they are regularly absent or perform poorly when at work, school, or in everyday life due to their substance abuse, they have legal problems as a result of substance use, and they continue to use the substance despite awareness that the substance use is causing physical or emotional problems.

\section{How common is Substance use disorder?}

Statistics Canada found that 2.6 per cent of Canadians were dependant on alcohol and that less than one per cent was dependent on illegal drugs. These numbers, however, do not reflect the full impact of substance use problems in Canada as substance use disorders are rarely documented.

What are the risk factors and causes of substance use disorder?

Many people develop substance use disorders for a number of reasons, such as anxiety or depressive disorders, a family history of substance use disorder, being prone to the effects of stress and tension, or experiencing psychosocial problems (e.g., loss of a job, family problems, and relationship breakdown). In addition, substance use disorders are believed to have both physiological and psychological components.

What are some treatment options for substance use disorder?

There are many effective treatment options, some of which include counselling, detoxification facilities, and medication. These treatment options have been supported by decades of research. Community support groups may also be very helpful in assisting people to resolve their substance use. Those who have a serious disorder may need a referral to a specialist drug and alcohol service.

\section{An important note}

Substance use disorder receives a lot of negative media attention. The media often stereotypes individuals with substance use problems as deviants that don't engage in society like the rest of the population and who are of low socio-economic status. The reality of substance abusers is that the majority are just like everyone else. It is also important to note that substance use disorders are considered to be mental disorders under the Diagnostic and Statistical Manual of Mental Disorder (DSM). The DSM provides a standard criterion for the classification of all diagnosable mental disorders in North America.

\section{What is Depression?}


Clinical depression (also called Major Depressive Disorder or MDD) is confirmed by the presence of at least five of the following symptoms for at least a two week period: sadness, loss of interest in usual activities, changes in appetite, changes in sleep, changes in sexual desire, difficulties in concentration, a decrease in activities or social withdrawal, increased self criticism or reproach, and thoughts of, or actual plans related to suicide. Depression is often a recurring condition, as a person who has had one episode of clinical depression is at high risk for repeated experiences. Unfortunately, depression interferes with a person's ability or desire to get help, which makes the initial steps to seek treatment and support extremely difficult.

\section{How common is depression?}

Approximately 5\% of Canadian men and 10\% of Canadian women will experience clinical depression at some point in their life. Depression affects all people in all cultures across the world.

\section{What are the risk factors and causes of depression?}

Although causes of clinical depression are complex and vary from individual to individual, it is now clear that a variety of factors increase the risk of a person experiencing clinical depression. Having a parent who has been clinically depressed, physical illness or ongoing disability, the death or separation of parents, major negative life events (in particular, events related to interpersonal loss or failure), pervasive negative thinking, physical or emotional deprivation, and previous episodes of depression are some risk factors for depression. Although there are a number of external factors that can trigger depression, chemical changes in the brain can lead to depression without any external precipitating factor.

\section{What are some treatment options for depression?}

Depression can be treated and managed. Psychological therapy and drug therapy are successful treatment options. Psychological treatments are roughly as successful as drug treatment for depression. However, because some of the drug therapies lead to a quick response they may be effectively combined with psychological treatments, which provide for longer term change. Cognitive behavioural therapy (CBT) helps a depressed individual change the negative, depressive thoughts and behaviour that contribute to depression, and replaces them with more helpful thoughts and behaviour.

Medication (antidepressants) can be used to adjust brain chemicals to improve mood. Drugs used for treating depression are not addictive or habit-forming. When depression is in remission, the drugs can be slowly tapered off and stopped.

\section{An important note}

Besides the personal struggle, people with depression also have to deal the public's misunderstanding of the disorder. Unfortunately, the media takes depressive symptoms out of context for entertainment value by depicting individuals with depression as antisocial, dangerous, lacking will power, and having uncontrollable emotions. However, people with depression usually pose a higher risk of harm to themselves (due to suicide) than to other people.

\section{What is Bipolar disorder?}

Bipolar disorder (previously known as Manic-Depressive Illness) is a mental disorder that is characterized by severe mood swings cycling between periods of intense 'highs' 
(mania or hypomania) and periods of intense 'lows' (depression). In mania, the individual experiences elevated moods, elation, or highly irritable moods that last for at least one week. This considerable increase in mood is accompanied by high levels or energy, combined with a noticeable decreased need for sleep. In the most severe forms, mania can be accompanied by psychotic symptoms such as hallucinations or delusions and almost always requires hospitalization. In the depressive phase of bipolar disorder, symptoms of clinical depression need to be present for at least two weeks. Individuals experiencing mania often lack self-awareness and do not recognize that they are ill, a clinical symptom called anosognosia.

\section{How common is bipolar disorder?}

In Canada, 2.2\% of individuals will experience bipolar disorder at some point in their lifetime. Bipolar disorder usually starts in late adolescence or early adulthood, but it can also begin as early as childhood.

\section{What are the risk factors and causes of bipolar disorder?}

Although researchers don't know exactly what causes bipolar, they do know that genes and chemicals in the brain play a strong role in making people vulnerable to developing the disorder.

In addition, stress alone does not cause bipolar disorder, but episodes of mania or depression are often triggered by stressful life events.

What are some treatment options for bipolar disorder?

Bipolar disorder is a highly recurrent disorder, meaning that most individuals with bipolar will experience several episodes during the course of their lifetime. Drug therapy is essential for the treatment of bipolar disorder. It usually involves the use of one or more mood stabilizers, such as lithium, combined with other medications. There is also strong evidence that psychological interventions such as Cognitive Behavioural Therapy can be added to drug therapy in order to help people better manage their illness and reduce repeated experiences of mood episodes. Individuals with bipolar may require hospitalized treatment to prevent self-destructive, impulsive behaviour. Hospital stays can be as brief as two weeks and as long as six months.

\section{An important note}

Unfortunately, the media often depicts persons with bipolar disorder as murderous individuals, which only adds to the stigma surrounding bipolar disorder. Many symptoms are taken out of context for entertainment or shock value by depicting an extreme example of bipolar disorder. However, people with bipolar (manic and depressive states) are generally not dangerous, and usually pose a higher risk of harm to themselves (due to suicide) than to other people.

\section{What is Schizophrenia?}

Schizophrenia is a serious disorder that is related to a range of behavioural and thinking problems. Despite common myths, schizophrenia does not refer to multiple personalities, but rather a loss of contact with reality. The symptoms of schizophrenia are different from person to person. Symptoms, at least in a milder form, tend to last for a long time and long-term treatment is usually necessary. People with schizophrenia often have difficulties with perception (hallucinations and delusions), behaviour and emotions (reduced experience of emotions, avoiding other people, lack of motivation), thoughts 
processes (attention, memory, speed of processing information), and social functioning (forming and maintaining relationships).

\section{How common is Schizophrenia?}

Approximately $1 \%$ of the world's population meet the criteria for a diagnosis of schizophrenia. Symptoms often start in late adolescence or young adulthood, and may occur for many years before diagnosis.

\section{What are the risk factors and causes of Schizophrenia?}

Having a parent, sister, or brother with schizophrenia is a risk factor for developing the disorder. However, this does not mean that you are guaranteed to have schizophrenia; it just means that you have a higher chance than people who do not have a family member with this disorder.

Many other factors affect brain development and risk for schizophrenia. Examples include a mother having a serious illness or a long period of malnutrition while pregnant, low birth weight, oxygen deprivation during birth, and serious illness during early infancy. Additionally, there are experiences in a person's environment that may increase their likelihood of developing psychotic symptoms. Examples of this include childhood abuse, war zone exposure, and poverty.

What are some treatment options for Schizophrenia?

Although there is no cure for Schizophrenia, research suggests that the most effective treatment plan is a combination of antipsychotic medication and psychological therapies that help people make changes in real-world behaviour. As more effective treatments are developed, people with schizophrenia are better able than ever before to function in society, even though some may continue to have symptoms.

Drug therapy can help manage biochemical imbalances in many people with schizophrenia, lessen hallucinations and delusions, and help maintain coherent thoughts. However, they usually have serious side effects contributing to non-compliance with medication and relapse.

Cognitive Behavioural Therapy (CBT) is an active, collaborative type of therapy that focuses on a person's thoughts and core believes, and the behaviours that are related to these thoughts. In CBT for schizophrenia, a person learns to question and re-evaluate the source and meaning of their hallucinations and delusions.

Cognitive Remediation Therapy also focuses on training people to improve their thinking abilities such as attention, memory, reasoning, and information processing.

\section{An important note}

Schizophrenia is often misunderstood by the public. The disorder often receives media attention, but as with many news stories related to mental illness, many facts are taken out of context for entertainment or shock value. In particular, popular stories and media reports about people with schizophrenia sometimes make it seem like these individuals are dangerous or violent. In fact, people with schizophrenia are generally not dangerous, and usually pose a higher risk of harm to themselves (due to suicide) than to other people. As well, people with psychotic disorders are more likely to be victims of violent crime than to be violent.

\section{What is Psychosis?}

Psychosis is a serious but treatable medical condition that reflects a disturbance in brain functioning. It is characterized by some loss of contact with reality and can dramatically 
change a person's thoughts, beliefs, perceptions and/or behaviours. Symptoms vary from person to person and can change over time. A psychotic episode occurs in two phases; the length of each phase varies from person to person. In phase one, prodrome, signs are vague and hardly noticeable. There may be changes in the way some people describe their feelings, thoughts, and perceptions. In phase two, acute, there are clear psychotic symptoms, such as hallucinations, delusions, and/or confused thinking.

\section{How common is Psychosis?}

Psychosis is a medical condition which affects approximately $3 \%$ of the population. It affects males and females equally and tends to emerge during adolescence and young adulthood. However, it sometimes emerges gradually over time, so that in the early stages, symptoms might be dismissed or ignored.

\section{What are the risk factors and causes of Psychosis?}

Persons with a family history of serious mental illness are at increased risk of developing psychosis. However, when psychosis occurs for the first time it is difficult to know the cause. Psychosis is associated with a number of medical conditions including schizophrenia, depression, bipolar (manic-depressive) disorder and substance use disorder, among others. Because the first episode of psychosis can signal a variety of conditions, it is important to seek a thorough medical assessment.

\section{What are some treatment options for Psychosis?}

Psychosis can be effectively treated. Low doses of anti-psychotic medications are a key component of treatment, along with education and support for the individual and their family. Treatment strategies are aimed at allowing the individual to maintain their daily routine as much as possible. There have been tremendous advances in the treatment of psychosis during recent years, reducing the need for hospital stays and promoting faster, fuller recovery. Typically, psychosis does not disappear on its own. Instead, if left untreated, the condition can worsen and severely disrupt the lives of individuals and families.

\section{An important note}

Psychosis is often misunderstood by the public and is often misinterpreted as schizophrenia. The disorder often receives media attention, but as with many news stories related to mental illness, many facts are taken out of context for entertainment or shock value. In particular, popular stories and media reports about people with psychosis or schizophrenia sometimes make it seem like these individuals are dangerous or violent. In fact, people with psychosis are generally not dangerous, and usually pose a higher risk of harm to themselves (due to suicide) than to other people. As well, people with psychotic disorders are more likely to be victims of violent crime than to be violent.

Substance use disorders are:

a) a problem only among lower income or socio-economic layers of society

b) mental disorders under the DSM

c) fictions disorders generated as an excuse for irrational behaviour

Individuals with depression:

a) are a danger to the public

b) can easily snap out of it

c) pose a higher risk of harm to themselves than to other people

Individuals with Bipolar disorder who are experiencing mania: 
a) are less prone to risky behaviour

b) lack self-awareness and do not recognize that they are ill

c) become extremely withdrawn

Individuals with schizophrenia:

a) are extremely violent and dangerous

b) are more likely to be victims of violent crime than to be violent

c) pose no risk of self harm

Psychosis is associated to:
a) schizophrenia
b) depression
c) bipolar disorder
d) substance use disorder
e) all of the above 


\section{Appendix D}

\section{Diabetes Education}

Diabetes is a chronic condition that results from the body's inability to sufficiently produce and/or properly use insulin. According to the Canadian Diabetes Association, more than three million Canadians have diabetes. There are three main types of diabetes, type 1 diabetes, type 2 diabetes and gestational diabetes.

\section{Type 1 Diabetes}

Type 1 diabetes is an autoimmune disease in which a persons' pancreas stops producing insulin, a hormone that enables people to get energy from food. The immune system attacks and destroys the insulin-producing beta cells in the pancreas. The pancreas then produces little or no insulin. Insulin is a hormone that controls the amount of glucose in the blood. Just to survive, people with type 1 diabetes must take multiple injections of insulin daily or continually infuse insulin through a pump.

At present, scientists do not know exactly what causes the body's immune system to attack cells within the pancreas. However, they believe that autoimmune, genetic, and environmental factors, possibly viruses, are involved. Approximately 10 per cent of people with diabetes have type 1 diabetes. It develops most often in children and young adults but can appear at any age.

Symptoms of type 1 diabetes usually develop over a short period, although cell destruction in the pancreas can begin years earlier. Symptoms may include increased thirst and urination, constant hunger, weight loss, blurred vision, and extreme fatigue. If not diagnosed and treated with insulin, a person with type 1 diabetes can lapse into a lifethreatening diabetic coma, also known as diabetic ketocidosis.

Type 1 diabetes is usually diagnosed in childhood, adolescence, or young adulthood, and lasts a lifetime.

\section{Type 2 Diabetes}

The most common form of diabetes is type 2 diabetes. About 90 percent of people with diabetes have type 2. This form of diabetes is most often associated with older age, obesity, family history of diabetes, previous history of gestational diabetes, physical inactivity, and certain ethnicities. About 80 percent of people with type 2 diabetes are overweight or obese.

Type 2 diabetes is increasingly being diagnosed in children and adolescents, especially among African American, Mexican American, and Pacific Islander youth.

When type 2 diabetes is diagnosed, the pancreas is usually producing enough insulin, but for unknown reasons the body cannot use the insulin effectively, a condition called insulin resistance. After several years, insulin production decreases. The result is the same as for type 1 diabetes - glucose builds up in the blood and the body cannot make efficient use of its main source of fuel.

The symptoms of type 2 diabetes develop gradually. Their onset is not as sudden as in type 1 diabetes. Symptoms may include fatigue, frequent urination, increased thirst and hunger, weight lose, blurred vision, and slow healing of wounds and sores. However, some people have no symptoms.

\section{Gestational Diabetes}

A third type of diabetes, gestational diabetes, is a temporary condition that occurs during pregnancy. If affects approximately 2 to 4 per cent of all pregnancies (in the non- 
Aboriginal population) and involves an increased risk of developing diabetes for both mother and child. Some women develop gestational diabetes late in pregnancy. Although this form of diabetes usually disappear after the birth of the baby, women who have gestational diabetes have a 40 to 60 percent chance of developing type 2 diabetes within 5 to 10 years. Maintaining a reasonable body weight and being physically active may help prevent development of type 2 diabetes.

Gestational diabetes is caused by the hormones of pregnancy or a shortage of insulin. Women with gestational diabetes may not experience any symptoms.

\section{Is diabetes serious?}

If left untreated or improperly managed, diabetes can result in a variety of complications, including heart disease, kidney disease, eye disease, and nerve damage. The first step in preventing or delaying the onset of these complications is recognizing the risk factors, as well as signs and symptoms of diabetes.

\section{What are the risk factors for diabetes?}

If you are aged 40 or older, you are at risk for type 2 diabetes and should be tested at least every three years. If any of the following risk factors apply, you should be tested earlier and/or more often.

- Being a member of a high-risk group (Aboriginal, Hispanic, Asian, South Asian or African descent)

- Being overweight (especially if you carry most of your weight around your middle)

- Having a parent, brother or sister with diabetes

- Having health complications that are associated with diabetes

- Giving birth to a baby that weighed more than $9 \mathrm{lb}$

- High blood pressure

- High cholesterol or other fats in the blood

- Having been diagnosed with schizophrenia, polycystic ovary syndrome, or acanthosis nigricans (darkened patches of skin)

\section{What are the symptoms?}

Signs and symptoms of diabetes include the following:

- Unusual thirst

- Frequent urination

- Weight change (gain or loss)

- Extreme fatigue or lack of energy

- Blurred vision

- Frequent or recurring infections

- Cuts or bruises that are slow to heal

- Tingling or numbness in the hands or feet

- Trouble getting or maintaining an erection

It is important to recognize, however, that many people who have type 2 diabetes can display no symptoms.

\section{Can you prevent diabetes?}


Research shows that lifestyle changes can help prevent or delay the onset of type 2 diabetes. A healthy meal plan, weight control and physical activity are important prevention steps.

\section{How is diabetes treated?}

People with diabetes can expect to live active, independent and vital lives if they make a lifelong commitment to careful diabetes management, which includes the following:

Education: Diabetes education is an important first step. All people with diabetes need to be informed about their condition.

Physical activity: Regular physical activity helps your body lower blood glucose levels, promotes weight loss, reduces stress and enhances overall fitness.

Nutrition: What, when and how much you eat all play an important role in regulating blood glucose levels.

Weight Management: Maintaining a healthy weight is especially important in the management of type 2 diabetes.

Medication: type 1 diabetes is always treated with insulin. Type 2 diabetes is managed through physical activity and meal planning and may require medications and/or insulin to assist your body in controlling blood glucose more effectively.

Lifestyle Management: Learning to reduce stress levels in day-to-day life can help people with diabetes better manage their disease.

Blood Pressure: High blood pressure can lead to eye disease, heart disease, stroke and kidney disease, so people with diabetes should try to maintain blood pressure levels of less than 130/180 $\mathrm{mmHg}$.

Reference: Canadian Diabetes Association and the National Diabetes Information Clearinghouse (NDIC)

If left untreated or improperly managed, diabetes can result in:
a. Liver disease
b. Depression
c. Eye disease

Type 2 diabetes usually develops in:
a. Childhood
b. Adulthood
c. You are born with type 2 diabetes

Approximately how many Canadians have diabetes?

a. One million

b. Two million

c. Three million 


\section{Appendix E}

\section{Trial Transcript: Substance Use Disorder Jury Instructions}

Mike Smith is charged with second degree murder. The charge reads:

You must find Mike Smith not guilty of second degree murder unless the Crown has proven beyond a reasonable doubt that Smith is the person who committed the offence on the date and in the place described in the indictment. Specifically, the Crown must prove each of the following essential elements beyond a reasonable doubt:

1. That Mike Smith committed an unlawful act;

2. That Mike Smith's unlawful act caused Robert Warner's death; and

3. That Mike Smith had the intent required for murder.

If you are satisfied beyond a reasonable doubt of all these essential elements, you must find Mike Smith guilty of second degree murder.

The defendant, Mike Smith claims to have been mentally ill at the time that the crime charged in the indictment was allegedly committed. Since the law does not hold a person criminally accountable for his or her conduct while mentally ill (not able to appreciate), not criminally responsible on account of mental disorder can be used as a defence against the crime charged. The accountability of defendant Smith at the time of the alleged offence is, therefore, a question which you must decide.

To be found not criminally responsible, the defence must prove by clear and convincing evidence that:

1. Mike Smith had a severe mental disorder or defect at the time that the acts constituting the crime were committed, and

2. As a result of this severe mental disorder or defect, Mike Smith was not able to understand what he was doing or to understand that what he was doing was wrong.

The defendant must prove that he was mentally ill at the time of the offence by clear and convincing evidence; that is, the defendant must show that it is highly probable that he was mentally ill at that time.

In making your decision, you may consider evidence of the defendant's mental condition before or after the crime charged and you may consider not only the statements and opinions of any experts who have testified, but also all of the other evidence received in the case.

If you find that the defendant committed the acts described in the essential elements of Second Degree Murder, but that the defendant was not criminally responsible at the time that the acts were committed, you must find the defendant Not Criminally Responsible on account of Mental Disorder. 
Applying all of the other instructions given to you, you may find defendant Smith guilty if you decide Smith does not meet the requirements of Not Criminally Responsible on account of Mental Disorder.

Even though the defendant has raised the issue of mental illness, the Crown still has the burden of proving all the essential elements of the offence beyond a reasonable doubt.

FACTS IN EVIDENCE (agreed to by the defence and Crown)

On Friday, December 11, 2012 at approximately 10:30pm, Mike Smith entered a local 7-11 convenience store. When Mike Smith entered the store, the cashier, Robert Warner, was opening inventory boxes of cigarettes with a packing knife. Smith was noticed browsing the aisles by several other customers because of his 'jittery' behaviour and obvious efforts to stay out of the view of the prominently displayed surveillance cameras. After he had selected several items from the shelves, he approached the cashier to pay. The cashier, Robert Warner, stopped opening the cigarette boxes, put his packing knife down on the counter, and began ringing up Smiths purchase. During this time, surveillance cameras show Smith looking around nervously. At one point another customer dropped a can of pop, causing Smith to suddenly jerk his head in the direction of the noise.

Warner informed Smith of the total cost. The cameras show Smith reaching in his pocket and beginning to pull out his wallet. As the clerk reached behind the counter, Mr. Smith yelled out "NO!" picked up the packing knife from the counter, and stabbed Warner's neck, hitting his carotid artery. As Warner fell to the ground, the tapes show Mr. Smith looking over the counter at the victim, who was rapidly losing blood. He dropped the knife on the countertop, slowly sat on the floor, and began rocking back and forth. He continued in this manner until the police arrived. Robert Warner died of severe blood loss.

CHARGE: The defendant, Mike Smith, is charged with second degree murder.

\section{POLICE OBSERVATIONS:}

The defendant, Mike Smith, age 30 was arrested for the murder of Robert Warner. When police arrived at the scene, Smith was observed seated on the floor, his knees pulled up to his chest, slowly rocking back and forth. He appeared dazed by the sudden police presence and was not immediately responsive to officers' orders for him to lie down on the floor. He was handcuffed, placed in a police car, and taken to central booking.

During the ride to central booking, the two officers in the squad car noticed that Smith was moving his lips, but they were unable to hear any sounds coming from him. In addition, he would smile and nod his head up and down from time to time; on one occasion he began to laugh. Once at the police station, he was photographed and fingerprinted. It was noted that when the flash on the camera went off he began looking around the room nervously. He was jerking his upper body back and forth, as if trying to avoid something. When asked about this, he responded, "Laser beams.....can't you see them?........beam...dream...team...cream..." and began laughing. In light of his behaviour, 
the police did not ask him if he would like to waive his right to remain silent and they postponed questioning him. A public defender was contacted and after a brief meeting with Smith, the police were informed that Smith would not be making any statements. He was deranged. On the advice of the public defender he pled Not Criminally Responsible on account of Mental Disorder.

\section{MEDICAL RECORD}

Mr. Smith was given a breathalyzer exam when in police custody. His bloodalcohol level was three times the legal limit for driving a motor vehicle. He underwent detoxification following his arrest and had been held without bail.

\section{CROWN SUMMARY}

Ladies and gentlemen of the jury, the essential elements of second degree murder, each of which the Crown must prove beyond a reasonable doubt, are:

1. that the defendant committed an unlawful act,

2. that the defendant caused the death of the decedent; and

3. that, at the time the defendant did so, he had the specific intent to kill or seriously injure the decedent, or acted in conscious disregard of an extreme risk of death or serious bodily injury to the decedent.

The facts in this case are not in dispute. On the night of December 11, 2012, Mike Smith stabbed and killed Robert Warner. You have seen the surveillance camera tapes which captured the entire event. The defendant meets the first and second elements of second degree murder; this is not in dispute by either side. The defendant further, by his own admission, "had the specific intent to kill or seriously injure the decedent." Thus, his actions and admission satisfy all of the elements necessary to convict him of second degree murder.

The reason we are here today is to determine whether the defendant is going to be held responsible for his actions. In pleading Not Criminally Responsible on account of Mental Disorder, the defence actually assumes the burden of proof. It is true that the persecution always assumes the burden of proof in establishing guilt versus innocence, because the defendant is assumed to be innocent until proven guilty. However, the law has established that the defendant is assumed to be sane unless the defence can prove otherwise. In other words, the burden for proving criminal responsibility rests with the defence, not with the prosecution.

In this case, the defence would have you believe that at the time of the offence, the defendant, Smith, was not capable of knowing the difference between right and wrong. If Smith was incapable of determining the difference, why was he seen on the video surveillance tapes looking nervously around the store before he stabbed and killed the cashier, Mr. Warner? Such behaviour could only reflect that he knew he was about to perpetrate an act which was wrong.

The attorney for the defendant would have you believe that Smith suffers from a terrible mental disease that controls his behaviour. Once in the grips of this disease, alcoholism, his ability to distinguish right from wrong or to conform his behaviour to the mandate of the law is rendered useless, according to what the defendant would have you believe. But, the prosecution has demonstrated that this is not true. Alcoholism, though termed by some as a 'disease', has never been proven to be such. Yes, alcohol in excess 
can cause confused judgment. But in this case, the defence would have you believe that Mr. Smith was in the middle of a paranoid delusion, causing him to believe that an unarmed man in a non-threatening environment was about to kill him.

The question at hand is not actually whether the defendant, Mike Smith, was in charge of his mental abilities at the time the crime occurred. The question is one of voluntary action. Smith went of his own volition, to a bar to have drinks with some friends. He knew he was an alcoholic. At the bar he ended up consuming three times the legal limit for the operation of a motor vehicle.

Is being drunk a crime? No. But his previous experience with drinking has demonstrated to him and to the court that he knew he was unable to control his drinking. Of even greater importance is that according to the law, drunkenness is not a legally mitigating factor in criminal responsibility, intoxication does not erase one's responsibility for their actions. The only reason that the defendant is pleading Not Criminally Responsible on account of Mental Disorder is that he is attempting to convince you that he has a disease which makes him lose control. The Supreme Court of Canada has not agreed that alcoholism is a disease or mental illness.

The defence claims that Mr. Smith's intoxicated state was so severe that he was experiencing 'delusions' which caused him to believe that others were out to harm him. They would have you believe that these delusions caused the defendant to fear for his life and subsequently kill Mr. Warner. You, the jury, must consider whether the defendant had any power to control or prevent his actions over the course of this delusion. The evidence presented clearly demonstrates that Smith could have avoided the fatal delusion by not going to the bar; but he chose to do so. Furthermore, the Criminal Code of Canada indicates that, "it is not a defence to an offence referred to in subsection (3) that the accused, by reason of self-induced intoxication, lacked the general intent or the voluntariness required to commit the offence, where the accused departed markedly from the standard of care as described in subsection (2).'

The prosecution has established that Mr. Smith had the power to avert the tragic death of Mr. Warner, and that he did not take the necessary precautions. We urge the jury to reject the defendant's plea of Not Criminally Responsible on account of Mental Disorder and return a verdict of Guilty.

\section{DEFENCE SUMMARY}

Members of the jury, my client has a terrible, insidious disease; he is an alcoholic. It is because of this disease that he inadvertently took the life of Robert Warner, a cashier at 7-11. On the night in question he admits to having been on his boat fishing, practicing with his new fishing rod. Upon docking his boat, he ran into several friends and followed these friends to the local bar to have a drink. Because of his compulsion, the disease of alcoholism, one drink turned into two and three and more. He left the bar and drove to 711 to pick up some snack food.

While standing in line to pay for his food, Mr. Smith was becoming increasingly paranoid that his life was in danger. This paranoid fear is the central delusion in this case - a delusion which caused the defendant to lose his grip on reality. He had become convinced that the cashier was going to harm him in some way. After ringing up his purchase, Warner, the cashier, began to reach under the counter for a bag. In Mr. Smith's delusional state, he was convinced that Warner was reaching for a gun with which to 
shoot him. Reacting to this danger, in self defence, he grabbed the packing knife from the counter and stabbed Warner's carotid artery.

Mr. Smith has suffered from the disease of alcoholism for some time. He has spent a month in a hospital rehabilitation program, has attended counselling sessions for alcoholism, and has attended Alcoholics Anonymous meetings. He is aware that he suffers from a debilitating disease which has brought him before this court today. Mr. Smith's disease of alcoholism, a compulsion to drink, has been documented by the hospital rehabilitation center where he resided, of his own volition, for a month. It has further been supported by the counsellor he saw after his discharge. Mr. Smith was attending sessions once a week with this counsellor and was seeing great improvement; however, the counselling sessions were too expensive for Mr. Smith to continue. Given his improvement, Mr. Smith decided to stop counselling sessions and tackle his alcoholism on his own with the skills his counsellor taught him.

There is no question that he suffers from a mental disease and all the complications that accompany it. It was the mental disease of alcoholism which led $\mathrm{Mr}$. Smith to experience the compulsion to continue drinking that night, despite his knowledge that he was carrying a firearm. It was the same disease which stripped him of his voluntary control over the quantity of alcohol consumed. Finally, it was the quantity of alcohol consumed which led to a temporary substance induced psychosis, causing him to have a paranoid delusion of persecution (which can be defined as strongly held beliefs in the face of evidence which conclusively prove these beliefs cannot be true) that made him think Mr. Warner, the cashier, was about to kill him. Believing that his life was in danger, he reacted with lethal force.

As the prosecution indicated in their closing statement, the Supreme Court has not agreed that alcoholism is a disease. But on the other hand, they have not clearly disagreed. However, R. v. Daviault (1994) looked at the Leary Rule, which eliminated the defence of intoxication for 'general intent' criminal offences. The Supreme Court of Canada found that the Leary rule was unconstitutional and in violation of both section 7 and 11(d) of the Canadian Charter of Rights and Freedoms. They ruled that intoxication can be used as a defence where it is so extreme that it is akin to automatism or Insanity. Although the courts do not clearly determine whether alcoholism is or is not a disease, they have decided that extreme intoxication can be akin to Insanity.

It was also a result of this disease that he could not appreciate the possible consequences of the possession of a firearm while drunk. It was a result of his disease that he could not distinguish between right and wrong, or the nature or consequences of his actions when he stabbed Mr. Warner in the neck. If not for this disease, Mr. Smith would never have picked up the knife and stabbed Mr. Warner. If he did not suffer from this disease, he would have been cognizant of the dangers of doing so. With this in mind, we urge you to find Mr. Smith Not Criminally Responsible on account of Mental Illness. 


\section{Appendix F}

\section{Trial Transcript: Schizophrenia}

Mike Smith is charged with second degree murder. The charge reads:

You must find Mike Smith not guilty of second degree murder unless the Crown has proven beyond a reasonable doubt that Smith is the person who committed the offence on the date and in the place described in the indictment. Specifically, the Crown must prove each of the following essential elements beyond a reasonable doubt:

1. That Mike Smith committed an unlawful act;

2. That Mike Smith's unlawful act caused Robert Warner's death; and

3. That Mike Smith had the intent required for murder.

If you are satisfied beyond a reasonable doubt of all these essential elements, you must find Mike Smith guilty of second degree murder.

The defendant, Mike Smith claims to have been mentally ill at the time that the crime charged in the indictment was allegedly committed. Since the law does not hold a person criminally accountable for his or her conduct while mentally ill (not able to appreciate), not criminally responsible on account of mental disorder is a defence to the crime charged. The sanity of defendant Smith at the time of the alleged offence is, therefore, a question which you must decide.

To be found not criminally responsible, the defendant must prove by clear and convincing evidence that:

1. Mike Smith had a severe mental disorder or defect at the time that the acts constituting the crime were committed, and

2. As a result of this severe mental disorder or defect, Mike Smith was not able to understand what he was doing or to understand that what he was doing was wrong.

The defendant must prove that he was mentally ill at the time of the offence by clear and convincing evidence, that is, the defendant must show that it is highly probable that he was mentally ill at that time.

In making your decision, you may consider evidence of the defendant's mental condition before or after the crime charged and you may consider not only the statements and opinions of any experts who have testified, but also all of the other evidence received in the case.

If you find that the defendant committed the acts described in the Essential Elements of Second Degree Murder, but that the defendant was mentally ill and not criminally responsible at the time that the acts were committed, you must find the defendant Not Criminally Responsible on account of Mental Disorder.

Applying all of the other instructions given to you, you may find defendant Smith guilty if you decide Smith does not meet the requirements of Not Criminally Responsible on account of Mental Disorder. 
Even though the defendant has raised the issue of mental illness, the Crown still has the burden of proving all the essential elements of the offence beyond a reasonable doubt.

FACTS IN EVIDENCE (agreed to by the defence and Crown)

On Friday, December 11, 2012 at approximately 10:30pm, Mike Smith entered a local 7-11 convenience store. When Mike Smith entered the store, the cashier, Robert Warner, was opening inventory boxes of cigarettes with a packing knife. Smith was noticed browsing the aisles by several other customers because of his 'jittery' behaviour and obvious efforts to stay out of the view of the prominently displayed surveillance cameras. After he had selected several items from the shelves, he approached the cashier to pay. The cashier, Robert Warner, stopped opening the cigarette boxes, put his packing knife down on the counter, and began ringing up Smiths purchase. During this time, surveillance cameras show Smith looking around nervously. At one point another customer dropped a can of pop, causing Smith to suddenly jerk his head in the direction of the noise.

Warner informed Smith of the total cost. The cameras show Smith reaching in his pocket and beginning to pull out his wallet. As the clerk reached behind the counter, $\mathrm{Mr}$. Smith yelled out "NO!" picked up the packing knife from the counter, and stabbed Warner's neck, hitting his carotid artery. As Warner fell to the ground, the tapes show Mr. Smith looking over the counter at the victim, who was rapidly losing blood. He dropped the knife on the countertop, slowly sat on the floor, and began rocking back and forth. He continued in this manner until the police arrived. Robert Warner died of severe blood loss.

CHARGE: The defendant, Mike Smith, is charged with second degree murder.

\section{POLICE OBSERVATIONS:}

The defendant, Mike Smith, age 30 was arrested for the murder of Robert Warner. When police arrived at the scene, Smith was observed seated on the floor, his knees pulled up to his chest, slowly rocking back and forth. He appeared dazed by the sudden police presence and was not immediately responsive to officers' orders for him to lie down on the floor. He was handcuffed, placed in a police car, and taken to central booking.

During the ride to central booking, the two officers in the squad car noticed that Smith was moving his lips, but they were unable to hear any sounds coming from him. In addition, he would smile and nod his head up and down from time to time; on one occasion he began to laugh. Once at the police station, he was photographed and fingerprinted. It was noted that when the flash on the camera went off he began looking around the room nervously. He was jerking his upper body back and forth, as if trying to avoid something. When asked about this, he responded, "Laser beams.....can't you see them?........beam...dream...team...cream..." and began laughing. In light of his behaviour, the police did not ask him if he would like to waive his right to remain silent and they postponed questioning him. A public defender was contacted and after a brief meeting with Smith, the police were informed that Smith would not be making any statements. 
He was deranged. On the advice of the public defender he pled Not Criminally Responsible on account of Mental Disorder.

\section{MEDICAL RECORD}

Since his arrest, defendant Smith has been placed on an anti-psychotic medication. He has been held for psychiatric observation.

\section{CROWN SUMMARY}

Ladies and gentlemen of the jury, the essential elements of second degree murder, each of which the Crown must prove beyond a reasonable doubt, are:

1. that the defendant committed an unlawful act,

2. that the defendant caused the death of the decedent; and

3. that, at the time the defendant did so, he had the specific intent to kill or seriously injure the decedent, or acted in conscious disregard of an extreme risk of death or serious bodily injury to the decedent.

The facts in this case are not in dispute. On the night of December 11, 2012, Mike Smith stabbed and killed Robert Warner. You have seen the surveillance camera tapes which captured the entire event. The defendant meets the first and second elements of second degree murder; this is not a dispute by either side. The defendant further, by his own admission, 'had the specific intent to kill or seriously injure the decedent.' Thus, his action and admission satisfy all of the elements necessary to convict him of second degree murder.

The reason we are here today is to determine whether the defendant is going to be held responsible for his actions. In pleading Not Criminally Responsible on account of Mental Disorder, the defence actually assumes the burden of proof. It is true that the prosecution always assumes the burden of proof in establishing guilt versus innocence, because the defendant is assumed to be innocent until proven guilty. However, the law has established that the defendant is assumed to be sane unless the defence can prove otherwise. In other words, the burden for proving criminal responsibility rests in the defence, not with the prosecution. In this case, the defence would have you believe that at the time of the offence, the defendant, Smith, was not capable of knowing the difference between right and wrong. If Smith was incapable of determining the difference, why was he seen on the video surveillance tapes looking nervously around the store before he stabbed and killed the cashier, Mr. Warner? Such behaviour could only reflect that he knew he was about to perpetrate an act which was wrong.

Ladies and Gentlemen of the jury, please look at the defendant, Mr. Smith [pointing to the defendant]. Throughout this trial he has been well dressed, his hygiene very good, his mood stable. His attention appears very focused and we have not seen any visual evidence of a mental illness or disease. He hasn't been looking around in a paranoid manner; we see no symptoms of delusions.

In the case before you there is little question that Mr. Smith killed Robert Warner. The act was witnessed by others and recorded on a surveillance camera. What you, the jury, must decide is Mr. Smith's level of responsibility for the stabbing of Mr. Warner, the 7-11 cashier.

Our expert witness and the defence's expert witness state that in the past, Smith has suffered from paranoid schizophrenia. However, while the defence counsel will 
undoubtedly argue that it was the same schizophrenia which led first to his decision to discontinue anti-psychotic medication and second to the criminal act itself, the prosecution does not agree.

While on anti-psychotic medication, Smith's judgement was no longer impaired and he no longer suffered from delusions of persecution; his speech was no longer disturbed, and he was fully cognizant of his surroundings. With his mental abilities intact, and in therapy for a diagnosis of paranoid schizophrenia, he decided to discontinue his medication. This decision, in light of his regained mental ability, was totally irresponsible. He made a decision which he knew would jeopardize his mental health, failing to take into account the ramifications of his possible behaviours.

Another point of consideration is the connection between Mr. Smith's mental illness and his actions on December 11, 2012. He claims that due to his 'delusions of persecution', he was convinced that Mr. Warner, in reaching for a bag, was actually reaching for a gun with which he intended to kill the defendant. Was Mr. Smith's fear for his life a reasonable concern? No. Was his fear of the deceased based on any rational evidence? No. Was he able to appreciate the nature and consequences of his actions when he stabbed Mr. Warner? We believe so. Members of the jury, while Mr. Smith may suffer from a mental illness, he was not so delusional at the time of the offence that he did not know what he was doing. He was sane. We urge you to return the only verdict appropriate in this case, Guilty.

\section{DEFENCE SUMMARY}

Members of the jury, Mike Smith suffers from a very severe mental illness known as paranoid schizophrenia. Please take a good look at him [pointing towards the defendant]. The composed, seemingly rational person you see before you is a product of medicine, anti psychotic medication. However, you have all heard the idiom, 'never judge a book by its cover.' To judge the inner workings of Mr. Smith's mind and mental illness based on his external appearance while he is on anti-psychotic medication is a grave mistake.

You have heard medical testimony in which the defendant has been positively diagnosed with paranoid schizophrenia. Mr. Smith has been in the care of a psychiatrist for over five years because of an initial psychotic break from reality which occurred when he was 23 years old. Prior to age 23, there was no recorded history of mental illness in Mr. Smith's life. In his late teens and early twenties his parents had noticed occasional periods where he would 'act strange,' as if he was 'somewhere else.' These periods would not last very long and were very mild in severity.

Shorty after his $23^{\text {rd }}$ birthday, Mr. Smith began reluctantly expressing to his parents and some close friends that he occasionally felt as though others were talking about him behind his back. Initially his friends and parents didn't take his complaints or suspicions very seriously. But soon after his complaints began he got into a shoving match with his best friend because he heard voices which told him that his friend was badmouthing him. This incident led to treatment with his current psychiatrist, a diagnosis of Paranoid Schizophrenia, and a course of anti-psychotic medication.

Since the beginning of his treatment, Mr. Smith has shown very good results on anti-psychotic medication. He no longer feels that others are 'out to get him' and the voices that he once heard are now silent. His delusions of persecution (which can be 
defined as strongly held beliefs in the face of evidence which conclusively prove these beliefs cannot be true) have gone into almost complete remission. Because antipsychotic medication works so well, a great deal of social science research has addressed a very common problem: the paranoid schizophrenic who, feeling healed by the effects of medication, concludes there is no longer a need to take medication.

It has been demonstrated time and time again that refusing further medical treatment is a direct result of the disease itself. Even with all the benefits of antipsychotic medication, such as the near elimination of delusions, and disturbances in speech, the medication does not totally cure the disease of schizophrenia; remnants remain. It is those remnants which quietly convince a person with paranoid schizophrenia to stop taking their medication.

This is what happened to the defendant, Mr. Smith. Showing great improvement and a near return to normal functioning (known as the residual phase of schizophrenia), he decided under some level of irrational schizophrenic thinking, to discontinue his medication. This action took place approximately one month prior to the stabbing. This is just enough time for the anti-psychotic medication to completely leave his body. His wife began noticing changes in his behaviour; in particular, increased suspiciousness. His friends noticed similar changes as well.

Based on this testimony, it should be clear to the members of the jury that first, Mr. Smith suffers from paranoid schizophrenia. Second, at the time of the stabbing he was not taking any preventative medication. Third, the reason for not being on medication was a product of his mental illness or disease. Fourth, as a result of his mental illness or disease, he was experiencing delusions of persecution which have also occurred in his past. Finally, when Mr. Smith was in the 7-11 store on the night of the stabbing, his reaction with lethal force was, in his mind, truly justified. He was in fear of his life. The rationality of his fear, given his prior history and diagnosis of paranoid schizophrenia, is not the legal question to be decided here today. If you, the jury, feel (given his prior diagnosis and history) that Mr. Smith, in his own mind, experienced or perceived a threat to his own well being, then you must return the only proper verdict for this case: Not Criminally Responsible on account of Mental Disorder.

To return a verdict for Not Criminally Responsible on account of Mental Disorder you, the jury, do not need to understand what he believed. You need to understand why he believed what he did. The answer to that point is a severe mental illness or disease known as paranoid schizophrenia. Because of this mental illness, he stabbed the cashier. Keeping these facts in mind, the defence urges you to return a verdict of Not Criminally Responsible on account of Mental Disorder. 


\section{Appendix G}

\section{Trial Transcript: Bipolar Disorder}

Mike Smith is charged with second degree murder. The charge reads:

You must find Mike Smith not guilty of second degree murder unless the Crown has proven beyond a reasonable doubt that Smith is the person who committed the offence on the date and in the place described in the indictment. Specifically, the Crown must prove each of the following essential elements beyond a reasonable doubt:

1. That Mike Smith committed an unlawful act;

2. That Mike Smith's unlawful act caused Robert Warner's death; and

3. That Mike Smith had the intent required for murder.

If you are satisfied beyond a reasonable doubt of all these essential elements, you must find Mike Smith guilty of second degree murder.

The defendant, Mike Smith claims to have been mentally ill at the time that the crime charged in the indictment was allegedly committed. Since the law does not hold a person criminally accountable for his or her conduct while mentally ill (not able to appreciate), not criminally responsible on account of mental disorder is a defence to the crime charged. The sanity of defendant Smith at the time of the alleged offence is, therefore, a question which you must decide.

To be found not criminally responsible, the defendant must prove by clear and convincing evidence that:

1. Mike Smith had a severe mental disorder or defect at the time that the acts constituting the crime were committed, and

2. As a result of this severe mental disorder or defect, Mike Smith was not able to understand what he was doing or to understand that what he was doing was wrong.

The defendant must prove that he was mentally ill at the time of the offence by clear and convincing evidence, that is, the defendant must show that it is highly probable that he was mentally ill at that time.

In making your decision, you may consider evidence of the defendant's mental condition before or after the crime charged and you may consider not only the statements and opinions of any experts who have testified, but also all of the other evidence received in the case.

If you find that the defendant committed the acts described in the Essential Elements of Second Degree Murder, but that the defendant was mentally ill and not criminally responsible at the time that the acts were committed, you must find the defendant Not Criminally Responsible on account of Mental Disorder.

Applying all of the other instructions given to you, you may find defendant Smith guilty if you decide Smith does not meet the requirements of Not Criminally Responsible on account of Mental Disorder. 
Even though the defendant has raised the issue of mental illness, the Crown still has the burden of proving all the essential elements of the offense beyond a reasonable doubt.

FACTS IN EVIDENCE (agreed to by the defence and Crown)

On Friday, December 11, 2012 at approximately 10:30pm, Mike Smith entered a local 7-11 convenience store. When Mike Smith entered the store, the cashier, Robert Warner, was opening inventory boxes of cigarettes with a packing knife. Smith was noticed browsing the aisles by several other customers because of his 'jittery' behaviour and obvious efforts to stay out of the view of the prominently displayed surveillance cameras. After he had selected several items from the shelves, he approached the cashier to pay. The cashier, Robert Warner, stopped opening the cigarette boxes, put his packing knife down on the counter, and began ringing up Smiths purchase. During this time, surveillance cameras show Smith looking around nervously. At one point another customer dropped a can of pop, causing Smith to suddenly jerk his head in the direction of the noise.

Warner informed Smith of the total cost. The cameras show Smith reaching in his pocket and beginning to pull out his wallet. As the clerk reached behind the counter, $\mathrm{Mr}$. Smith yelled out "NO!" picked up the packing knife from the counter, and stabbed Warner's neck, hitting his carotid artery. As Warner fell to the ground, the tapes show Mr. Smith looking over the counter at the victim, who was rapidly losing blood. He dropped the knife on the countertop, slowly sat on the floor, and began rocking back and forth. He continued in this manner until the police arrived. Robert Warner died of severe blood loss.

CHARGE: The defendant, Mike Smith, is charged with second degree murder.

\section{POLICE OBSERVATIONS:}

The defendant, Mike Smith, age 30 was arrested for the murder of Robert Warner. When police arrived at the scene, Smith was observed seated on the floor, his knees pulled up to his chest, slowly rocking back and forth. He appeared dazed by the sudden police presence and was not immediately responsive to officers' orders for him to lie down on the floor. He was handcuffed, placed in a police car, and taken to central booking.

During the ride to central booking, the two officers in the squad car noticed that Smith was moving his lips, but they were unable to hear any sounds coming from him. In addition, he would smile and nod his head up and down from time to time; on one occasion he began to laugh. Once at the police station, he was photographed and fingerprinted. It was noted that when the flash on the camera went off he began looking around the room nervously. He was jerking his upper body back and forth, as if trying to avoid something. When asked about this, he responded, "Laser beams.....can't you see them?........beam...dream...team...cream..." and began laughing. In light of his behaviour, the police did not ask him if he would like to waive his right to remain silent and they postponed questioning him. A public defender was contacted and after a brief meeting with Smith, the police were informed that Smith would not be making any statements. 
He was deranged. On the advice of the public defender he pled Not Criminally Responsible on account of Mental Disorder.

\section{MEDICAL RECORD}

Following his arrest, Mr. Smith, with the consent of his attorney, was placed on an anti-psychotic medication due to his overt psychotic symptoms (delusions, hallucinations, etc.). Within 72 hours his psychotic symptoms were gone, leaving him in what appeared to be an extremely depressed state. As a result, he has now been placed on mood stabilizers. He has also been placed on suicide precaution, not because of any attempts or talk of wishes to die on his part, but due to the severity of his depressed mood.

\section{CROWN SUMMARY}

Ladies and gentlemen of the jury, the essential elements of second degree murder, each of which the Crown must prove beyond a reasonable doubt, are:

1. that the defendant committed an unlawful act,

2. that the defendant caused the death of the decedent; and

3. that, at the time the defendant did so, he had the specific intent to kill or seriously injure the decedent, or acted in conscious disregard of an extreme risk of death or serious bodily injury to the decedent.

The facts in this case are not in dispute. On the night of December 11, 2012, Mike Smith stabbed and killed Robert Warner. You have seen the surveillance camera tapes which captured the entire event. The defendant meets the first and second elements of second degree murder; this is not a dispute by either side. The defendant further, by his own admission, 'had the specific intent to kill or seriously injure the decedent.' Thus, his action and admission satisfy all of the elements necessary to convict him of second degree murder.

The reason we are here today is to determine whether the defendant is going to be held responsible for his actions. In pleading Not Criminally Responsible on account of Mental Disorder, the defence actually assumes the burden of proof. It is true that the prosecution always assumes the burden of proof in establishing guilt versus innocence, because the defendant is assumed to be innocent until proven guilty. However, the law has established that the defendant is assumed to be sane unless the defence can prove otherwise. In other words, the burden for proving criminal responsibility rests in the defence, not with the prosecution.

In this case, the defence would have you believe that at the time of the offence, the defendant, Smith, was not capable of knowing the difference between right and wrong. If Smith was incapable of determining the difference, why was he seen on the video surveillance tapes looking nervously around the store before he stabbed and killed the cashier, Mr. Warner? Such behaviour could only reflect that he knew he was about to perpetrate an act which was wrong.

Ladies and Gentlemen of the jury, please look at the defendant, Mr. Smith [pointing to the defendant]. Throughout this trial he has been well dressed, his hygiene very good, his mood stable. His attention appears very focused and we have not seen any visual evidence of a mental illness or disease. He hasn't been looking around in a paranoid manner; we see no symptoms of delusions. 
In the case before you there is little question that Mr. Smith killed Robert Warner. The act was witnessed by others and recorded on a surveillance camera. What you, the jury, must decide is Mr. Smith's level of responsibility for the shooting of Mr. Warner, the 7-11 cashier.

Our expert witness and the defences' expert witness state that in the past, Smith has suffered from bipolar disorder (Manic Depression). However, while the defence counsel will undoubtedly argue that it was Mr. Smith's uncontrollable manic state that led him to discontinue his mood stabilizer medication and to the criminal act itself, the prosecution does not agree.

While on mood stabilizers, Smith's judgement was no longer impaired and he no longer suffered from delusions, intense mood shifts, and he was fully cognizant of his surroundings. With his mental abilities intact, and in therapy for a diagnosis of bipolar, he decided to discontinue his medication. This decision, in light of his regained mental ability, was totally irresponsible. He made a decision which he knew would jeopardize his mental health, failing to take into account the ramifications of his possible behaviours.

Another point of consideration is the connection between Mr. Smith's mental illness and his actions on December 11, 2012. He claims that due to his 'delusions of persecution', he was convinced that Mr. Warner, in reaching for a bag, was actually reaching for a gun with which he intended to kill the defendant. Was Mr. Smith's fear for his life a reasonable concern? No. Was his fear of the deceased based on any rational evidence? No. Was he able to appreciate the nature and consequences of his actions when he stabbed Mr. Warner? We believe so. Members of the jury, while Mr. Smith may suffer from a mental illness, he was not so delusional at the time of the offence that he did not know what he was doing. He was sane. We urge you to return the only verdict appropriate in this case, Guilty.

\section{DEFENCE SUMMARY}

Members of the jury, Mike Smith suffers from a very severe mental illness known as Bipolar Disorder. Please take a good look at him [pointing towards the defendant]. The composed, seemingly rational person you see before you is a product of medicine, anti psychotic medication and mood stabilizers. However, you have all heard the idiom, 'never judge a book by its cover.' To judge the inner workings of Mr. Smith's mind and mental illness based on his external appearance while he is on anti-psychotic medication or mood stabilizers is a grave mistake.

Before you, I am displaying Mr. Smith's medical records which indicate that the defendant has been positively diagnosed with bipolar disorder. As these records show, Mr. Smith has been in the care of a psychiatrist for over five years because of an initial psychotic break from reality which occurred when he was 23 years old. Prior to age 23, there is no recorded history of mental illness in Mr. Smith's life. In his late teens and early twenties his parents had noticed that he would have intense mood swings but associated it to teenage hormones. In addition, his parents noticed occasional periods where he would 'act strange,' as if he was 'somewhere else.' These periods would not last very long and were very mild in severity.

Shorty after his $23^{\text {rd }}$ birthday, Mr. Smith began to have mixed episodes of deep depression and hypomania. When in periods of hypomania, he reluctantly expressed to his parents and some close friends that he occasionally felt as though he could 'make' 
objects look like something else and that he could hear others thoughts. Initially his friends and parents didn't take his experiences very seriously. But soon after his complaints began he got into a shoving match with his best friend since he was adamant that his friend was badmouthing him. He explained how he could read thoughts and therefore he knew that his friend had been badmouthing him. This incident led to treatment with his current psychiatrist, a diagnosis of bipolar disorder, a brief treatment of anti psychotic medication, and a course of mood stabilizer medication.

Since the beginning of his treatment, Mr. Smith has shown very good results on mood stabilizer medication. He no longer has consistent mood cycles and he no longer hears thoughts. His delusions of persecution (which can be defined as strongly held beliefs in the face of evidence which conclusively prove these beliefs cannot be true) have gone into almost complete remission. Even though mood stabilizers and antipsychotic medication work well for patients with bipolar disorder, each person's dose is different and can change over time. As a result, patients can slip into manic states, depressive states or have a break from reality and discontinue their medication.

When in a manic state, individuals often feel happy and even overconfident, feel rested on very little sleep, and have racing thoughts. However, it can also be accompanied by highly irritable moods, hallucinations, delusions, and over the top behaviour. Individuals may lose touch with reality causing them to discontinue their medication.

This is what happened to the defendant, Mr. Smith. Although Mr. Smith was showing great improvement, it had been documented by his psychiatrist that under moments of high stress he would become paranoid, thinking his meds were placebos. Often he would work through these stressful moments with his psychiatrist; however, it appears as though Mr. Smith did not divulge his most recent issues with psychiatrist. As a result, he decided under some level of irrational manic depressive thinking, to discontinue his medication. This action took place approximately two days prior to the shooting. His wife began noticing changes in his behaviour; in particular, increased suspiciousness and hyper active mood. His friends noticed similar changes as well. In addition, Mr. Smith failed to attend his psychiatric appointment the day of the stabbing.

Based on this testimony, it should be clear to the members of the jury that first, Mr. Smith suffers from bipolar disorder. Second, at the time of the stabbing he was not taking any preventative medication. Third, the reason for not being on medication was a product of his mental illness or disease. Fourth, as a result of his mental illness or disease, he was experiencing delusions of persecution which have also occurred in his past. Finally, when Mr. Smith was in the 7-11 store on the night of the stabbing, his reaction with lethal force was, in his mind, truly justified. He was in fear of his life. The rationality of his fear, given his prior history and diagnosis of bipolar disorder, is not the legal question to be decided here today. If you, the jury, feel (given his prior diagnosis and history) that Mr. Smith, in his own mind, experienced or perceived a threat to his own well being, then you must return the only proper verdict for this case: Not Criminally Responsible on account of Mental Disorder.

To return a verdict for Not Criminally Responsible on account of Mental Disorder you, the jury, do not need to understand what he believed. You need to understand why he believed what he did. The answer to that point is a severe mental illness or disease known as bipolar disorder. Because of this mental illness, he stabbed the cashier. 
Keeping these facts in mind, the defence urges you to return a verdict of Not Criminally Responsible on account of Mental Disorder. 


\section{Appendix $\mathbf{H}$}

\section{Trial Transcript: Depression}

Mike Smith is charged with second degree murder. The charge reads:

You must find Mike Smith not guilty of second degree murder unless the Crown has proven beyond a reasonable doubt that Smith is the person who committed the offence on the date and in the place described in the indictment. Specifically, the Crown must prove each of the following essential elements beyond a reasonable doubt:

1. That Mike Smith committed an unlawful act;

2. That Mike Smith's unlawful act caused Robert Warner's death; and

3. That Mike Smith had the intent required for murder.

If you are satisfied beyond a reasonable doubt of all these essential elements, you must find Mike Smith guilty of second degree murder.

The defendant, Mike Smith claims to have been mentally ill at the time that the crime charged in the indictment was allegedly committed. Since the law does not hold a person criminally accountable for his or her conduct while mentally ill (not able to appreciate), not criminally responsible on account of mental disorder is a defence to the crime charged. The sanity of defendant Smith at the time of the alleged offence is, therefore, a question which you must decide.

To be found not criminally responsible, the defendant must prove by clear and convincing evidence that:

1. Mike Smith had a severe mental disorder or defect at the time that the acts constituting the crime were committed, and

2. As a result of this severe mental disorder or defect, Mike Smith was not able to understand what he was doing or to understand that what he was doing was wrong.

The defendant must prove that he was mentally ill at the time of the offence by clear and convincing evidence, that is, the defendant must show that it is highly probable that he was mentally ill at that time.

In making your decision, you may consider evidence of the defendant's mental condition before or after the crime charged and you may consider not only the statements and opinions of any experts who have testified, but also all of the other evidence received in the case.

If you find that the defendant committed the acts described in the Essential Elements of Second Degree Murder, but that the defendant was mentally ill and not criminally responsible at the time that the acts were committed, you must find the defendant Not Criminally Responsible on account of Mental Disorder.

Applying all of the other instructions given to you, you may find defendant Smith guilty if you decide Smith does not meet the requirements of Not Criminally Responsible on account of Mental Disorder. 
Even though the defendant has raised the issue of mental illness, the Crown still has the burden of proving all the essential elements of the offence beyond a reasonable doubt.

FACTS IN EVIDENCE (agreed to by the defence and Crown)

On Friday, December 11, 2012 at approximately 10:30pm, Mike Smith entered a local 7-11 convenience store. When Mike Smith entered the store, the cashier, Robert Warner, was opening inventory boxes of cigarettes with a packing knife. Smith was noticed browsing the aisles by several other customers because of his 'jittery' behaviour and obvious efforts to stay out of the view of the prominently displayed surveillance cameras. After he had selected several items from the shelves, he approached the cashier to pay. The cashier, Robert Warner, stopped opening the cigarette boxes, put his packing knife down on the counter, and began ringing up Smiths purchase. During this time, surveillance cameras show Smith looking around nervously. At one point another customer dropped a can of pop, causing Smith to suddenly jerk his head in the direction of the noise.

Warner informed Smith of the total cost. The cameras show Smith reaching in his pocket and beginning to pull out his wallet. As the clerk reached behind the counter, $\mathrm{Mr}$. Smith yelled out "NO!" picked up the packing knife from the counter, and stabbed Warner's neck, hitting his carotid artery. As Warner fell to the ground, the tapes show Mr. Smith looking over the counter at the victim, who was rapidly losing blood. He dropped the knife on the countertop, slowly sat on the floor, and began rocking back and forth. He continued in this manner until the police arrived. Robert Warner died of severe blood loss.

CHARGE: The defendant, Mike Smith, is charged with second degree murder.

\section{POLICE OBSERVATIONS:}

The defendant, Mike Smith, age 30 was arrested for the murder of Robert Warner. When police arrived at the scene, Smith was observed seated on the floor, his knees pulled up to his chest, slowly rocking back and forth. He appeared dazed by the sudden police presence and was not immediately responsive to officers' orders for him to lie down on the floor. He was handcuffed, placed in a police car, and taken to central booking.

During the ride to central booking, the two officers in the squad car noticed that Smith was moving his lips, but they were unable to hear any sounds coming from him. In addition, he would smile and nod his head up and down from time to time; on one occasion he began to laugh. Once at the police station, he was photographed and fingerprinted. It was noted that when the flash on the camera went off he began looking around the room nervously. He was jerking his upper body back and forth, as if trying to avoid something. When asked about this, he responded, "Laser beams.....can't you see them?........beam...dream...team...cream..." and began laughing. In light of his behaviour, the police did not ask him if he would like to waive his right to remain silent and they postponed questioning him. A public defender was contacted and after a brief meeting with Smith, the police were informed that Smith would not be making any statements. 
He was deranged. On the advice of the public defender he pled Not Criminally Responsible on account of Mental Disorder.

\section{MEDICAL RECORD}

Following his arrest, Mr. Smith, with the consent of his attorney, was placed on an anti-psychotic medication due to his overt psychotic symptoms (delusion, hallucinations, etc). Within 72 hours his psychotic symptoms were gone, leaving him in an extremely depressed state. Mr. Smith has also been placed on anti-depressants and suicide precaution, not because of any attempts or talk of wishes to die on his part, but due to the severity of his depressed mood.

\section{CROWN SUMMARY}

Ladies and gentlemen of the jury, the essential elements of second degree murder, each of which the Crown must prove beyond a reasonable doubt, are:

1. that the defendant committed an unlawful act,

2. that the defendant caused the death of the decedent; and

3. that, at the time the defendant did so, he had the specific intent to kill or seriously injure the decedent, or acted in conscious disregard of an extreme risk of death or serious bodily injury to the decedent.

The facts in this case are not in dispute. On the night of December 11, 2012, Mike Smith stabbed and killed Robert Warner. You have seen the surveillance camera tapes which captured the entire event. The defendant meets the first and second elements of second degree murder; this is not in dispute by either side. The defendant further, by his own admission, 'had the specific intent to kill or seriously injury the decedent.' Thus, his actions and admission satisfy all the elements necessary to convict him of second degree murder. The reason we are here today is to determine whether the defendant is going to be held responsible for his actions. In pleading Not Criminally Responsible on account of Mental Disorder, the defence actually assumes the burden of proof. It is true that the prosecution always assumes the burden of proof in establishing guilt versus innocence, because the defendant is assumed to be innocent until proven guilty. However, the law has established that the defendant is assumed to be sane unless the defence can prove otherwise. In other words, the burden for proving Insanity rests with the defence, not with the prosecution.

In this case, the defence would have you believe that at the time of the offence, the defendant, Smith, was not capable of knowing the difference between right and wrong. If Smith was incapable of determining the difference, why was he seen on the video surveillance tapes looking nervously around the store before he stabbed and killed the cashier, Mr. Warner? Such behaviour could only reflect that he knew he was about to perpetrate an act which was wrong.

Mr. Smith did not know, nor did he ever have prior contact with Robert Warner. The first time he ever saw him was on December 11, 2012 when he, for no apparent reason, stabbed him once in the neck, killing him. He claims that he acted in self defence, but in defence of what? When he grabbed the knife, the cashier was bent over getting a bag from underneath the counter.

Mr. Smith, based on various records, appears to be a model individual who is rational, coherent and law-abiding. He is a foster parent. This is significant because in 
order to receive approval for a foster child, an individual must be investigated by the state social service agency. In the present case, the agency files indicate that over a two year probationary period Mr. Smith was subjected to at least ten scheduled visits and about the same number of unscheduled visits. The reports filed in every instance indicate that he was a responsible, caring foster parent who took excellent care of his foster child, maintained a safe environment, and was regularly employed. At the end of the probation period, in 2008, he and his wife petitioned the court for approval to adopt the foster child, which after another review process, was granted in early 2009. The strict adherence to this procedure demonstrates that Mr. Smith was obviously a very competent individual.

The foster care records indicate that Mr. Smith and his current wife were married early 2006. Friends and family have confirmed that Mr. Smith and his wife were married in early 2006, after living together for about one year. The couple were described by friends and family as 'in love', 'head over heels for each other', and 'couldn't be without each other.' Shortly after the couple had officially adopted their foster child, friends noticed that Mr. and Mrs. Smith did not seem as close and slowly started to drift apart. About 6 months ago, Mrs. Smith asked for a divorce which reportedly came as quite a shock for Mr. Smith since he didn't realize that anything was wrong with their relationship.

The defence is arguing that because of the stress of Mr. Smith's personal situation, he became clinically depressed and deranged, which eventually led to his gross over-reaction or misinterpretation of the actual chain of events in the 7-11 store on December 11, 2012. It should be safe to say that after the termination of a long term relationship, anyone may be heartbroken, gloomy, and miserable. Does that mean that everyone who is heartbroken has a mental disorder? No. Does that mean that when dealing with a break-up we are not accountable for our actions? No. Numerous individuals deal with break ups and effectively move on with their lives. Yes, we all go through stressful times, and we all feel down at times, but this does not mean we should not be responsible for our own actions.

Mr. Smith claims that due to his 'delusions of persecution', he was convinced that Mr. Warner, in reaching for a bag, was actually reaching for a gun with which he intended to kill the defendant. Mr. Smith's fear for his life was not a reasonable concern. His fear was not based on any rational evidence. We believe that he was able to appreciate the nature and consequences of his actions when he stabbed Mr. Warner. Members of the jury, while Mr. Smith may suffer from a broken heart, this does not exempt him from knowing what he was doing at the time of the offence. He was sane. We urge you to return the only verdict appropriate in this case, Guilty.

\section{DEFENCE SUMMARY}

Ladies and gentlemen of the jury, at the time the crime was committed, Mr. Smith was suffering from major depression with psychotic features. To understand the origins of his depression and psychosis, we must focus on Mr. Smith's history, his biological mother, and his current romantic situation. First, I must note that Mr. Smith is extremely passionate about the foster care system since he grew up in a great foster care home from the age of two, after he was taken away from his mothers care. His single mother suffered severely from major depressive disorder to the point that she could no longer provide the necessary needs for her child. Shortly after Mr. Smith was placed into foster 
care, his mother was admitted into a psychiatric hospital for suicidal thoughts and intentions. Although she was released for improvement and was placed in mandatory counselling, she committed suicide within 48 hours of being released. After Mr. Smith was placed in foster care, he had a good childhood and was adopted by his first foster parents. This is the reason why Mr. Smith wanted to raise a foster child. He felt as though he should pay it forward since he had such an excellent childhood with his foster parents.

Now I would like to address Mr. Smith's current marriage and separation. As the prosecution has mentioned, Mr. and Mrs. Smith separated about 6 months ago. The divorce was a complete shock to Mr. Smith as he was unaware that his wife had such negative feelings towards their relationship. As a result, Mr. Smith had a difficult time dealing with the break up. He agreed that once they adopted their foster child things changed, although he felt that things had changed for the better. In fact, he felt as though their family was now complete.

Shortly after the separation, Mrs. Smith moved out with their foster child which only devastated Mr. Smith more. The two quickly sold their house and Mr. Smith moved into a small two bedroom apartment. He explained that he was in an extremely depressive state at that point in time. About two weeks after the separation, Mr. Smith found out that Mrs. Smith was already in a new relationship. He quickly assumed that this was the reason for their separation which sent him further into depression. In addition to this, Mrs. Smith indicated that she no longer wanted anything to do with $\mathrm{Mr}$. Smith and she forbade him from seeing their foster child.

After this episode, Mr Smith stopped hanging out with friends, stopped attending his child's extracurricular activities, and began to frequently phone in sick for work. One witness recounted how he 'no longer seemed happy like before,' that 'he slowly began to look different, more unkempt.' Another friend said that he would stay in bed with no interest in anything else. This friend recounted a time where Smith did not leave his apartment for over a week. In addition, whenever friends called, Mr. Smith would weep on the phone but insist that nothing was wrong and instantly became irritable and annoyed.

The most poignant testimony came from a woman who was accustomed to seeing Mr. Smith out with his child every day after work at the school playground. After Mr. Smith's separation, she described him as "totally different. He would randomly show up at the playground when his child was not around. He wouldn't even talk to me or any of the other parents anymore. He sometimes would sit on a bench talking to himself and crying. In the few times he did speak to me recently, he would suddenly start crying for no reason at all."

Numerous friends reached out to Mr. Smith and sought to get him help. As a result, Mr. Smith was admitted into a psychiatric hospital and diagnosed with major depressive disorder. Mr. Smith was treated with anti depressants and regular counselling sessions, with great improvement. Unfortunately, Mr. Smith had numerous side effects from his antidepressant medication such as anxiety, nausea, restlessness, dizziness, headaches, and insomnia which impacted his daily life. Without the recommendation of his psychiatrist and counsellor, Mr. Smith stopped taking his mediation. However, when discontinuing his mediation, Mr. Smith's symptoms of major depression returned. 
After Smith was arrested he underwent a psychiatric assessment which confirmed the diagnosis of major depressive disorder. A direct result of this mental illness was the formulation of paranoid delusions of persecution and a loss of touch from reality. Based on his current personal situation, it should not be surprising that Mr. Smith became depressed and developed a stress-induced psychosis. He was unable to perceive reality in the same way that either you or I do. His reality consisted of living in sadness and seeing the world in grey. In addition, Mr. Smith may have been more susceptible to major depression since his mother suffered from the same disease before she ended her own life.

When Mr. Smith walked into the 7-11 store on December 11, 2012 he was suffering from a mental illness, a disease, brought on by psychological stress. Because of his completely distorted perception of reality he believed that the clerk, Mr. Warner, was intending to harm him. Whether this belief is accurate or not is not the issue; what is at issue is whether or not he truly believed that the cashier was going to harm him. Because of his mental illness, he was unable to control his beliefs and he was not capable of distinguishing right from wrong; he did not understand what he was doing because he was acting out of a delusional fear. For these reasons, I urge you to find my client, Mr. Smith, Not Criminally Responsible on account of Mental Disorder. 


\section{Appendix I}

\section{Juror Questionnaire}

INSTRUCTIONS: You will now answer a number of questions about what you have read in the trial transcript. Please answer these questions honestly and to the best of your ability. We ask that you do not turn back to earlier pages after you have completed them.

1. How do you find the defendant, Mike Smith?

Guilty of second degree murder Not Criminally Responsible on account of Mental Disorder

2. How confident do you feel in your verdict?
1
2
34
5
$\begin{array}{lll}6 & 7 & 8\end{array}$
9

10

Not at all

Somewhat Very

Confident

Confident

Confident

3. Please briefly explain why you choose the verdict that you indicated above.

4. Sentencing guidelines states that every person who commits second degree murder is guilty of an indictable offence and will be punished with life imprisonment with a parole ineligibility period of between 10 and 25 years.

a) Following these guidelines, IF YOU SELECTED GUILTY in the first question, what (if any) punishment do you believe the defendant deserves? (check only one)

no punishment

imprisonment

b) Following these guidelines, If you selected imprisonment, please indicate the number of years in prison the defendant should serve

c) years

d) Now, ignoring the guidelines, what recommendations would you make regarding the sentencing of the defendant?

5. After a verdict of NCRMD, the court may give the following dispositions: detention in-hospital, conditional discharge, or absolute discharge.

a) IF YOU SELECTED NCRMD in the first question, what (if any) disposition do you believe the defendant deserves?

(check only one) 
Detention in-hospital

Conditional discharge

Absolute discharge

b) If you selected detention in-hospital, please enter a number of years: years

c) If you selected conditional discharge, what condition would you place on the individual?

Live in a particular location

Mandated medication/treatment

Attend assessment for treatment/counselling

Banned from a particular location

Other.

d) Now, ignoring the set dispositions, what recommendations would you make regarding the disposition of the defendant? 
The next set of questions will address your perceptions of the trial

7. Consider the statements and arguments made by the defence in favour of Mike Smith.

a. How compelling was the defence's argument?

$\begin{array}{ccccccccc}1 & 2 & 3 & 4 & 5 & 6 & 7 & 8 & \begin{array}{c}\text { Very } \\ \text { Not at all }\end{array} \\ \text { compelling } & & & & \begin{array}{c}\text { Somewhat } \\ \text { compelling }\end{array} & & & & \end{array}$

b. To what extent do you feel this argument proves that Mike Smith is not criminally responsible on account of mental disorder?

$\begin{array}{ccccccccc}1 & 2 & 3 & 4 & 5 & 6 & 7 & 8 & 9 \\ \text { Not at all } & & & & \begin{array}{c}\text { Somewhat } \\ \text { Very much }\end{array}\end{array}$

c. To what extent did this argument influence your verdict?

$\begin{array}{ccccccccc}1 & 2 & 3 & 4 & 5 & 6 & 7 & 8 & 9 \\ \text { Not at all } & & & & \begin{array}{c}5 \\ \text { Somewhat }\end{array} & & & & \text { Very much }\end{array}$

8. Consider the statements and arguments made by the Crown against Mike Smith.

a. How compelling was the Crown's argument?

$\begin{array}{ccccccccc}1 & 2 & 3 & 4 & 5 & 6 & 7 & 8 & 9 \\ \text { Not at all } & & & & \begin{array}{c}\text { Somewhat } \\ \text { compelling }\end{array} & & & & \begin{array}{c}\text { Very } \\ \text { compelling }\end{array}\end{array}$

b. To what extent do you feel this argument proves that Mike Smith is guilty?

$\begin{array}{ccccccccc}1 & 2 & 3 & 4 & 5 & 6 & 7 & 8 & 9 \\ \text { Not at all } & & & & \text { Somewhat } & & & & \text { Very much }\end{array}$

c. To what extent did this argument influence your verdict?



9. What mental illness did the defendant, Mike Smith, have?

No Mental Illness

Depression

Schizophrenia

Bipolar disorder

Substance use disorder 
10. During the crime what happened to Robert Warner, the cashier?

He was stabbed

He was shot

He was hit with a baseball bat

11. Where did the crime take place?

The Beer Store

TD Canada Trust Bank

McDonalds

7-11 convenience store

\section{Perceptions of the Defendant}

The statements below assess your perceptions of the defendant. Each statement is followed by a scale. Please read each statement and circle the point on its scale that comes closest to showing how you feel.

1. To what extent do you think the defendant suffers from a mental disorder?

NO MENTAL

$\begin{array}{lllllllll}1 & 2 & 3 & 4 & 5 & 6 & 7 & 8 & 9\end{array}$

DISORDER

EXTREME MENTAL

DISORDER

2. To what extent do you think that the defendant appreciated that what he was doing was wrong before he acted?

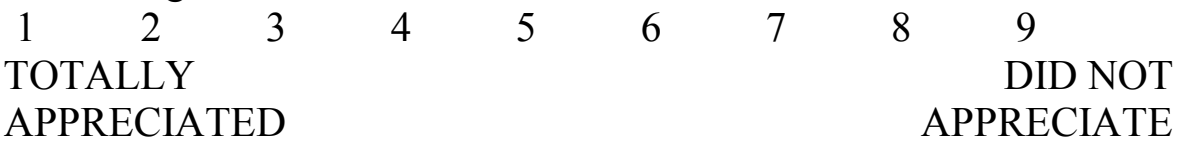

3. To what extent to you think the defendant was capable of perceiving that reasonable alternatives existed to what he did?

$\begin{array}{llllllll}1 & 2 & 3 & 4 & 5 & 6 & 7 & 8 \\ \text { NOT } & & & & & & \text { HIGHLY } \\ \text { CAPABLE } & & & & & & \text { CAPABLE }\end{array}$

4. To what extent do you think the defendant was capable of reasoning logically about his situation?

$\begin{array}{cccccccc}1 & 2 & 3 & 4 & 5 & 6 & 7 & 8 \\ \text { NOT } & & & & & & \text { HIGHLY } \\ \text { CAPABLE } & & & & & & \text { CAPABLE }\end{array}$

5. To what extent do you think the defendant was capable of acting differently than he did?




6. To what extent do you think the defendant couldn't help believing the things he believed?

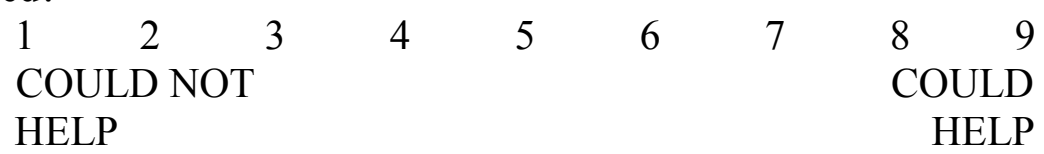

7. To what extent do you think the defendant was capable of rational behaviour?

$\begin{array}{llllllll}1 & 2 & 3 & 4 & 5 & 6 & 7 & 8 \\ \text { NOT } & & & & & & 9 \\ \text { CAPABLE } & & & & & & \text { CAPABLY } \\ \text { CAPABLE }\end{array}$

8. To what extent do you think the defendant should be blamed for what he did?

NOT AT ALL

$\begin{array}{rrrrrrrrr}1 & 2 & 3 & 4 & 5 & 6 & 7 & 8 & 9\end{array}$

COMPLETELY

9. To what extent do you think the defendant should be punished?

$\begin{array}{ccccccccc}1 & 2 & 3 & 4 & 5 & 6 & 7 & 8 & 9 \\ \text { NOT AT ALL } & & & & & & & & \text { SEVERELY }\end{array}$

\section{Perceptions of the Defendant's Disorder}

The statements below assess your perceptions of the defendant's disorder. Each statement is followed by a scale. Please read each statement and circle the point on its scale that comes closest to showing how you feel.

1. How much control did the defendant have over prevention of this condition?

NO CONTROL

$\begin{array}{lllllll}3 & 4 & 5 & 6 & 7 & 8 & 9\end{array}$

2. How much do you blame the defendant for this condition?



3. How much anger do you feel toward the defendant?

NO ANGER

$\begin{array}{lllllll}1 & 2 & 3 & 4 & 5 & 6 & 7\end{array}$

4. How much pity do you feel for the defendant?

122

NO PITY AT ALL

TOTAL CONTROL 
5. How willing would you be to personally assist the defendant with a small problem?

$\begin{array}{lll}1 & 2 & 3\end{array}$

45

56

NOT AT ALL WILLING

7 


\begin{tabular}{|c|c|c|c|c|c|c|c|}
\hline $\begin{array}{l}\text { 8. The not criminally responsible defence returns disturbed, } \\
\text { dangerous people to the streets. }\end{array}$ & 1 & 2 & 3 & 4 & 5 & 6 & 7 \\
\hline $\begin{array}{l}\text { 9. Mentally ill defendants who plead not criminally responsible } \\
\text { have failed to exert enough willpower to behave properly } \\
\text { like the rest of us. So, they should be punished for their } \\
\text { crimes like everyone else. }\end{array}$ & 1 & 2 & 3 & 4 & 5 & 6 & 7 \\
\hline $\begin{array}{l}\text { 10. As a last resort, defence attorneys will encourage their clients } \\
\text { to act strangely and lie through their teeth to appear } \\
\text { "mentally ill." }\end{array}$ & 1 & 2 & 3 & 4 & 5 & 6 & 7 \\
\hline $\begin{array}{l}\text { 11. Perfectly sane killers can get away with their crimes by } \\
\text { hiring high-priced lawyers and experts who misuse the not } \\
\text { criminally responsible defence. }\end{array}$ & 1 & 2 & 3 & 4 & 5 & 6 & 7 \\
\hline $\begin{array}{l}\text { 12. The not criminally responsible plea is a loophole in the law } \\
\text { that allows too many guilty people to escape punishment }\end{array}$ & 1 & 2 & 3 & 4 & 5 & 6 & 7 \\
\hline $\begin{array}{l}\text { 13. We should punish people who commit criminal acts, } \\
\text { regardless of their degree of mental disturbance. }\end{array}$ & 1 & 2 & 3 & 4 & 5 & 6 & 7 \\
\hline $\begin{array}{l}\text { 14. It is wrong to punish people who commit crime for crazy } \\
\text { reasons while gripped by uncontrollable hallucinations or } \\
\text { delusions. }\end{array}$ & 1 & 2 & 3 & 4 & 5 & 6 & 7 \\
\hline $\begin{array}{l}\text { 15. Most defendants who use the not criminally responsible } \\
\text { defence are truly mentally ill, not fakers. }\end{array}$ & 1 & 2 & 3 & 4 & 5 & 6 & 7 \\
\hline $\begin{array}{l}\text { 16. Some people with severe mental illness are out of touch with } \\
\text { reality and do not understand that their acts are wrong. These } \\
\text { people cannot be blamed and do not deserve to be punished. }\end{array}$ & 1 & 2 & 3 & 4 & 5 & 6 & 7 \\
\hline $\begin{array}{l}\text { 17. Many of the crazy criminals that psychiatrists see fit to return } \\
\text { to the streets go on to kill again. }\end{array}$ & 1 & 2 & 3 & 4 & 5 & 6 & 7 \\
\hline $\begin{array}{l}\text { 18. With slick attorneys and a sad story, any criminal can use the } \\
\text { not criminally responsible defence to finagle his way to } \\
\text { freedom. }\end{array}$ & 1 & 2 & 3 & 4 & 5 & 6 & 7 \\
\hline
\end{tabular}


19. It is wrong to punish someone for an act they commit because of any uncontrollable illness, whether it be epilepsy or mental illness.

\begin{tabular}{|l|l|l|l|l|l|l|}
1 & 2 & 3 & 4 & 5 & 6 & 7 \\
\hline
\end{tabular}

\section{Demographic Information}

We would like some very basic information about you. Please respond to the following:

1. Age: years old

2. Gender (check one): Man Woman

3. Education (highest grade completed in school)

4. Race/Ethnicity (Please check one):

Caucasian Latino/Latina Asian/Pacific Islander
African Canadian Aboriginal Canadian Other (specify)

5. Do you personally know someone who is mentally ill (check one) Yes No

If yes, please note your relationship and the kind of mental illness the person has:

6. Have you heard of the Not Criminally Responsible Reform Act introduced on February 8, 2013?

Yes No

If so, briefly describe what you know about the Not Criminally Responsible Reform Act: 


\section{Appendix K}

\section{MISS Scale}

\section{Questionnaire Instructions for Each Mental Illness Condition}

\section{Day’s Mental Illness Stigma Scale}

Factors are noted at the end of each item. Brackets indicate where illness names can be interchanged to present various mental illness conditions.

We are interested in your opinions about schizophrenia and people with schizophrenia in general

Please indicate the extent to which you agree or disagree with the statements listed below using the following scale:

$\begin{array}{ccccccc}1 & 2 & 3 & 4 & 5 & 6 & 7 \\ \text { Completely disagree } & & & & & \text { Completely agree }\end{array}$

1. There are effective medications for Schizophrenia, bipolar, depression, substance use disorder [mental illnesses] that allow people to return to normal and productive lives (Treatability)

2. I don't think that it is possible to have a normal relationship with someone with Schizophrenia, bipolar, depression, substance use disorder [a mental illness]. (Relationship disruption)

3. I would find it difficult to trust someone with Schizophrenia, bipolar, depression, substance use disorder [a mental illness]. (Relationship Disruption)

4. People with Schizophrenia, bipolar, depression, substance use disorder [mental illnesses] tend to neglect their appearance. (Hygiene)

5. It would be difficult to have a close meaningful relationship with someone with Schizophrenia, bipolar, depression, substance use disorder [a mental illness]. (Relationship Disruption)

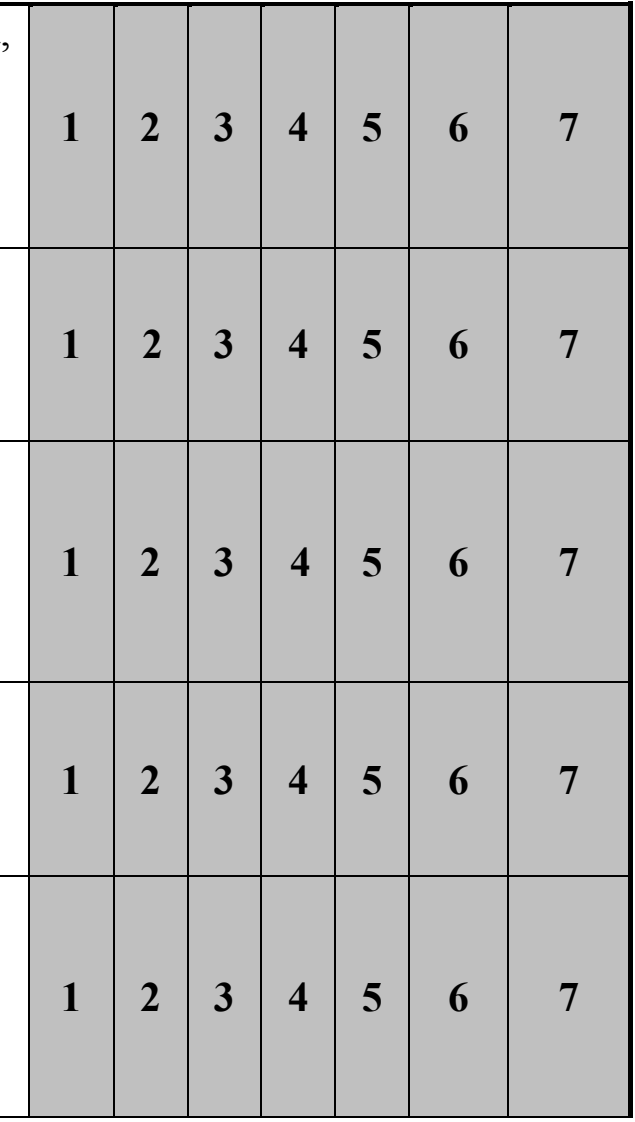




\begin{tabular}{|c|c|c|c|c|c|c|c|}
\hline $\begin{array}{l}\text { 6. I feel anxious and uncomfortable when I'm } \\
\text { around someone with Schizophrenia, bipolar, } \\
\text { depression, substance use disorder [a mental } \\
\text { illness]. (Anxiety) }\end{array}$ & 1 & 2 & 3 & 4 & 5 & 6 & 7 \\
\hline $\begin{array}{l}\text { 7. It is easy for me to recognize the symptoms of } \\
\text { Schizophrenia, bipolar, depression, substance use } \\
\text { disorder [mental illnesses]. (Visibility) }\end{array}$ & $\mathbf{1}$ & 2 & 3 & 4 & 5 & 6 & 7 \\
\hline $\begin{array}{l}\text { 8. There are no effective treatments for } \\
\text { Schizophrenia, bipolar, depression, substance use } \\
\text { disorder [mental illnesses]. (Treatability: } \\
\text { reverse-scored) }\end{array}$ & 1 & 2 & 3 & 4 & 5 & 6 & 7 \\
\hline $\begin{array}{l}\text { 9. I probably wouldn't know that someone had } \\
\text { Schizophrenia, bipolar, depression, substance use } \\
\text { disorder [a mental illness] unless I was told. } \\
\text { (Visibility; reverse scored) }\end{array}$ & 1 & 2 & 3 & 4 & 5 & 6 & 7 \\
\hline $\begin{array}{l}\text { 10. A close relationship with someone with } \\
\text { Schizophrenia, bipolar, depression, substance use } \\
\text { disorder [a mental illness] would be like living on } \\
\text { an emotional roller coaster. (Relationship } \\
\text { disruption) }\end{array}$ & 1 & 2 & 3 & 4 & 5 & 6 & 7 \\
\hline $\begin{array}{l}\text { 11. There is little that can be done to control the } \\
\text { symptoms of Schizophrenia, bipolar, depression, } \\
\text { substance use disorder [mental illness]. } \\
\text { (treatability; reverse scored) }\end{array}$ & 1 & 2 & 3 & 4 & 5 & 6 & 7 \\
\hline $\begin{array}{l}\text { 12. I think that a personal relationship with someone } \\
\text { with Schizophrenia, bipolar, depression, substance } \\
\text { use disorder [a mental illness] would be too } \\
\text { demanding. (Relationship Disruption) }\end{array}$ & 1 & 2 & 3 & 4 & 5 & 6 & 7 \\
\hline $\begin{array}{l}\text { 13. Once someone develops Schizophrenia, bipolar, } \\
\text { depression, substance use disorder [a mental } \\
\text { illness], he or she will never be able to fully } \\
\text { recover from it. (Recovery; reverse -scored) }\end{array}$ & 1 & 2 & 3 & 4 & 5 & 6 & 7 \\
\hline $\begin{array}{l}\text { 14. People with Schizophrenia, bipolar, depression, } \\
\text { substance use disorder [mental illnesses] ignore } \\
\text { their hygiene, such as bathing and using } \\
\text { deodorant. (Hygiene) }\end{array}$ & 1 & 2 & 3 & 4 & 5 & 6 & 7 \\
\hline
\end{tabular}




\begin{tabular}{|c|c|c|c|c|c|c|c|}
\hline $\begin{array}{l}\text { 15. Schizophrenia, bipolar, depression, substance use } \\
\text { disorder [Mental illnesses] prevent people from } \\
\text { having normal relationships with others. } \\
\text { (Relationship Disruption) }\end{array}$ & 1 & 2 & 3 & 4 & 5 & 6 & 7 \\
\hline $\begin{array}{l}\text { 16. I tend to feel anxious and nervous when I am } \\
\text { around someone with Schizophrenia, bipolar, } \\
\text { depression, substance use disorder [a mental } \\
\text { illness]. (Anxiety) }\end{array}$ & 1 & 2 & 3 & 4 & 5 & 6 & 7 \\
\hline $\begin{array}{l}\text { 17. When talking with someone with Schizophrenia, } \\
\text { bipolar, depression, substance use disorder [a } \\
\text { mental illness], I worry that I might say } \\
\text { something that will upset him or her. (Anxiety) }\end{array}$ & 1 & 2 & 3 & 4 & 5 & 6 & 7 \\
\hline $\begin{array}{l}\text { 18. I can tell that someone has Schizophrenia, } \\
\text { bipolar, depression, substance use disorder [a } \\
\text { mental illness] by the way he or she acts. } \\
\text { (Visibility) }\end{array}$ & 1 & 2 & 3 & 4 & 5 & 6 & 7 \\
\hline $\begin{array}{l}\text { 19. People with Schizophrenia, bipolar, depression, } \\
\text { substance use disorder [mental illnesses] do not } \\
\text { groom themselves properly. (Hygiene) }\end{array}$ & 1 & 2 & 3 & 4 & 5 & 6 & 7 \\
\hline $\begin{array}{l}\text { 20. People with Schizophrenia, bipolar, depression, } \\
\text { substance use disorder [mental illnesses] will } \\
\text { remain ill for the rest of their lives. (Recovery; } \\
\text { reverse scored) }\end{array}$ & 1 & 2 & 3 & 4 & 5 & 6 & 7 \\
\hline $\begin{array}{l}\text { 21. I don't think that I can really relax and be myself } \\
\text { when I'm around someone with Schizophrenia, } \\
\text { bipolar, depression, substance use disorder [a } \\
\text { mental illness]. (Anxiety) }\end{array}$ & 1 & 2 & 3 & 4 & 5 & 6 & 7 \\
\hline $\begin{array}{l}\text { 22. When I am around someone with Schizophrenia, } \\
\text { bipolar, depression, substance use disorder [a } \\
\text { mental illness] I worry that he or she might harm } \\
\text { me physically. (Anxiety) }\end{array}$ & 1 & 2 & 3 & 4 & 5 & 6 & 7 \\
\hline $\begin{array}{l}\text { 23. Psychiatrists and psychologists have the } \\
\text { knowledge and skills needed to effectively treat } \\
\text { Schizophrenia, bipolar, depression, substance use } \\
\text { disorder [mental illnesses]. (Professional } \\
\text { efficacy) }\end{array}$ & 1 & 2 & 3 & 4 & 5 & 6 & 7 \\
\hline $\begin{array}{l}\text { 24. I would feel unsure about what to say or do if I } \\
\text { were around someone with Schizophrenia, } \\
\text { bipolar, depression, substance use disorder [a } \\
\text { mental illness]. (Anxiety) }\end{array}$ & 1 & 2 & 3 & 4 & 5 & 6 & 7 \\
\hline
\end{tabular}




\begin{tabular}{|c|c|c|c|c|c|c|c|}
\hline $\begin{array}{l}\text { 25. I feel nervous and uneasy when I'm near someone } \\
\text { with Schizophrenia, bipolar, depression, } \\
\text { substance use disorder [a mental illness]. } \\
\text { (Anxiety) }\end{array}$ & 1 & 2 & 3 & 4 & 5 & 6 & 7 \\
\hline $\begin{array}{l}\text { 26. I can tell that someone has Schizophrenia, } \\
\text { bipolar, depression, substance use disorder [a } \\
\text { mental illness] by the way that he or she talks. } \\
\text { (Visibility) }\end{array}$ & 1 & 2 & 3 & 4 & 5 & 6 & 7 \\
\hline $\begin{array}{l}\text { 27. People with Schizophrenia, bipolar, depression, } \\
\text { substance use disorder [mental illnesses] need to } \\
\text { take better care of their grooming (bathe, clean } \\
\text { teeth, use deodorant). (Hygiene) }\end{array}$ & 1 & 2 & 3 & 4 & 5 & 6 & 7 \\
\hline $\begin{array}{l}\text { 28. Mental health professionals, such as psychiatrists } \\
\text { and psychologists, can provide effective } \\
\text { treatments for Schizophrenia, bipolar, depression, } \\
\text { substance use disorder [mental illnesses]. } \\
\text { (Professional Efficacy) }\end{array}$ & 1 & 2 & 3 & 4 & 5 & 6 & 7 \\
\hline
\end{tabular}




\section{Appendix L}

\section{Example of Mechanical Turk Recruitment Notice}

Study Name: Juror decisions in Insanity defence trials within the Canadian Courtroom

Requestor: Kristin Fenwick (Principal Investigator) and Dr. Evelyn Maeder (Faculty Sponsor)

HIT Expiration Date: (1 month)

Time Allotted: $45-60$ Minutes

Reward: 1 dollar

HITs available: 480

Description: This study asks participants to act as jurors in a criminal trial. Participants will render a verdict and complete a questionnaire. Warning: Participant might get upset from reading about a criminal case. This study has been approved by the Carleton University Ethics Committee for Psychological Research (\#13-045).

Keywords: Insanity, jury, law, juror, trial, psychology, study, questionnaire, experiment,

Qualifications required: Canadian citizen, 18 years of age or older, high proficiency in the English language, no prior convictions

This study has received clearance by the Carleton University Psychology Research Ethics Board (Reference \#13-045, insert ethics reference number once obtained). 


\section{Appendix M}

\section{Informed Consent}

The purpose of an informed consent is to make sure that you understand the purpose of the study and your involvement as a participant. The informed consent must include enough information regarding the study for you to be able to make a well-informed decision regarding whether or not you would like to partake in the study.

Title: Juror decisions in Insanity defence trials within the Canadian Courtroom

Research personnel: The study is being conducted by Dr. Evelyn Maeder from the Institute of Criminology and Criminal Justice at Carleton University, and Master's student Kristin Fenwick from the Department of Psychology.

Purpose: The purpose of this study is to evaluate mental health and legal attitudes and decision-making.

Task requirements: You have been asked to participate in a study concerning mental health attitudes, legal attitudes, and decision-making. During this study you are asked to read a trial transcript involving a charge of NCRMD. You are asked to read the entire case and then determine a verdict as well as answer several other opinion-related questions. This study will take you approximately 45 minutes to complete and you will be compensated with 1 dollar.

Potential Risk/Discomfort: You will be asked to answer questions regarding your attitudes about certain sensitive topics (e.g. cultural stereotypes, beliefs, and values), and you may become uncomfortable with the nature of the questions. At any time, you may discontinue your involvement in this study and you will still be compensated for your participation.

Right to withdraw: In addition, you may refrain from answering any questions on the questionnaire if you are uncomfortable or otherwise do not want to. At the end of the study, you will be asked if you would like to withdraw your data from the study and will have the option of doing so immediately if you should so wish. If at any point you choose to withdraw, you will still be compensated for your participation.

Anonymity/confidentiality: The data collected in this experiment are strictly confidential. All data are coded such that your name is not associated with the responses you provide. Any identifying information associated with your code will be confined to a single page that will be separated from your questionnaire, and kept in a separate, secured file by the research investigators, who will keep this information confidential. We collect data through the software Qualtrics, which uses servers with multiple layers of security to protect the privacy of the data (e.g., encrypted websites and pass-word protected storage). Please note that Qualtrics is hosted by a server located in the USA. The United States Patriot Act permits U.S. law enforcement officials, for the purpose of an anti-terrorism 
investigation, to seek a court order that allows access to the personal records of any person without that person's knowledge. In view of this we cannot absolutely guarantee the full confidentiality and anonymity of your data. With your consent to participate in this study you acknowledge this.

Should I require further information regarding this study, I can contact:

Dr. Evelyn Maeder

Institute of Criminology and Criminal Justice

Tel. 613-520-2600 ext. 2421

Kristin Fenwick, Master's Student

Department of Psychology

kristinfenwick@cmail.carleton.ca

\section{Should I have any ethical concerns regarding this study, I can contact:}

Dr. Avi Parush

Chair, REB for Psychological Research, Department of Psychology, Carleton University Tel. 613-520-2600 ext. 6026

Should I have any other concerns regarding this study, I can contact:

Dr. Anne Bowker

Chair of Department of Psychology, Carleton University

Tel. 613-520-2600 ext. 8218

This study has been approved by the Carleton University Ethics Committee for Psychological Research (\#13-045).

I have read the above form and understand the conditions of my participation. My participation in this study is voluntary, and I understand that if at any time I wish to leave the experiment, I may do so without having to give an explanation and with no penalty whatsoever. Furthermore, I am also aware that the data gathered in this study are confidential and anonymous with respect to my personal identity. By checking this box, I'm indicating that I agree to participate in this study.

I have read the above form and understand the conditions of my participation. My participation in this study is voluntary, and I understand that if at any time I wish to leave the experiment, I may do so without having to give an explanation and with no penalty whatsoever. Furthermore, I am also aware that the data gathered in this study are confidential and anonymous with respect to my personal identity. By checking this box, I'm indicating that I disagree to participate in this study. 


\section{Appendix N}

\section{Study Debriefing Form}

Thank you for your participation in this study. This is a debriefing form which will clarify the purpose of our study and why we are interested in this issue.

What are we trying to learn in this research and how was this study designed?

The purpose of this study is to determine whether education can affect juror attitudes towards mental illness as well as verdicts rendered in not criminally responsible on account of mental disorder (NCRMD) cases. The trial transcript that you read was not an actual case, but instead fabricated for the purpose of this study. We randomly assigned you to one of two education conditions (mental health education: mental illness or diabetes and defence education: NCRMD or duress), and systematically changed the defendants mental illness (between schizophrenia, substance abuse, depression, and bipolar disorder). We are interested in seeing how your verdict and perceptions of the defendant may relate to other variables related to the legal system in order to determine if those variables might affect participants' verdicts, responsibility ratings, and attitudes towards the mentally ill. In addition, we are interested in investigating gender differences in attitudes toward the NCRMD defence, as well as in decision-making in trials involving the NCRMD defence.

Why was the use of deception necessary?

Deception occurs when information is intentionally omitted or when misinformation is intentionally delivered. In our study, we were not able to inform you of the specific purpose of our study. Since the not criminally responsible defence may be related to bias the true nature of the study had to be concealed in order to elicit the most genuine participant response possible. If the true nature of the study is concealed participants may be less biased in their answers and judgement; thus stimulating the best possible true juror decision-making. Please be aware that you are able to withdraw your data from this study if you wish without penalty and you will still be awarded full credit for taking part in this study.

\section{What are our hypotheses and predictions?}

We predict that defendant mental illness will have an effect of defendant perceptions and mental illness stigma. Specifically, we hypothesize that schizophrenia and substance abuse will generate more negative defendant perceptions and mental illness stigma in comparison to depression and bipolar disorder. In addition, we hypothesize that mental illness education will increase positive defendant perceptions and decrease mental illness stigma when compared to the diabetes education group. Furthermore, we predict that mental illness education will independently reduce mental illness stigma and increase NCRMD verdicts. In addition, we hypothesize that combined mental illness and NCRMD education will increase the effect on verdicts when compared to mental illness education exclusively. Lastly, we predict that verdict decisions are reached via various levels and combinations of paths. Specifically, defendant mental illness and education 
will impact on jurors mental illness attitudes, and that these specific attitudes in turn will predict juror verdict decisions.

\section{Where can I learn more?}

- Mansouri, N., Gharaee, B., Shariat, S. V., Bolhari, J., Nooraie, R. Y., Rahimi Movaghar, A., et al. (2009). The change in attitude and knowledge of health care personnel and general population following trainings provided during integration of mental health in Primary Health Care in Iran: A systematic review. International Journal of Mental Health Systems, 3(15).

- Skeem, J. L. (1999). Understanding juror decision making and bias in Insanity defense cases: The role of lay conceptions and case-relevant attitudes (Doctoral disseration). Retrieved from ProQuest

- Dissertations and Thesis Database. (AAT 9948543) Skeem, J. L., Louden, J. E., \& Evans, J. (2004). Venireperson's attitudes toward the Insanity defense: Developing, refining, and validating a scale. Law and Human Behaviour , 28 (6), 623-648.

- Statistics Canada (March 17, 2009) Section A: Overview of issues-Mental health and the Criminal Justice System. Retrieved from: http://www.statcan.gc.ca/pub/85-561-m/2009016/section-a-eng.htm

You can also contact the researchers involved in this study:

- Dr. Evelyn Maeder, Institute of Criminology and Criminal Justice, Tel. 613-5202600 ext. 2421 or evelyn_maeder@carleton.ca

- Kristin Fenwick, Masters Student, kristinfenwick@cmail.carleton.ca

Should you have any ethical concerns, please contact:

- Dr. Avi Parush, Chair, REB for Psychological Research, Department of Psychology, Carleton University, Tel. 613-520-2600 ext. 6026

Should you have any other concerns, please contact:

- Dr. Anne Bowker, Chair of Department of Psychology, Carleton University, Tel. 613-520-2600 ext. 8218

Is there anything I can do if I found this experiment emotionally draining?

Given the content of the case vignette you may become anxious or upset. If this experiment has caused you any emotional distress, please contact your doctor, a counsellor, go to the nearest hospital, call 9-1-1, or call a local crisis line. The following crisis line centres are confidential and anonymous:

- The National Suicide Prevention Line 1-800-273-8255

- Mental Health Crisis Line 1-888-737-4668

- The Canada Suicide \& Crisis Hotline at 1-800-448-1833

- The Mental Health Service Information Ontario line 1-866-532-2600

- Health and Counselling Services at Carleton University at 613-520-6674 located at 2600 Carleton Technology and Training Centre 


\section{Appendix 0}

\section{Study Consent-to-keep-data Form}

The purpose of consent-to-keep-data form is to make sure that you are able to make an informed decision regarding whether or not you would like your data included in this study. We include this form after explaining the true purpose of our study and the reasons for which deception was necessary. This form is meant to give you an opportunity to withdraw your data from the study, now that you are aware of its purpose.

I understand that I was not informed of the true purpose of this study prior to my participation in the study. I understand the reasons regarding the necessity of the use of deception in this study.

I do continue to consent to the use of my data. I understand that I was not informed of the true purpose of this study prior to my participation in the study. I understand the reasons regarding the necessity of the use of deception in this study. By checking this box, I'm indicating that I consent to the use of my data.

I do not continue to consent to the use of my data. I understand that I was not informed of the true purpose of this study prior to my participation in the study. I understand the reasons regarding the necessity of the use of deception in this study. By checking this box, I'm indicating that I do not consent to the use of my data. 